\title{
Bronchial hyperresponsiveness: animal models and clinical aspects
}

$\mathrm{PhD}$ Thesis

Dorottya Czövek MD

Department of Medical Physics and Informatics

University of Szeged, Hungary

2013 


\section{TABLE OF CONTENTS}

1 INTRODUCTION

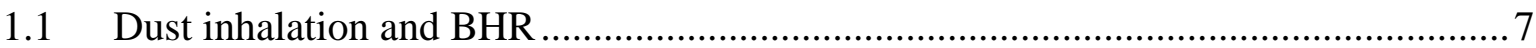

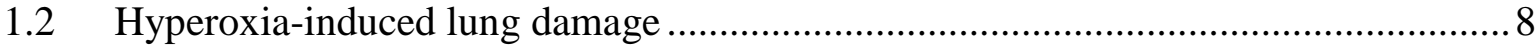

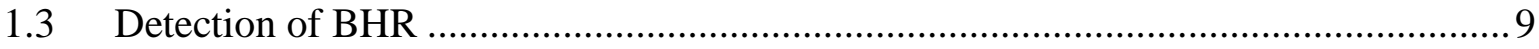

2 AIMS OF THE STUDIES INCLUDED IN THE PRESENT THESIS ......................... 11

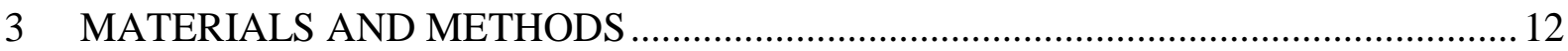

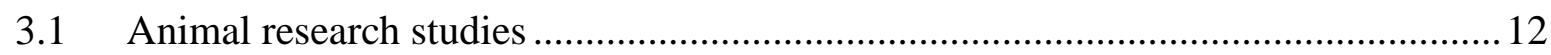

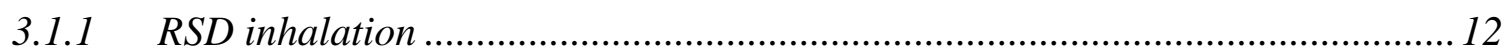

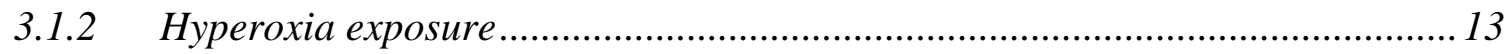

Clinical research study on asthmatic children .............................................. 14

3.3 Lung function measurements .................................................................. 15

3.3.1 Respiratory mechanics- FOT …............................................................. 15

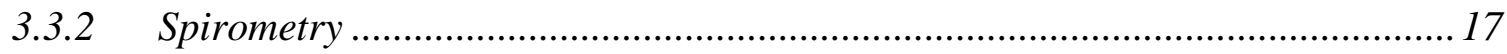

3.3.3 Plethysmography in rats exposed to hyperoxia or room air ............................. 17

3.4 Bronchoprovocation and reversibility tests ................................................. 18

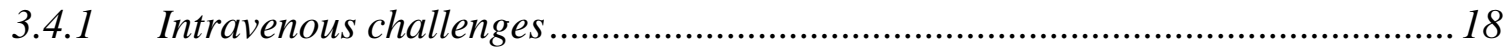

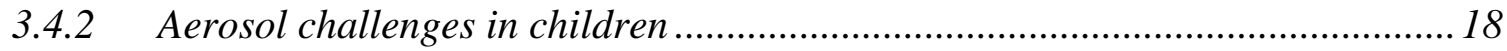

3.5 Lung inflammation, morphological and biochemical assessments in rats ................ 19

3.5.1 Lung histology following RSD inhalation .................................................... 19

3.5.2 Bronchoalveolar lavage and lung histology in hyperoxic and normal rats....... 19

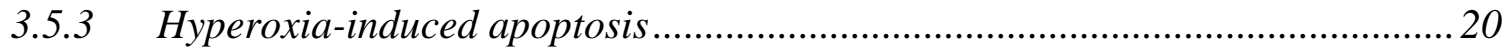

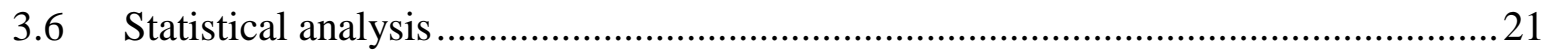

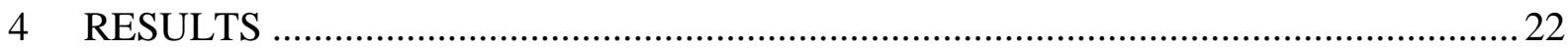

4.1 Basal respiratory mechanical parameters in animal studies ................................22

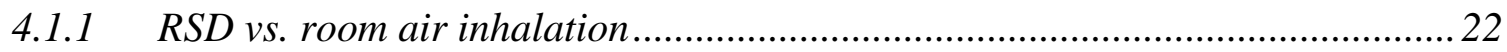


4.1.2 Hyperoxia vs. room air exposure 22

4.2 Changes in lung mechanics following bronchial challenges 23

4.2.1 MCh challenges after RSD or room air exposures . 23

4.2.2 MCh provocations after exposure to hyperoxia or room air ............................2 24

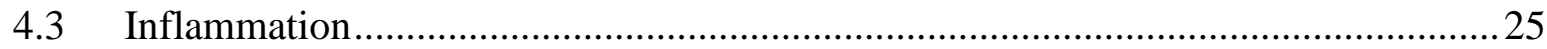

4.3.1 Inflammatory response after RSD inhalation ...................................................2. 25

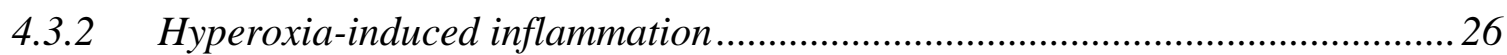

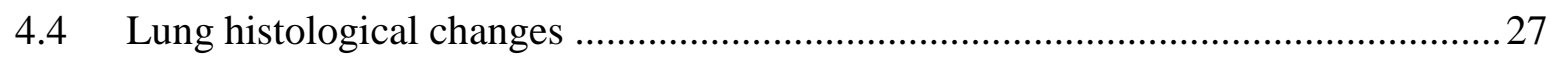

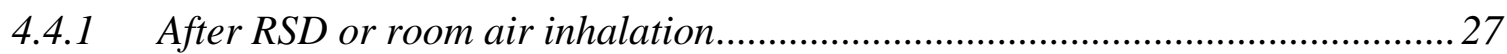

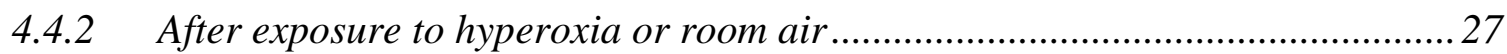

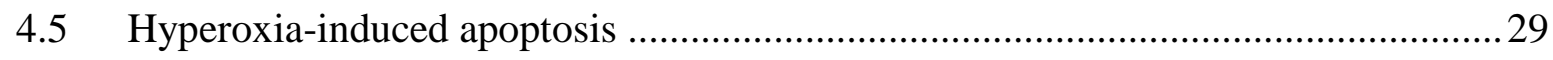

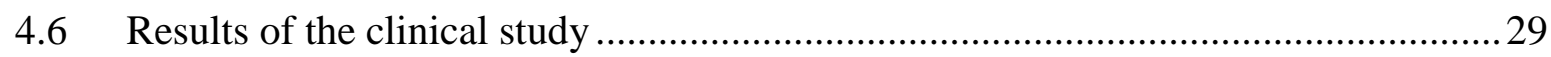

4.6.1 Basal lung functional and mechanical parameters in asthmatic children .........29

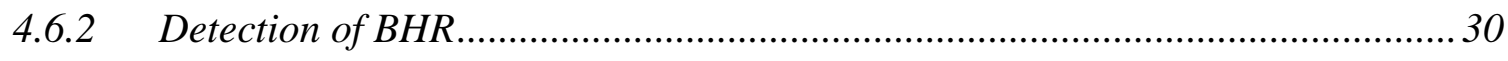

4.6.3 Comparison of the parameters obtained by spirometry and FOT .....................33

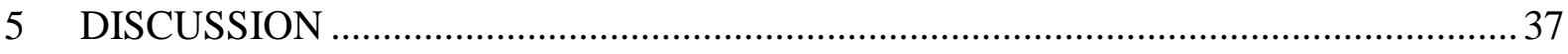

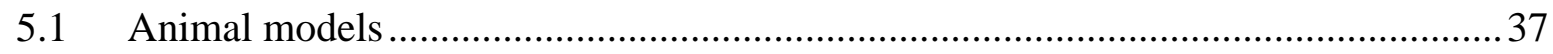

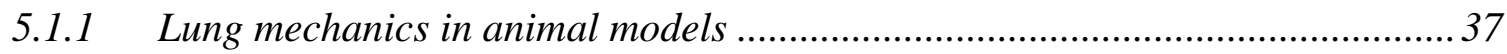

5.1.2 Mechanisms underlying BHR following hyperoxia exposure ............................ 39

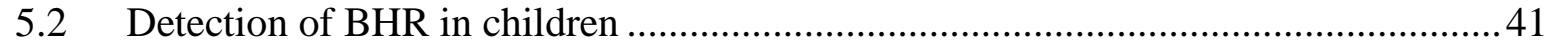

5.2.1 Relationships between the parameters obtained with the FOT and spirometry. 42

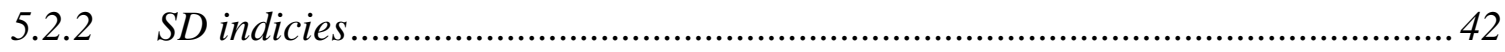

5.2.3 Effects of deep inspiration on the lung fuction ................................................ 43

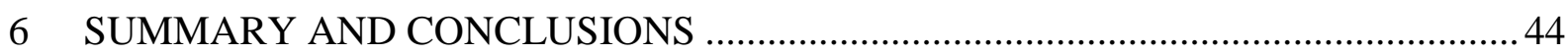

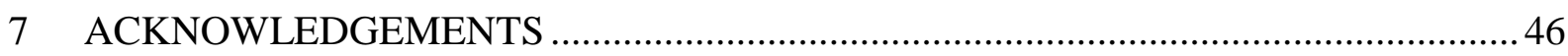

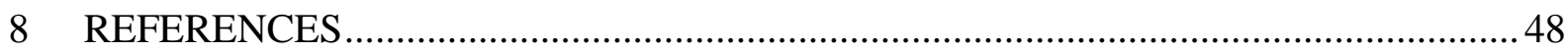


List of papers included in this thesis

I. Petak F, Czovek D, Novak Z: Spirometry and forced oscillations in the detection of airway hyperreactivity in asthmatic children. Pediatric Pulmonology 47:(10) pp. 956965. (2012)

II. Czovek D, Novak Z, Somlai C, Asztalos T, Tiszlavicz L, Bozoki Z, Ajtai T, Utry N, Filep A, Bari F, Petak F: Respiratory consequences of red sludge dust inhalation in rats. Toxicology Letters 209:(2) pp. 113-120. (2012)

III. Czovek D, Petak F, Donati Y, Belin X, Pache JC, Barazzzone C, Habre W: Prevention of the early phase of hyperoxia-induced lung injury by sildenafil or vasoactive intestinal peptide. Submitted to Respiratory Research (2013) 


\section{Tables and figures}

Figure 1. Experimental set-up for RSD exposure.

Figure 2. Experimental protocol after RSD or room air exposure on day 15.

Figure 3. Experimental protocol after hyperoxia or room air exposure on day 4.

Figure 4. Experimental set-up for FOT measurements.

Figure 5. Baseline values of LFOT parameters after inhalation of RSD or room air.

Figure 6. Mechanical parameters normalized to body weight under baseline conditions, during and after MCh challenges in rats exposed to room air and subjected to hyperoxia with or without any additional treatment.

Figure 7. Airway and respiratory tissue parameters measured after MCh challenges relative to the baseline values in the control rats and in rats exposed to RSD.

Figure 8. Equivalent doses of $\mathrm{MCh}$ required to cause a $50 \%$ elevation in airway resistance $\left(E D_{50}\right)$ and the end-expiratory lung volumes (EELV) measured in rats exposed to room air subjected to hyperoxia with or without any additional treatment.

Figure 9. Histological sections obtained in a representative control rat and in another rat exposed to RSD.

Figure 10. Total cells, the repartition to PMN cells and the protein content of the BALF obtained from rats exposed to room air subjected to hyperoxia with or without any additional treatment.

Figure 11. Numbers of control and RSD-treated rats with different severity scores based on the histopathological evaluations.

Figure 13. Mean linear intercept values and percentage of edema surface were determined from the lung sections of the rats in the protocol groups following exposure to hyperoxia or room air.

Figure 12. Representative images of hematoxylin/eosin-stained lung sections collected from control rats exposed to room air, rats subjected to hyperoxia without any additional treatment, and hyperoxic rats treated with either sildenafil or VIP. 
Figure 14. Percentages of TUNEL-positive nuclei counted in lung cryosections collected from rats exposed to room air subjected to hyperoxia without any additional treatment and hyperoxic rats treated either with sildenafil or VIP.

Figure 15. Lung function parameters obtained with spirometry or forced oscillations in individual asthmatic children under the baseline condition, following inhalations of increasing doses of His and after inhalation of Sal.

Figure 16. Lung function parameters obtained with spirometry or forced oscillations in individual asthmatic children under the baseline condition, following inhalations of normal saline and increasing doses of MCh, and after inhalation of Sal.

Figure 17. Correlations observed between spirometric and resistance parameters obtained with forced oscillations following aerosolized His or MCh challenges in individual asthmatic children.

Figure 18. SD index of the lung function parameters obtained with spirometry and forced oscillations following His or MCh challenges.

Table 1. Percentages of short- and long-term variability of the lung function parameters determined with spirometry or FOT in the main study group of 12 children. Values in parentheses: values obtained in 8 additional children where the FOT was performed without spirometry. Variability was defined as the standard deviation of the percentage changes between the data obtained in the first and second tests.

Table 2. Percentage changes in the resistance parameters where the His and MCh provocation tests became positive according to the ATS/ERS guidelines (a 20\% decrease in FEV1 or the appearance of clinical symptoms). SW: positive response (20\% decrease in FEV1 and the appearance of wheeze); W: wheeze, clinical symptoms appeared 


\section{Glossary of terms}

\begin{tabular}{|c|c|}
\hline ANOVA & $=$ analysis of variance \\
\hline ATS & $=$ American Thoracic Society \\
\hline $\mathrm{AX}$ & $\begin{array}{l}=\text { the area between the reactance curve and } \\
\text { the } \mathrm{x} \text { axis }\end{array}$ \\
\hline BALF & $=$ bronchoalveolar lavage fluid \\
\hline BALT & =bronchus-associated lymphoid tissue \\
\hline BHR & $=$ bronchial hyperresponsiveness \\
\hline cGMP & $=$ cyclic guanosine monophosphate \\
\hline $\mathrm{CO}_{2}$ & $=$ carbon dioxide \\
\hline dUTP & $=$ deoxyuridinetriphosphate \\
\hline $\mathrm{ED}_{100}$ & $\begin{array}{l}=\text { the methacholine dose causing a } 100 \% \\
\text { increase in the airway resistance }\end{array}$ \\
\hline $\mathrm{ED}_{50}$ & $\begin{array}{l}=\text { the methacholine dose causing a } 50 \% \\
\text { increase in the airway resistance }\end{array}$ \\
\hline EELV & $=$ end-expiratory lung volume \\
\hline ERS & = European Respiratory Society \\
\hline $\mathrm{FEF}_{25-75}$ & $\begin{array}{l}=\text { forced expired flow between } 25 \% \text { and } \\
75 \% \text { of the volume expired }\end{array}$ \\
\hline $\mathrm{FEV}_{1}$ & $\begin{array}{l}=\text { forced expiratory volume in the first } \\
\text { second of expiration }\end{array}$ \\
\hline FOT & $=$ forced oscillation technique \\
\hline $\mathrm{Fr}$ & $=$ resonant frequency \\
\hline FVC & $=$ functional vital capacity \\
\hline G & $=$ tissiou damping \\
\hline GINA & $=$ Global Initiative for Asthma \\
\hline $\mathrm{H}$ & $=$ elastance \\
\hline$\eta$ & $=$ lung tissue hysteresivity \\
\hline His & $=$ histamine \\
\hline Iaw & = airway inertance \\
\hline ID & $=$ internal diameter \\
\hline
\end{tabular}

$\mathrm{j} \quad=$ imaginary unit

LFOT = forced oscillations at low frequenties

$\mathrm{MCh}=$ methacholine

MLI =mean linear intercept

NO = nitric oxide

$\mathrm{O}_{2} \quad=$ oxygen

$\mathrm{P}_{\mathrm{box}} \quad=$ box pressure

PBS = phosphate-buffered saline

PDE = phosphodiesterase

$\mathrm{PMN}=$ polymorphonuclear cells

$\mathrm{P}_{\mathrm{tr}} \quad=$ tracheal pressure

$\mathrm{R}_{4-24}=$ average resistance between 4 and $24 \mathrm{~Hz}$

$\mathrm{R}_{6} \quad=$ resistance at $6 \mathrm{~Hz}$

Raw = airway resistance

ROS = reactive oxygen species

RSD $\quad=$ red sludge dust

Sal $\quad=$ salbutamol

$\mathrm{SD} \quad=$ standard deviation

TdT = terminal deoxynucleotidyl transferase

TUNEL = terminal deoxynucleotidyl transferasemediated deoxyuridinetriphosphate nick end-labeling

VEGF = vascular endothelial growth factor

VIP = vasoactive intestinal peptide

Zrs = imput impedance of the respiratory system 


\section{INTRODUCTION}

Asthma, the most frequent chronic lung disease in childhood, is a considerable health problem worldwide. Asthma is a heterogeneous condition with numerous different phenotypes, which can be explained by complex environmental/genetic interactions. Since breathing is a process involving adaptation to environmental changes, various detrimental changes in the lung function or structure may be related to alterations in the ambient conditions. Besides biophysical and economic/psychosocial causes, environmental factors can also pose a high risk of the development of asthma or asthma-like symptoms. Exposure to indoor/outdoor allergens, tobacco smoke or air pollution and an urban lifestyle may also play a part in the emergence of the disorder. Such stimuli can provoke an immune response leading to an imbalance in the production of anti-inflammatory/inflammatory cytokines. The chronic presence of inflammation results in a hypersensitive reaction in the airways, which is a characteristic feature of asthma. This bronchial hyperresponsiveness (BHR) is manifested in exaggerated responses to a wide range of seemingly harmless stimuli involving a constriction of the airway smooth muscle, an elevated secretion of the submucosal glands and swelling of the bronchial wall.The mechanisms underlying BHR are not completely understood, since it can be related to both asthmatic and non-asthmatic, non-atopic disorders. In adults, a strong relationship has been demonstrated between airway remodeling and BHR, whereas the development of these severe structural changes in children is exceptionally rare, which may be anticipated from the normal basal lung functional parameters in the periods between the exacerbations. In the early stages of the disease therefore, genetic factors and existing inflammation are most probably responsible for the development of BHR. In humans, the effects of environmental and genetic factors in the pathogenesis of asthma cannot be distinguished. Inbred animals, however, may serve as ideal models via which to investigate the roles of environmental factors and inflammation without the confounding influence of the genetic background.

\subsection{Dust inhalation and BHR}

Previous studies have indicated that the inhalation of various dust particles may involve longterm adverse pulmonary effects that may promote the development of chronic obstructive 
pulmonary disease (27), sarcoid-like pulmonary disease (36) and diffuse parenchymal lung disease (86); furthermore, airway irritation following the inhalation of ambient particulate matter contributes to an increased prevalence and the exacerbation of asthma $(17,42,45,63$, 92). The unfortunate red sludge disaster that occurred when the pond dam of a red sludge reservoir plant burst on October 42010 gave rise to an extreme situation and health hazard in the area near the Hungarian town of Ajka. The $600,000-700,000 \mathrm{~m}^{3}$ of toxic red sludge that streamed out from the damaged reservoir flooded 3 towns and affected 4 other residential areas, in some places in a depth of up to 2 meters, and rapidly covered an agricultural area of about $40 \mathrm{~km}^{2}$. Health professionals agreed that the most important health risk was related to the inhalation of the red sludge dust (RSD) formed when the red sludge dried and its particles were swept into the atmosphere by the wind. Since the atmosphare may also be contaminated the RSD if the common dry storage method is used for the deposition of this byproduct, this environmental threat may additionally involve workers or inhabitants in regions neighboring plants where alumina is produced from bauxite by the Bayer process.

\subsection{Hyperoxia-induced lung damage}

The initial mechanisms of inflammation and the subsequent BHR are related to the increased production of reactive oxygen species (ROS). In developing, immature lungs, the fact that the antioxidant system is underrepresented also contributes to the imbalance in the oxidant/antioxidant regulation. ROS molecules can be produced excessively by oxygen $\left(\mathrm{O}_{2}\right)$ toxicity cause both direct and indirect damages at molecular and cellular levels leading to apoptosis and the activation of an inflammatory response.

$\mathrm{O}_{2}$ therapy involving prolonged exposure to an elevated concentration of $\mathrm{O}_{2}$ is routinely applied in clinical practice to enhance oxygenation in the presence of compromised gas exchange. While the adverse pulmonary consequences of $\mathrm{O}_{2}$ toxicity have been well established, hyperoxia exposure is often required in clinical situations involving severerly compromised oxygenation, such as in premature neonates $(9,38-40)$ or in patients with acute lung injuries (93). Since prolonged exposure to an elevated $\mathrm{O}_{2}$ concentration poses the risk of long-term adverse alterations in the lung architecture and pulmonary function (78), the prevention of hyperoxia-induced lung injury is of major importance. Although the molecular, structural and functional changes in the lungs are manifested simultaneously in the early 
phase of hyperoxia-induced lung damage, these concomitant alterations are poorly characterized. Moreover, previous studies assessed the functional changes only in long-lasting animal models in which the airway and vascular remodeling had already taken place $(14,34$, $35,82,87)$. It is therefore of fundamental importance to develop an animal model with which the short-term effects of hyperoxia on inflammation and BHR can be systematically characterized. With such a model, the effectiveness of preventive strategies against $\mathrm{O}_{2}$ toxicity can also be investigated. Many previous studies have highlighted the roles of epithelial and endothelial cell injuries following hyperoxia and the consequent decrease in nitric oxide (NO) production in the lungs, which may lead to an imbalance in the relaxation/constrictive regulation of the smooth muscle $(54,61,83)$. NO activates the enzyme guanylate cyclase, which facilitates stimulation of the enzyme protein kinase $G$ by cyclic guanosine monophosphate (cGMP), leading to a decrease in the intracellular $\mathrm{Ca}^{2+}$ level and then to relaxation of the smooth muscle (41). Besides this major regulatory role, NO also affects the lung structural development, including alveolarization (6), and is involved as a mediator of the non-adrenergic, non-cholinergic nervous system in the pathogenesis of the inflammatory response and in the regulation of the pulmonary circulation (25). These functions are inactivated in a hyperoxic environment (11), which compromises the effect of NO and NOdependent pathways by increasing the activity of cGMP-dependent phosphodiesterases (PDEs), resulting in impaired airway relaxation (44) and abnormal angiogenesis (20, 44). Thus, restoration of the NO-dependent processes with a $\mathrm{PDE}_{5}$ inhibitor, such as sildenafil, may provide an effective protection against the development of lung injury following hyperoxia (44). The lack of the NO-mediated effects may also be compensated by enhancing the vasoactive intestinal peptide (VIP) pathway, which additionally regulates the smooth muscle tone, and potentiates the release of NO from the endothelium and the VIP/NOcontaining nerve fibers $(1,3,52)$. All these mechanisms indicate that influencing these pathways may be beneficial in the protection against hyperoxia-induced lung injury.

\subsection{Detection of BHR}

The assessment of BHR plays a key role in the diagnosis of asthma $(12,15,29,43)$. Since asthma frequently begins during childhood, the early diagnosis and adequate treatment of asthma in an early state significantly improve the prognosis and the quality of life (79). In older children or adults, the BHR can be detected indirectly by performing spirometry during 
airway challenges with an inhaled bronchoconstrictor agonist. Carefully dosed and monitored bronchoconstrictors such as methacholine $(\mathrm{MCh})$, histamine (His), adenosine, cold air or exercise provoke the symptoms resulting in the airway obstruction which reflects the worsening of the lung function and the appearance of clinical signs. The confirmatory test for the lung function in asthma is based on forced expiratory maneuvers beginning at school age. The airway obstruction leads to a reduced airflow during forced exhalation (e.g. the average forced expired flow between $25 \%$ and $75 \%$ of the volume expired- $\mathrm{FEF}_{25-75}$ ) and smaller partial expiratory lung volumes (e.g. the forced expiratory volume in the first second of expiration- $\mathrm{FEV}_{1}$ ). The forced vital capacity (FVC) may be normal because of the hyperinflated lungs in asthma and a diminished ratio $\mathrm{FEV}_{1} / \mathrm{FVC}$ is therefore also an informative sign of the obstruction. Although forced expiratory maneuvers furnish valuable parameters to through which detect BHR, such measurement of the lung function in young (preschool) children is limited by their inability to provide the close cooperation necessary for spirometry.

The forced oscillation technique (FOT) has gained increasing attention for the measurement of respiratory mechanics in children because this approach requires no special breathing maneuvers $(22,69)$. Furthermore, the FOT measures the input impedance of the respiratory system (Zrs) with, its real part directly reflecting the overall airway caliber and the imaginary part related to the elasticity of the respiratory tissues. Thus, in contrast with spirometry, the FOT provides direct information on the mechanical properties of the airways and the respiratory tissues. These beneficial properties of the FOT have resulted in numerous previous studies in which the lung function was assessed in children with no respiratory disease (30, $64,88)$, or with various lung diseases such as cystic fibrosis $(23,24,49,77,88)$, neonatal chronic lung disease $(88,90)$, wheezy bronchitis $(68,88,94,95)$ or asthma $(12,29,43,64$, 88). Despite the potential of the FOT to detect early bronchoconstriction following different challenges, the sensitivity of this method for the detection of BHR has not been systematically compared with that of the gold standard spirometry in asthmatic children. The efficiency of FOT in the detection of BHR has already been confirmed in animal studies and this technique has been shown to be an appropriate method for the assessment of changes in airway and respiratory tissue mechanics. 


\section{AIMS OF THE STUDIES INCLUDED IN THE PRESENT THESIS}

The main goals of the studies included in the present thesis are related to the attainment of a greater understanding of the underlying mechanisms of BHR. Specifically, the studies were designed with three particular aims:

- To investigate the consequences of chronic RSD inhalation on the airway and respiratory tissue mechanics in an animal model. We further set out to explore whether chronic RSD exposure leads to BHR, which is the hallmark feature of airway susceptibility.

- To unravel the links between the morphological, biochemical and functional changes in the early phase of hyperoxia exposure and to assess the effectiveness of preventive treatment by enhancing the NO/cGMP pathway in an animal model of short-term $\mathrm{O}_{2}$ exposure in immature rats. We hypothesized that sildenafil and VIP have the potential to exert protection in the early phase of hyperoxia-induced lung damage and BHR by inhibiting the initiation of the cascade mechanism that leads to an irreversible lung injury in developing lungs.

- To establish which FOT parameter is most appropriate for the detection of BHR in asthmatic children, and more specifically to compare the sensitivities of the FOT and spirometry during airway challenges involving the inhalation of various direct stimuli commonly utilized in clinical practice (His and MCh). 


\section{MATERIALS AND METHODS}

The RSD exposure protocol was approved by the Experimental Ethics Committee of the University of Szeged (I-74-17/2010) and the Animal Health and Welfare Office of the local authorities in Hungary. The experimental protocols on Sprague-Dawley rats were approved by the Experimental Ethics Committee of the University of Geneva and the Animal Welfare Committee of the Canton of Geneva (1051/3691/II).

The clinical research protocol was approved by the Clinical Ethics Committee of the University of Szeged (Ref. No. WHO2803).

\subsection{Animal research studies}

\subsubsection{RSD inhalation}

Certified red sludge samples were obtained from the local office of the National Directorate General for Disaster Management in Devecser 10 days after the disaster. The red sludge was dried in an oven at $60{ }^{\circ} \mathrm{C}$ for $24 \mathrm{~h}$ and the resulting dry material was mechanically ground to form a powder containing fine particles able to furnish a cloud of RSD in an air flow. The

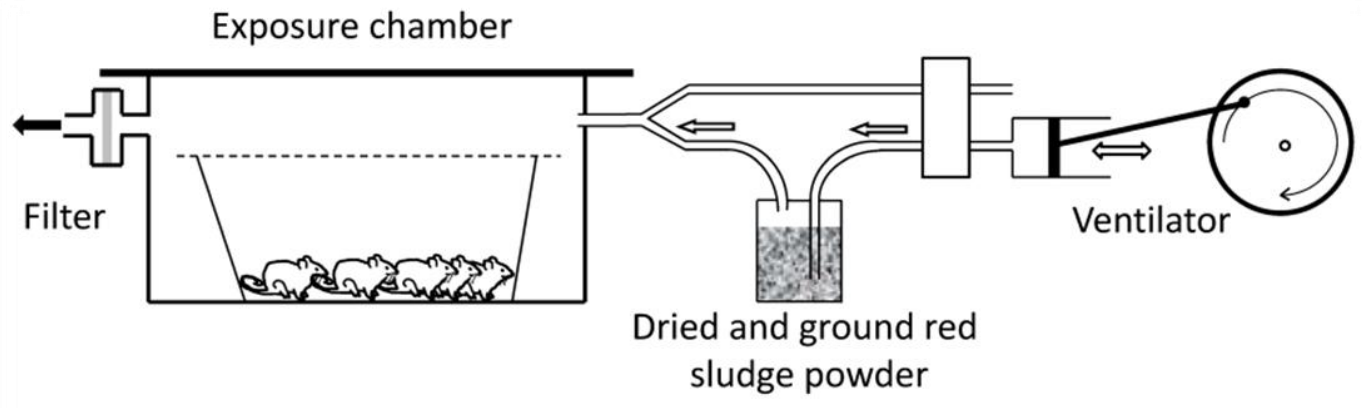

Figure 1. Experimental set-up for RSD exposure.

particle size distribution was determined. The resulting RSD was then placed in a sealed glass container with two tubes passing through its lid. The internal end of one of these tubes was immersed in the RSD and the other end was attached to the inspiratory port of a small animal ventilator (model 683, Harvard Apparatus Co. Inc., South Natick, MA, USA). The internal end of the other tube was kept above the RSD, while the other end was connected to the inlet of the exposure chamber. This system cyclically raises a cloud of dust in the RSD container during the inspiratory phases of the ventilator. The airborne flow of RSD by wind was 
mimicked by shaking the glass container containing the RSD for 20-30 s every 60-90 min, which intensified the access of particles to the inspiratory port and subsequently increased the RSD concentration in the exposure chamber. Since the ventilator frequency was maintained at 50 strokes/min with the stroke volume set at $30 \mathrm{ml}$ during exposure, this apparatus ensured the supply of fresh ambient gas into the exposure chamber, which contained a maximum of 5 animals at a time. The exposure chamber was connected to the atmosphere via a bacterial filter in order to avoid contamination of the room air with RSD particles (Fig. 1.)

Two groups of male Wistar rats were studied (weight range 350-455 g). The animals in the RSD group were exposed to RSD in the exposure chamber for a continuous period of $8 \mathrm{~h}$ a day for 2 weeks $(n=10)$. The animals in the control group underwent the same procedure except that they were allowed to breathe room air $(n=11)$. The rats in both groups had access to food and water ad libitum throughout the entire exposure period. The experiment was performed on day 15 (Fig. 2.).

\begin{tabular}{|c|c|c|c|c|c|}
\hline $\begin{array}{c}\text { ip. } \\
\text { Chloralhydrate }\end{array}$ & $\begin{array}{c}\text { intubation, } \\
\text { preparation }\end{array}$ & $\begin{array}{c}\text { pipecuronium } \\
\text { bromide }\end{array}$ & $\begin{array}{c}\text { FOT } \\
\text { baseline }\end{array}$ & $\begin{array}{c}\text { FOT } \\
\text { bronchoprovocation }\end{array}$ & histology \\
\hline
\end{tabular}

Figure 2. Experimental protocol after RSD or room air exposure on day 15.

\subsubsection{Hyperoxia exposure}

Weanling male Sprague-Dawley rats (80-125 g) were exposed to either hyperoxia $\left(>95 \% \mathrm{O}_{2}\right)$ or normoxia (room air, Group $\mathrm{C}, \mathrm{n}=8$ ) for $72 \mathrm{~h}$. The hyperoxia-exposed animals were randomized to 3 groups: no additional treatment (Group $\mathrm{HC}, \mathrm{n}=8$ ), the oral administration of sildenafil (20 mg/day; Pfizer, Zürich, Switzerland Group; HS, n=7) or the ip injection of VIP (150 $\mu \mathrm{g}$ /day; Sigma-Aldrich, Buchs, Switzerland, Group; HV, $\mathrm{n}=8)$, in both cases starting simultaneously with the commencement of the exposure to hyperoxia.

During the 72-h $\mathrm{O}_{2}$ or room air exposure, the rats were kept in a 98-1 sealed normobaric Plexiglas chamber (Elega, Geneva, Switzerland). The chamber was opened for a short time $(<5 \mathrm{~min})$ to allow delivery of the daily treatments. The $\mathrm{O}_{2}$ and carbon dioxide $\left(\mathrm{CO}_{2}\right)$ levels were checked twice a day (Datex, Helsinki, Finland). The $\mathrm{CO}_{2}$ level in the box was maintained below $1 \%$ by using a $\mathrm{CO}_{2}$ absorber (Sodasorb, Asid Bonz $\mathrm{GmbH}$, Herrenberg, Germany). Food and water were available ad libitum. 
The experiment was performed on day 4 (Fig. 3.).

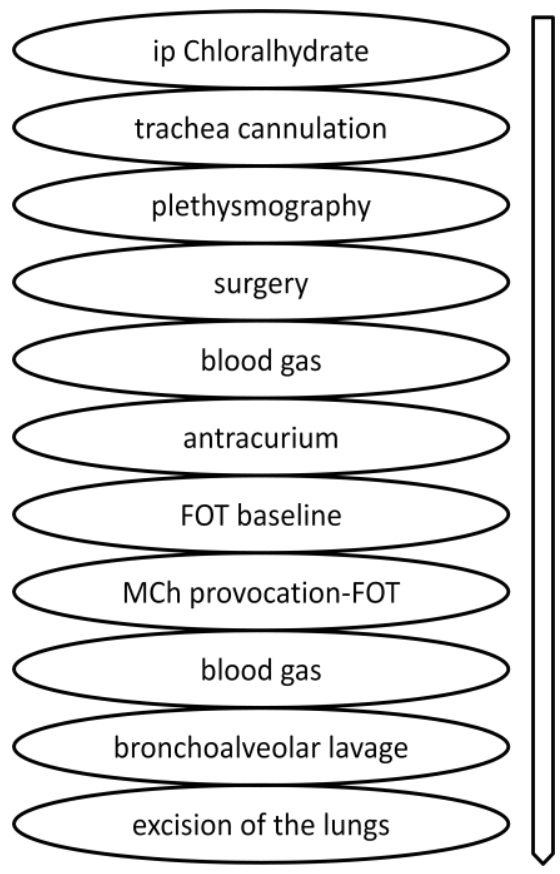

Figure 3. Experimental protocol after hyperoxia or room air exposure on day 4. The animals were mechanically ventilated (model 683; Harvard Apparatus, South Natick, MA, USA) with a tidal volume of $8 \mathrm{ml} / \mathrm{kg}$, a respiratory rate of 110 breaths $/ \mathrm{min}$ and a positive end-expiratory pressure of $2.5 \mathrm{cmH}_{2} \mathrm{O}$. Anesthesia was maintained with the repeated administration of $50 \mathrm{mg}$ of chloral hydrate every hour. After completion of the end-expiratory lung volume (EELV) measurements, a femoral artery was cannulated and attached to a pressure transducer (model 156 PCE 06-GW2; Honeywell, Zürich, Switzerland) to allow monitoring of the systemic blood pressure. The femoral vein was also catheterized for drug delivery. This line was used for the MCh provocation (Bichsel AG, Interlaken, Switzerland). Intratracheal pressure, systemic blood pressure, ECG and rectal temperature were monitored throughout the experiments (Biopac, Santa Barbara, CA, USA). Body temperature was maintained at $37 \pm 0.5^{\circ} \mathrm{C}$ through use ofa homeothermic blanket system (Homeothermic monitor; Harvard Apparatus, Edenbridge, UK).

\subsection{Clinical research study on asthmatic children}

Twenty asthmatic children (5 girls and 15 boys, age range 5-18 years) were enrolled into the study. Asthma was diagnosed according to the Global Initiative for Asthma (GINA) guidelines (8), based on the previous history of recurrent coughing, wheezing, shortness of breath (at rest or following exercise), and the symptomatic improvement following shortacting bronchodilator administration. Each child and/or their guardian completed the informed consent document, which was approved by the Clinical Ethics Committee of the University of Szeged (Ref. No. WHO2803). Seventeen children did not receive any regular asthma medication during one month prior to the study; they used only inhaled salbutamol (Sal) occasionally as needed. Three children used inhaled corticosteroid as maintenance (budesonide $200 \mu \mathrm{g}$ twice a day) and Sal (200 $\mu \mathrm{g}$ as needed) as rescue therapy. Only patients who did not need Sal during $8 \mathrm{~h}$ before the visit were included in the study. The children visited the pulmonary function laboratory twice in 2 weeks. On the first occasion His provocations were performed, and 2 weeks later the measurements were repeated with MCh challenges. 


\subsection{Lung function measurements}

\subsubsection{Respiratory mechanics- FOT}

The frequency ranges studied in the various protocols were chosen in accordance with the research question and the measurement conditions. Thus, a low-frequency oscillation technique (LFOT) was applied in rats in order to assess the airway and respiratory tissue mechanics (elastance- $\mathrm{H}$ and damping- $\mathrm{G}$ ) separately. Otherwise, the medium frequency range was studied in spontaneously breathing children since it provides detailed information concerning the mechanical status of the airways and the respiratory tissue elasticity without the need for an apneic period.

\subsubsection{Measurements in rats}

Zrs was estimated with the LFOT, as described in detail previously (73). Briefly, the tracheal cannula was connected to a loudspeaker-in-box system generating a composite signal containing 23 components at low frequencies $(0.5-20.75 \mathrm{~Hz})$. The forcing signal was driven through a 100-cm-long and 2-mm-ID polyethylene wave-tube into the trachea during 6-s apneic periods. Two identical pressure transducers (Model 33NA002D; ICSensors, Malpitas, CA, USA) were used to measure the lateral pressures at the loudspeaker and at the

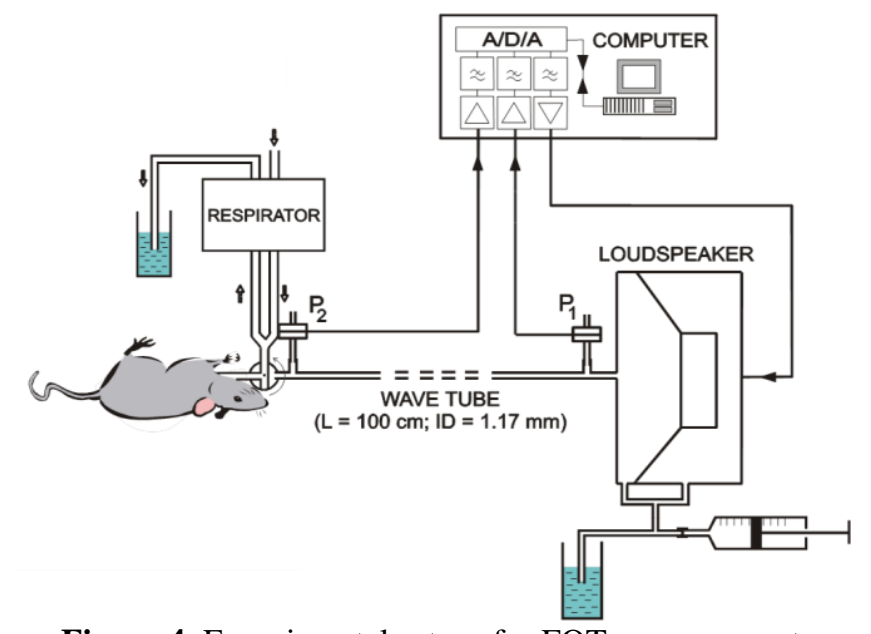

Figure 4. Experimental set-up for FOT measurements. tracheal end of the wave-tube (Fig. 4.). A deep inspiration to a pressure of $30 \mathrm{cmH}_{2} \mathrm{O}$ was applied before the first FOT measurement so as to standardize the volume history. The mechanical ventilation was then paused at end-expiration, and 4-6 6-s-long recordings were collected at 1-min intervals between each measurement under baseline conditions and following MCh provocations. Zrs was calculated by applying the transmission line theory (91). A model including frequency-independent resistance (Raw), inertance (Iaw) and a constant-phase tissue compartment with tissue parameters for $\mathrm{G}$ and elastance $\mathrm{H}$ was fitted to the ensemble-averaged Zrs spectra (31): 


$$
\mathrm{Zrs}=\mathrm{Raw}+\mathrm{j} \omega \mathrm{Iaw}+(\mathrm{G}-\mathrm{jH}) / \omega^{\alpha}
$$

where $j$ is the imaginary unit, $\omega$ is the angular frequency $(2 \pi f)$ and $\alpha=2 / \pi \arctan (H / G)$. The parameters Raw and Iaw can be attributed to the airways, while $\mathrm{G}$ and $\mathrm{H}$ represent the viscous (damping or resistive component) and elastic properties, respectively, of the respiratory tissues. The lung tissue hysteresivity $(\eta)$ was calculated as $\eta=\mathrm{G} / \mathrm{H}(21)$. The model was fitted to each average impedance spectrum by minimizing the differences between the measured and the modeled impedance data. The optimization procedure was used with a relative (weighted) fitting criterion: the differences between the measured and modeled impedance values were normalized by the impedance magnitude at each frequency point (32).

\subsubsection{Measurements with the classical setup in human patients}

The FOT measurements were performed in accordance with the European Respiratory Society (ERS) guidelines (69). To measure Zrs during spontaneous breathing, a commercially available device (i2m, Chess Medica, Oostakker, Belgium) was applied. Briefly, a loudspeaker was used to generate the pseudorandom broad-band oscillatory pressure signals containing integer multiple frequencies between 4 and $48 \mathrm{~Hz}$. The forcing signal was applied to the child via a disposable bacterial filter and a mouthpiece (Type PBF-30, Piston Ltd, Budapest, Hungary). Zrs was obtained from 8-s-long measurements while the child performed normal breathing during the oscillatory measurements. The equipment was calibrated by measuring known impedances prior to the measurements. The additional impedance of the bacterial filter and mouthpiece was determined and the Zrs spectra were corrected for this equipment component.

During the 8-s-long data-recording periods, the children sat upright, wearing a noseclip and breathing quietly through the mouthpiece. They were asked to support their cheeks with their palms during these maneuvres in order to minimize upper airway shunting. The Zrs recordings were accepted if the coherence functions between the pressure and flow signals were generally greater than 0.95 , no leak was noted around the mouthpiece, and no technical artefact occurred due to coughing, swallowing or glottis closure.

The changes in the resistive properties of the respiratory system were evaluated by calculating the average resistance between 4 and $24 \mathrm{~Hz}\left(\mathrm{R}_{4-24}\right)$ and by extracting the resistance at $6 \mathrm{~Hz}$ $\left(\mathrm{R}_{6}\right.$; the lowest frequency where the resistance was reliably measured). The elasticity of the 
respiratory system was assessed by calculating the sum of all negative values in the imaginary part of Zrs from $4 \mathrm{~Hz}$, which corresponds to the area between the reactance curve and the $\mathrm{x}$ axis $(\mathrm{AX})$, and resonant frequency $(\mathrm{Fr})$ was also extracted.

\subsubsection{Spirometry}

Spirometry is the gold standard lung function measurement in the clinical practice. Since the forced expiratory maneuvers need a high level of cooperation from the patient, this measurement technique can be used only in the clinical research field. In our study on asthmatic children, spirometry was performed in accordance with the American Thoracic Society (ATS)/ERS recommendations (59). Forced expiratory flow-volume curves were measured by means of a commercial spirometer (Type PDD-301/s, Piston Ltd, Budapest, Hungary), including a screen pneumotachograph equipped with a differential pressure transducer. The flow signal was integrated to obtain the changes in lung volume during the forced expiratory maneuvers. $\mathrm{FEV}_{1}, \mathrm{FVC}$ and $\mathrm{FEF}_{25-75}$ were extracted from the recordings. Three technically acceptable reproducible measurements were made, and the highest values of the spirometric parameters were extracted for the final analyses.

\subsubsection{Plethysmography in rats exposed to hyperoxia or room air}

End-expiratory lung volume (EELV) was measured at a positive end-expiratory pressure of $2.5 \mathrm{cmH}_{2} \mathrm{O}$ by using a whole-body plethysmograph $(620 \mathrm{ml})$, as detailed previously (37). The rats were anesthetized with an ip injection of chloral hydrate $(350 \mathrm{mg} / \mathrm{kg})$ for the surgical preparation of the tracheotomy and the trachea cannulation. Briefly, the rats were placed in a supine position in a sealed Plexiglas chamber. The tracheal cannula was connected to the respirator and also to a pressurized $\left(2.5 \mathrm{cmH}_{2} \mathrm{O}\right)$ loudspeaker chamber. Before the measurement, the mechanical ventilation was paused, the plethysmograph was opened to the atmosphere and the trachea was opened to the loudspeaker chamber to equilibrate the lungs to a pressure of $2.5 \mathrm{cmH}_{2} \mathrm{O}$. The airway opening and the plethysmograph box were then closed until the first few breathing efforts generated by the animal against the closed trachea. Six-toeight breathing maneuvers were recorded for $10 \mathrm{~s}$ by measuring the tracheal $\left(\mathrm{P}_{\text {tr }}\right)$ and box $\left(\mathrm{P}_{\mathrm{box}}\right)$ pressure changes. The recordings of $\mathrm{P}_{\mathrm{box}}$ were then corrected for the thermal properties of the plethysmograph. Via Boyle's law, EELV was calculated from the relationship between the corresponding changes in $\mathrm{P}_{\text {tr }}$ and $\mathrm{P}_{\mathrm{box}}(37)$. 


\subsection{Bronchoprovocation and reversibility tests}

\subsubsection{Intravenous challenges}

\subsubsection{Assessment of BHR with iv bolus of MCh}

An iv bolus of $\mathrm{MCh}$ at a dose of $2 \mu \mathrm{g} / \mathrm{kg}$ was administered into the tail vein, and Zrs was recorded $20 \mathrm{~s}, 1 \mathrm{~min}$ and $2 \mathrm{~min}$ after the injection. Previous experiments had revealed that the peak response occurs at $20 \mathrm{~s}$ after the MCh injection, and the effect is diminished 2 min later (65). Following this transient constriction, the animal was allowed to recover, and further iv MCh challenges were given with elevation of the MCh dose to 4, 8 and $16 \mu \mathrm{g} / \mathrm{kg}$. The peak increases in the mechanical parameters were observed $20 \mathrm{~s}$ after the MCh injection; these increases were related to those obtained from the average of the three baseline Zrs recordings. The MCh dose causing a $100 \%$ increase in Raw $\left(\mathrm{ED}_{100}\right)$ was calculated by linear interpolation of the dose-response curves from the individual animals.

\subsubsection{Stable bronchoconstriction with infused MCh}

To assess the lung responsiveness, MCh was infused iv in incremental doses from 4 to 8 and $16 \mu \mathrm{g} / \mathrm{kg} / \mathrm{min}$. The development of stable bronchoconstriction (Raw values within 5\%) required $5 \mathrm{~min}$. Three $\mathrm{Zrs}$ data recordings were collected and ensemble-averaged under steady-state conditions $6 \mathrm{~min}$ after the onset of MCh provocation at each infusion level. After the last dose, a 15-min period was allowed for the rat to recover from the bronchoconstriction and 3 further Zrs recordings were made and ensemble-averaged. The equivalent dose causing a $50 \%$ increase in Raw $\left(\mathrm{ED}_{50}\right)$ was calculated by linear interpolation.

\subsubsection{Aerosol challenges in children}

Increasing doses of aerosolized (Voyage Mefar jet nebulizer, Italy) His (Sigma-Aldrich Ltd, Budapest, Hungary) were administered to the children for 2 min via a face mask, in doubling doses ranging from 0.5 to $16 \mathrm{mg} / \mathrm{ml}$. A set of Zrs recordings and three forced expiratory maneuvers for spirometry were collected after each dose. An interval of at least 5 min was allowed between two consecutive doses. The study was terminated before the highest dose of histamine, or if $\mathrm{FEV}_{1}$ decreased by more than $20 \%$ and/or clinical symptoms of wheeze or a persistent cough were noted $(10,16)$. To detect the reversibility of the bronchoconstriction, the challenge protocol was terminated in all children by administering $400 \mu \mathrm{g}$ of inhaled Sal 
(Ventolin; GlaxoSmithKline, Greenford, UK), followed by the final assessment of Zrs and spirometry. The children revisited the lung function laboratory 2 weeks later. The baseline FOT and spirometry were performed identically as detailed above. Aerosolized saline as the solvent of the agonists was then administered for $2 \mathrm{~min}$, and both the FOT and spirometry were repeated. The bronchoprovocation tests with increasing doses of $\mathrm{MCh}(0.5$ to $8 \mathrm{mg} / \mathrm{ml}$ for $2 \mathrm{~min}$ ) and the broncholysis with Sal was then repeated in the same manner as detailed above.

\subsection{Lung inflammation, morphological and biochemical assessments in rats}

\subsubsection{Lung histology following RSD inhalation}

Representative lung tissue sections (from the mid portion of both lungs) were embedded in paraffin blocks. Transhilar horizontal sections (perpendicular to the longitudinal axes of the lung from the hilum) were embedded in paraffin. Two 5- $\mu \mathrm{m}$ sections were prepared in each lung specimen and were stained with hematoxylin-eosin. All slides were examined by the same investigator in a blind fashion and in a random sequence. A lung injury score was used to quantify the changes in lung morphometry observed under a light microscope. The degree of microscopic injury was scored with regard to the following variables: blood congestion (hyperemia), infiltration of perivascular and perialveolar inflammatory cells (lymphocytes, plasma cells and macrophages), and the presence of bronchus-associated lymphoid tissue (BALT) or its hyperplasia. The severity of injury was graded as follows for each of the four variables: no injury (None), injury involving up to one-third of the field (Mild), injury involving up to two-thirds of the field (Moderate) and diffuse injury throughout the field (Severe).

\subsubsection{Bronchoalveolar lavage and lung histology in hyperoxic and normal rats}

Since inflammation plays an important role in the development of hyperoxia-induced lung injury, bronchoalveolar lavage fluid (BALF) was collected in order to analyze the inflammatory response to hyperoxia in the lungs. The lungs were instilled with $3 \mathrm{ml}$ of phosphate-buffered saline (PBS, $37^{\circ} \mathrm{C}$ ) via the tracheal cannula at a pressure of $20 \mathrm{cmH}_{2} \mathrm{O}$. From the withdrawn BALF, the total cell number was counted in a Neubauer hemocytometer by using the trypan blue exclusion method. The BALF was then centrifuged at $200 \mathrm{x} g$ for 10 
min at $4{ }^{\circ} \mathrm{C}$. The BALF supernatant was collected to assess the protein content (PIERCE BCA assay kit; Rockford, IL, USA). The cell pellet was resuspended at $10^{6}$ cells/ml in PBS containing $1 \%$ bovine serum albumin, and the level of alveolar cell repartition was determined on cytospin after May-Grünwald Giemsa staining. At the end of the experiment, the left lung was clamped to avoid the formalin fixation. The right lung was fixed with $4 \%$ formaldehyde under a pressure of $20 \mathrm{cmH}_{2} \mathrm{O}$ and embedded in paraffin. The 6- $\mu \mathrm{m}$ sections were stained with hematoxylin-eosin. Full-section images were captured with a MIRAX MIDI system (Carl Zeiss MicroImaging $\mathrm{GmbH}$ ). Digitalized images were analyzed for perivascular edema by using Panoramic Viewer software (3DHISTECH, Budapest, Hungary) and for lung alveolar geometric structure and density by mean linear intercept (MLI) measurement, using Image J software (version 1.46r, NIH, Bethesda, USA) by the same investigator in a blind fashion and in a random sequence.

\subsubsection{Hyperoxia-induced apoptosis}

The left lung was clamped, removed and preserved in Optimal Cutting Temperature Compound at $-80{ }^{\circ} \mathrm{C}$. Terminal deoxynucleotidyl transferase (TdT)-mediated deoxyuridinetriphosphate (dUTP) nick end-labeling (TUNEL) was performed on lung cryosections according to the protocol for the In Situ Cell Death Detection Fluorescein Kit (Roche, Mannheim, Germany). Briefly, 6- $\mu \mathrm{m}$ lung slices were fixed with 4\% formaldehyde for $10 \mathrm{~min}$ at room temperature and next permeabilized for 2 min with $0.1 \%$ Triton X-100 in $0.1 \%$ sodium citrate at $4{ }^{\circ} \mathrm{C}$. The slices were then incubated with the labeling mix containing TdT and fluorescein-labeled dUTP for $1 \mathrm{~h}$ at $37^{\circ} \mathrm{C}$. Fluorescent staining of total nuclei was performed with $250 \mathrm{ng} / \mathrm{ml} \mathrm{4',6-diamidino-2-phenylindole} \mathrm{(Sigma)} \mathrm{for} 5 \mathrm{~min}$ at room temperature. The slides were mounted with FluorSave Reagent (Calbiochem, Nottingham, UK). Images for analysis were acquired by confocal microscopy (LSM 510 Meta; Carl Zeiss MicroImaging GmbH, Jena, Germany) and cells were counted by using MetaFluor Fluorescence Ratio Imaging Software (version 7.7.6; Molecular Devices, Sunnyvale, USA). The ratio of the number of apoptotic nuclei as a percentage of the total number of nuclei was calculated. 


\subsection{Statistical analysis}

In the animal studies, the Shapiro-Wilk test was used to test data for normality. The mechanical parameters were normally distributed. Accordingly, two-way repeated measures analysis of variances (ANOVA), with variables of MCh dose (baseline, 4, 8, $16 \mu \mathrm{g} / \mathrm{kg} / \mathrm{min}$, or baseline, 2, 4, 8, $16 \mu \mathrm{g} / \mathrm{kg}$ ) and groups (C, HC, HS and HV or RSD and Control Groups), was used to evaluate the effects of hyperoxia or RDS inhalation on the lung responsiveness to the bronchoconstrictor provocation. The MCh doses causing a 50 or $100 \%$ increase in Raw $\left(\mathrm{ED}_{50}\right.$ or $\left.\mathrm{ED}_{100}\right)$ were calculated by linear interpolation of the dose-response curves from the individual animals.

To analyze the effects of hyperoxia on the inflammatory response (total cell number, percentage of polymorphonuclear cells-PMN and protein), or on the functional and structural changes (ED ${ }_{50}$, EELV, MLI and edema) and on the apoptosis, one-way ANOVA with the post hoc Holm-Šidák test was used in the event of normal distribution. When the distribution was not normal, ANOVA on ranks was applied for the statistical analysis.

Since the histological data following RSD inhalation were not distributed normally, the Wilcoxon signed rank test was used to compare these findings between the protocol groups.

In the human study, short-term variability in the spirometric and FOT parameters was defined as the standard deviation of percentage changes between measurements before and after saline inhalations, while long-term variability was determined by calculating the standard deviation of the percentage changes between the two baseline values at the two visits. The SD index for each parameter was calculated as the difference between the post-test and the basal value divided by the short-term SD. The Kolmogorov-Smirnov test was used to test data for normality. The changes in the FOT and spirometric parameters were assessed by using oneway ANOVA tests on repeated measures. The relationships between the continuous variables (i.e. the FOT and spirometry indices) were examined by means of Pearson correlation tests. Pairwise comparisons were performed by using the Student-Newman-Keuls multiple comparison procedures.

The values are reported as means \pm SE. Statistical significance was accepted at the level $\mathrm{p}<0.05$. The statistical tests were performed with a SigmaPlot software package (version 11 , Systat Software, Inc. Chicago, IL, USA) 


\section{RESULTS}

\subsection{Basal respiratory mechanical parameters in animal studies}

\subsubsection{RSD vs. room air inhalation}

Figure 5. illustrates the baseline values of the airway and respiratory tissue mechanical parameters for the rats in both groups. RSD exposure did not lead to any significant change in Raw ( $\mathrm{p}=0.65)$ or $\eta(\mathrm{p}=0.90)$. There was a tendency for $\mathrm{G}$ and $\mathrm{H}$ to increase in the rats exposed to RSD, but these differences did not reach the level of statistical significance $(p=0.071$ and $\mathrm{p}=0.10$, respectively).
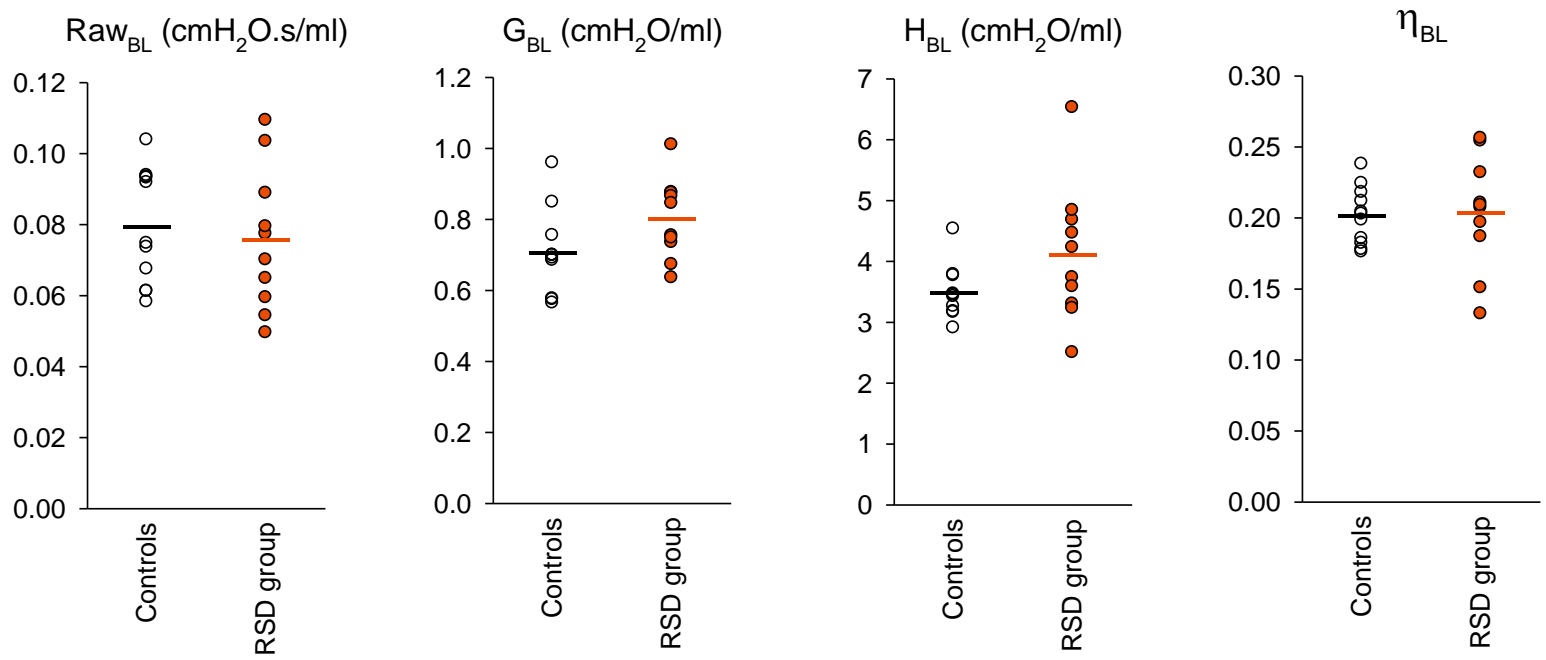

Figure 5. Baseline (BL) values of airway resistance (Raw), respiratory tissue damping (G) and elastance (H), and hysteresivity $(\eta)$ in individual rats (circles). Horizontal lines denote the group means.

\subsubsection{Hyperoxia vs. room air exposure}

Since a significant difference in the body weight (BW) was found between the groups, the mechanical parameters were corrected by BW. There was no evidence of a statistical significance in the baseline values of Raw BW following hyperoxia exposure, whereas $\mathrm{G} \cdot \mathrm{BW}$ was significantly elevated in Group $\mathrm{HC}$ ( $\mathrm{p}<0.01$ vs. Group $\mathrm{C}$ ), and $\mathrm{H} \cdot \mathrm{BW}$ was also higher in Groups HC $(p<0.05)$ and HV (p<0.01) (Fig. 6.). 
Exposure to hyperoxia significantly increased EELV in the rats in Group HC (Fig. 8B.; $\mathrm{p}<0.001$ vs. Groups C, HS and HV), but this was blocked by the sildenafil and VIP treatments.
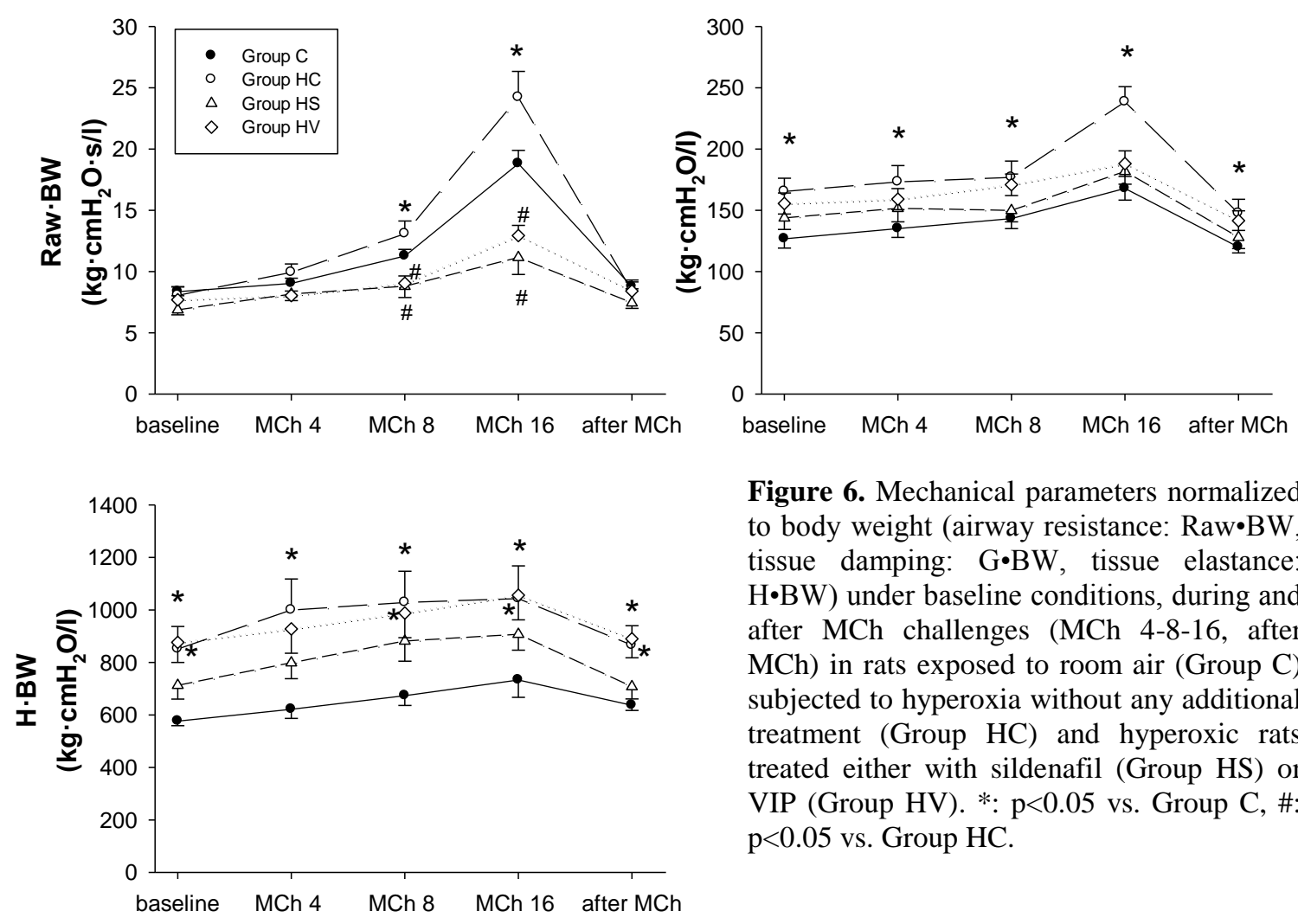

Figure 6. Mechanical parameters normalized to body weight (airway resistance: Raw $\bullet \mathrm{BW}$, tissue damping: $\mathrm{G} \cdot \mathrm{BW}$, tissue elastance: $\mathrm{H} \bullet \mathrm{BW})$ under baseline conditions, during and after MCh challenges (MCh 4-8-16, after $\mathrm{MCh}$ ) in rats exposed to room air (Group C) subjected to hyperoxia without any additional treatment (Group HC) and hyperoxic rats treated either with sildenafil (Group HS) or VIP (Group HV). *: p<0.05 vs. Group C, \#: $\mathrm{p}<0.05$ vs. Group HC.

\subsection{Changes in lung mechanics following bronchial challenges}

\subsubsection{MCh challenges after RSD or room air exposures}

The changes in the airway and tissue parameters in the control and RSD-exposed animals following the MCh challenges are demonstrated in Fig. 7. MCh caused marked dosedependent increases in Raw, $G$ and $\eta(p<0.001)$, while the increases in $H$ were less pronounced, but still statistically highly significant $(\mathrm{p}<0.001)$.

The significant interactions revealed between MCh and RSD by two-way ANOVA ( $<<0.01$ ) indicated that RSD inhalation affected the magnitude of the MCh-induced increases in Raw, i.e. BHR developed in the RSD group. The presence of BHR following chronic RSD inhalation was also reflected in the significantly lower $\mathrm{ED}_{100}$ values in the RSD group than in 
the controls $(5.3 \pm 0.2$ vs. $7.5 \pm 0.9 \mu \mathrm{g} / \mathrm{kg}$, respectively, $\mathrm{p}<0.05)$. The tissue parameters were not affected significantly by RSD inhalation $(p=0.69, p=0.15$ and $p=0.37$ for $G, H$ and $\eta$, respectively).
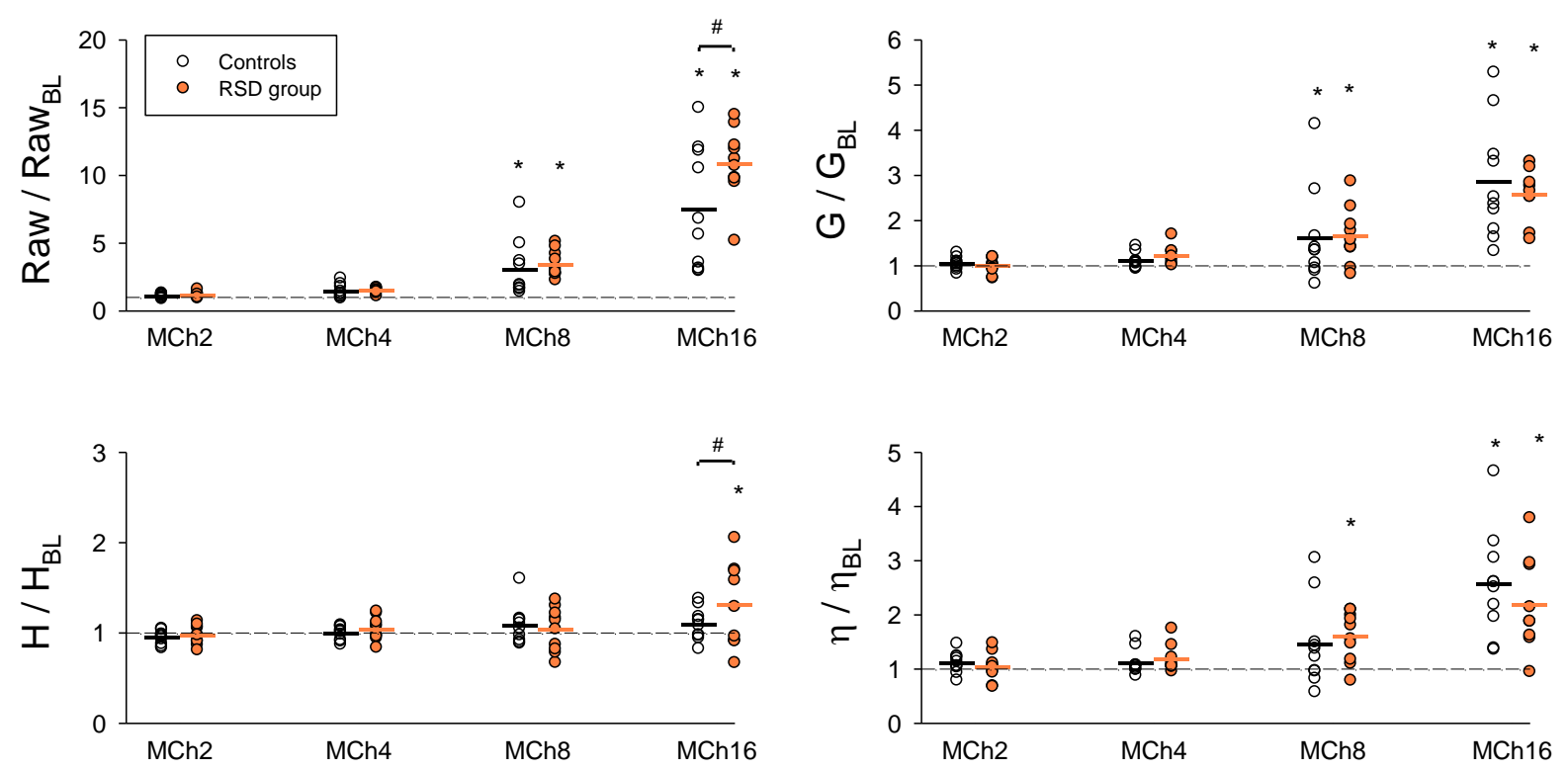

Figure 7. Airway and respiratory tissue parameters measured after MCh challenges relative to the baseline (BL) values in the control rats (closed circles) and in rats exposed to RSD (open circles). Horizontal lines denote the group mean values. *: $\mathrm{p}<0.05$ vs. the baseline; $\#$ : $\mathrm{p}<0.05$ between the groups.

\subsubsection{MCh provocations after exposure to hyperoxia or room air}

The development of BHR was apparent from the significantly greater responses to MCh in the rats in Group HC ( $\mathrm{p}<0.05$ and $\mathrm{p}<0.001$, at the second and third doses of MCh vs. Group C, respectively), whereas a significant reduction in the lung responsiveness to $\mathrm{MCh}$ was obvious in the hyperoxic rats treated with sildenafil (Group HS, p $<0.001$ at the third dose of MCh vs. Group C) or VIP (Group HV, p<0.001 at the third dose of MCh vs. Group C). The enhanced lung responsiveness in Group HC was also manifested in the significantly greater increases in $\mathrm{G} \cdot \mathrm{BW}$ in response to $\mathrm{MCh}(\mathrm{p}<0.005)$, whereas there was no evidence of an enhanced response in this parameter following either sildenafil or VIP treatment. No statistically significant treatment-dependent differences were observed in the slight MCh-induced elevations in $\mathrm{H} \cdot \mathrm{BW}$. All mechanical parameters exhibited a complete recovery by $15 \mathrm{~min}$ after the last MCh dose, with no statistically significant difference from their initial values (Fig. 6.). 
The difference due to hyperoxia in the airway responsiveness to $\mathrm{MCh}$ is also reflected in the statistically significantly decreased $\mathrm{ED}_{50}$ value (Fig. 8A) in Group $\mathrm{HC}$ as compared with Group C $(\mathrm{p}<0.01)$. Both sildenafil and VIP treatments significantly elevated this hyperoxiainduced lowering in $\mathrm{ED}_{50}(\mathrm{p}<0.01$ and $\mathrm{p}<0.001$, respectively).
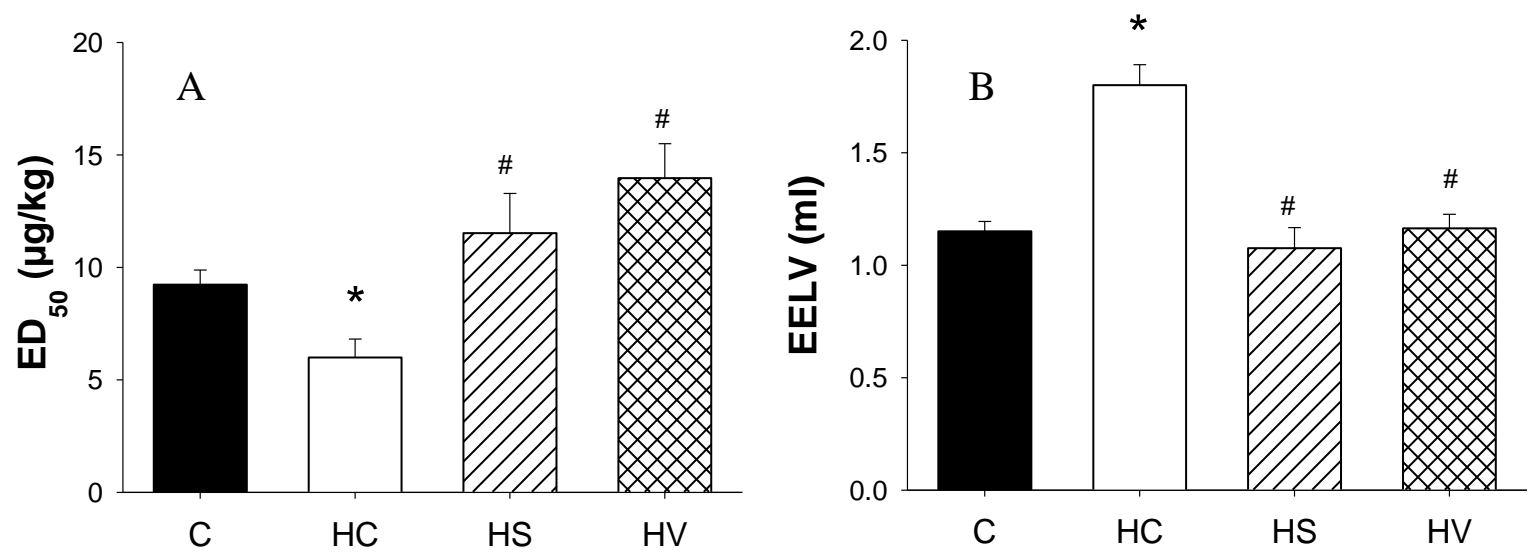

Figure 8. Equivalent doses of MCh required to cause a 50\% elevation in airway resistance (ED50, panel A) and the end-expiratory lung volumes (EELV, panel B) measured in rats exposed to room air (Group C) subjected to hyperoxia without any additional treatment (Group HC) and hyperoxic rats treated either with sildenafil (Group HS) or VIP (Group HV). *: p<0.05 vs. Group C, \#: p<0.05 vs. Group HC.

\subsection{Inflammation}

\subsubsection{Inflammatory response after $R S D$ inhalation}
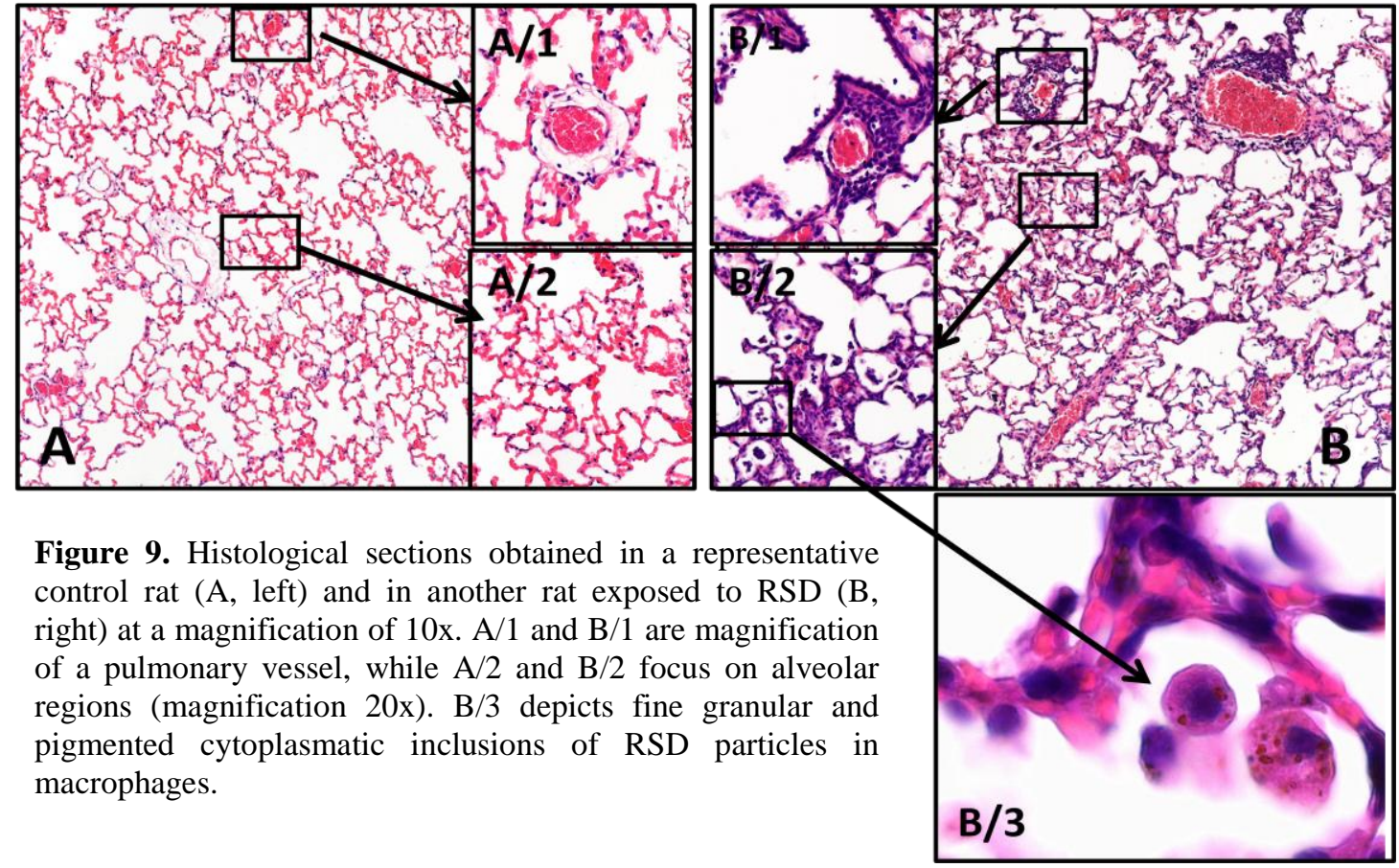

Figure 9. Histological sections obtained in a representative control rat (A, left) and in another rat exposed to RSD (B, right) at a magnification of $10 x . A / 1$ and $B / 1$ are magnification of a pulmonary vessel, while $\mathrm{A} / 2$ and $\mathrm{B} / 2$ focus on alveolar regions (magnification 20x). B/3 depicts fine granular and pigmented cytoplasmatic inclusions of RSD particles in macrophages. 
Representative histological sections in lungs obtained from rats in both groups are demonstrated in Fig. 9. Inhalation of RSD led to the perivascular infiltration (in decreasing sequence of particle amount in the lymphocytes, plasma cells, eosinophils, mastocytes and neutrophils) and the perialveolar infiltration (in decreasing sequence in macrophages, lymphocytes and plasma cells) of inflammatory cells. In the alveolar areas which exhibited an inflammatory response, RSD particles were recovered as fine, granular and pigmented cytoplasmatic inclusions in the alveolar macrophages.

\subsubsection{Hyperoxia-induced inflammation}

The alterations in the cellular profile and the protein content of the BALF are outlined in Fig. 10. Hyperoxia led to an increased number of inflammatory cells in the BALF collected from the animals in Group HC (Fig. 10A, p $<0.001$ vs. Group C and $\mathrm{p}<0.01$ vs. Groups HS and HV). The repartition of the cell types differed in Group HC from that in the other groups of rats; the percentage of PMN cells was significantly increased (Fig. 10B, p<0.001 vs. Groups $\mathrm{C}$, HS and HV). The protein content of the supernatant was significantly elevated in Group HC relative to Group C (Fig. 10C, $\mathrm{p}<0.001$ ), while there was no evidence of a significant change in the sildenafil- or VIP-treated animals as compared with Groups HC and C (Fig. 10C).

A

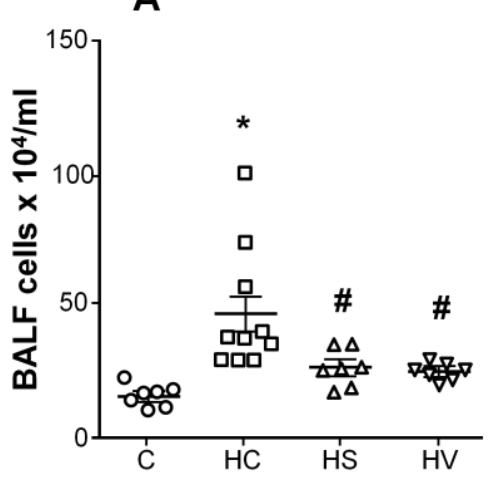

B

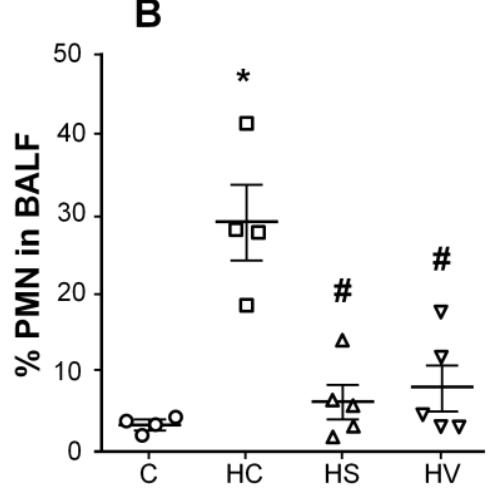

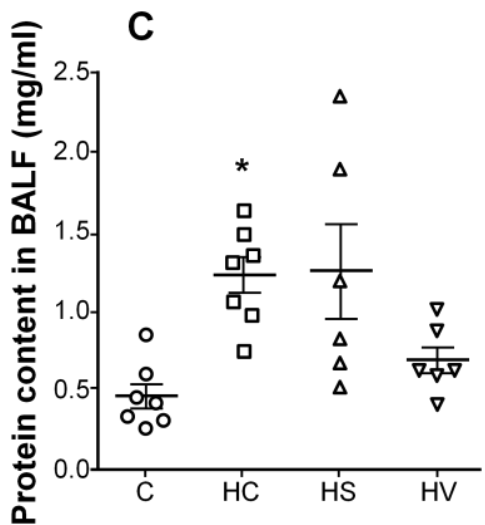

Figure 10. Total cells (panel A), the repartition to PMN cells (panel B) and the protein content (panel C) of the BALF obtained from rats exposed to room air (Group C) subjected to hyperoxia without any additional treatment (Group HC) and hyperoxic rats treated either with sildenafil (Group HS) or VIP (Group HV). *: p<0.05 vs. Group C, \#: p<0.05 vs. Group HC. 


\subsection{Lung histological changes}

\subsubsection{After RSD or room air inhalation}

Figure 11. depicts the histological findings. Chronic exposure to RSD induced the development of mild hyperemia $(\mathrm{p}<0.05)$ and the mild-to-moderate infiltration of inflammatory cells into the perivascular $(\mathrm{p}<0.01)$ or perialveolar $(\mathrm{p}<0.001)$ areas. No difference in BALT hyperplasia was observed between the two groups $(\mathrm{p}=0.43)$.
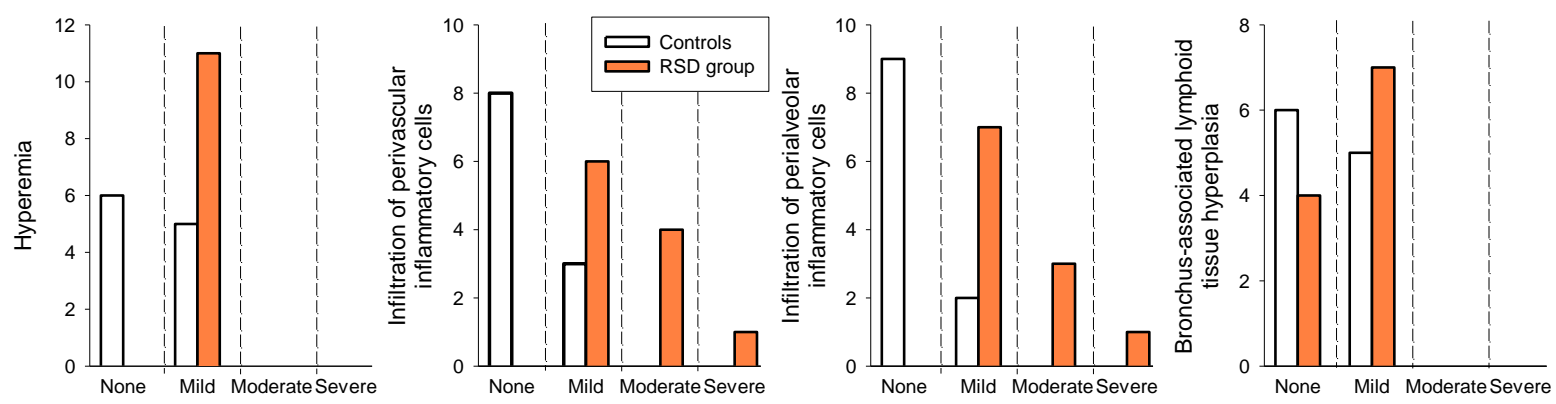

Figure 11. Numbers of control (closed bars) and RSD-treated rats (open bars) with different severity scores based on the histopathological evaluations.

\subsubsection{After exposure to hyperoxia or room air}

The histological findings are depicted in Fig. 12. The lung sections of untreated animals subjected to hyperoxia (Group HC) revealed an aberrant alveolarization with decreased alveolar septation and consequently enlarged alveolar spaces in comparison with normoxiaexposed lungs (Group C). These changes are expressed by the significantly increased MLI value (Fig. 13A, p<0.001 vs. Group C). When sildenafil (Group HS) or VIP (Group HV) treatment was applied concomitantly with hyperoxia, the normal alveolarization was preserved, as indicated by the MLI values, which exhibited no statistically significant difference from those for the normoxia group (Fig. 13A). 

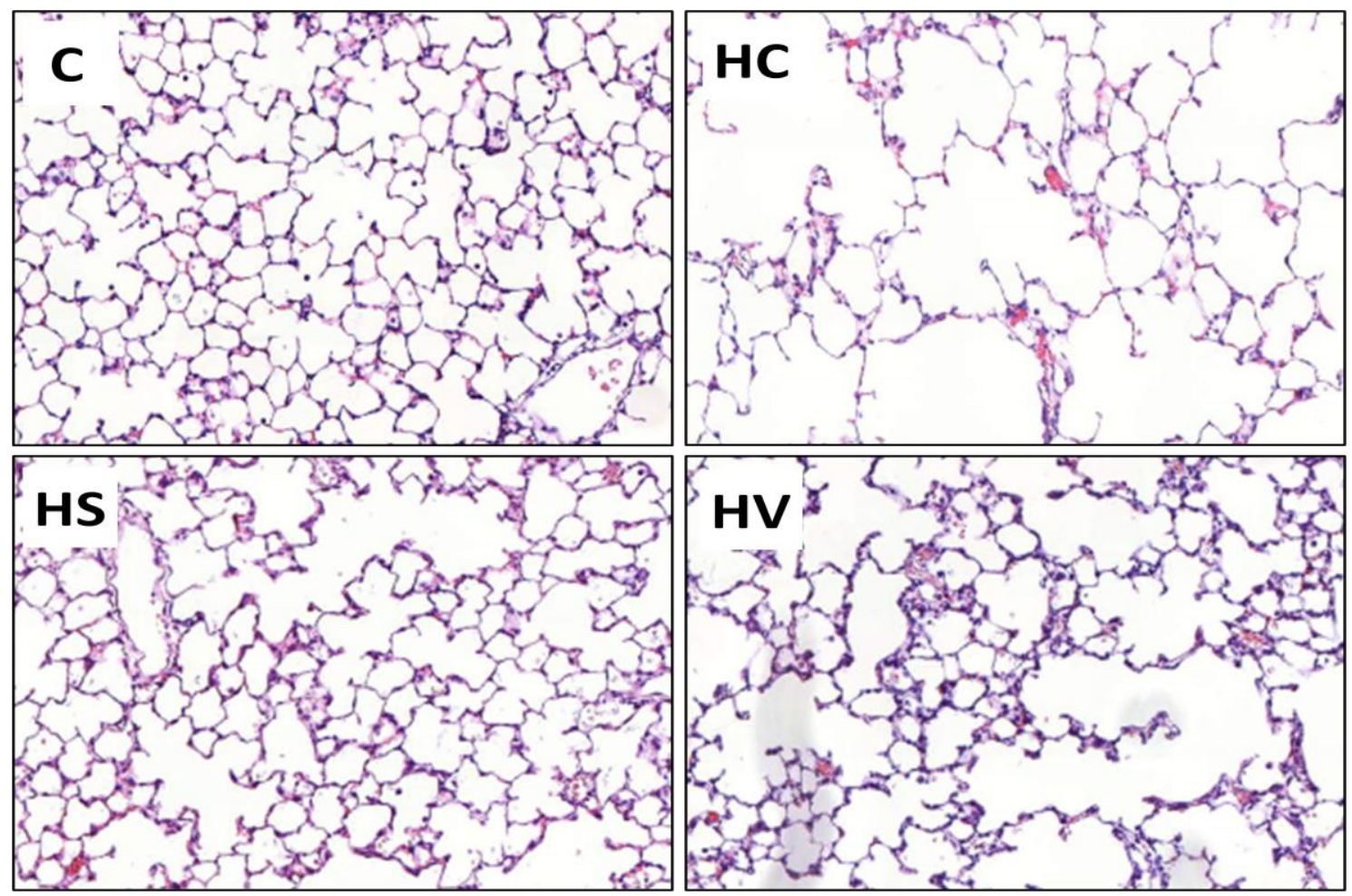

Figure 12. Representative images of hematoxylin/eosin-stained lung sections collected from control rats exposed to room air (C), rats subjected to hyperoxia without any additional treatment $(\mathrm{HC})$, and hyperoxic rats treated with either sildenafil (HS) or VIP (HV).

The $72 \mathrm{~h}$ of hyperoxia led to a vascular leakage, as revealed by the manifest edema around the pulmonary vessels (Fig. 13B). The ratio of the edema surface area to the total surface area of the lung sections was significantly greater in the non-treated animals exposed to hyperoxia than in the controls $(p<0.001)$ or in the hyperoxia-treated rats $(p<0.001$ and $p<0.01$ vs. Group HS and HV, respectively).
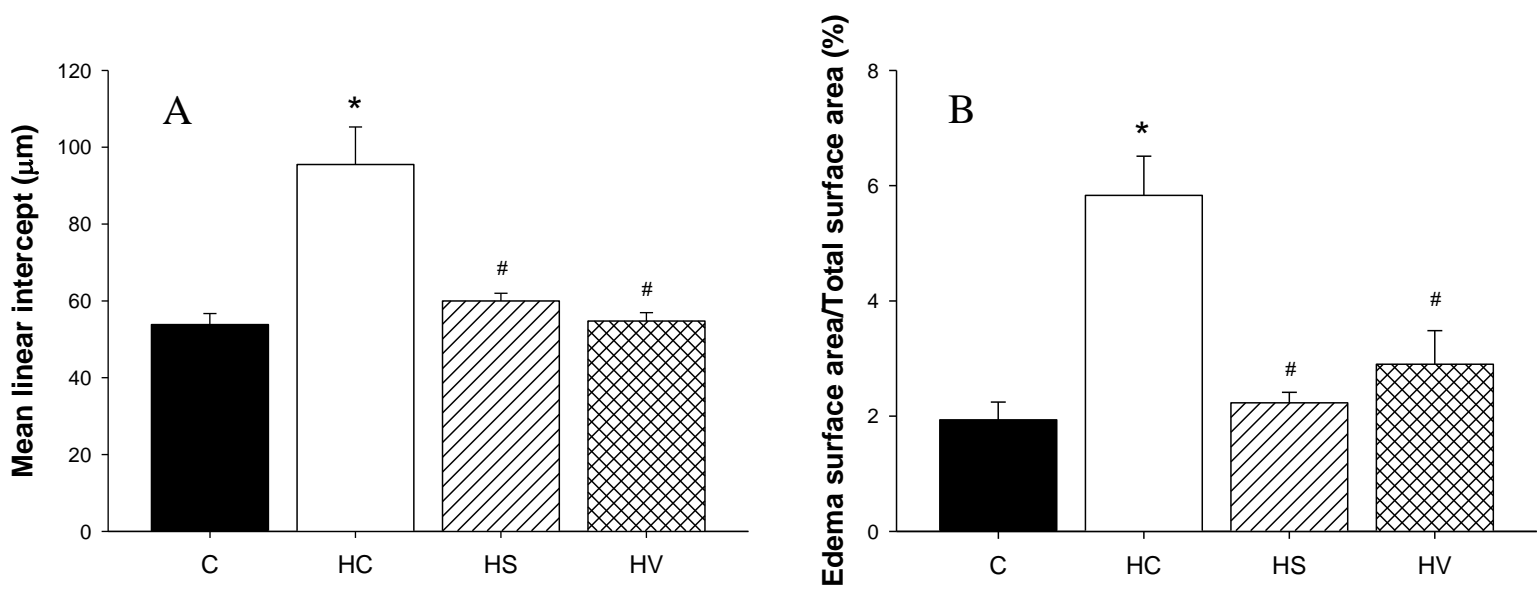

Figure 13. Mean linear intercept values (panel A) and percentage of edema surface (panel B) were determined from the lung sections of the rats in the protocol groups. *: $p<0.05$ vs. Group C, \#: $p<0.05$ vs. Group HC. 


\subsection{Hyperoxia-induced apoptosis}

For each lung cryosection, the total number of nuclei and the number that were TUNELpositive were counted in 10 independent randomized microscopic fields, representing at least 500 nuclei (506 to 1190); these results are presented in Fig. 14.

A

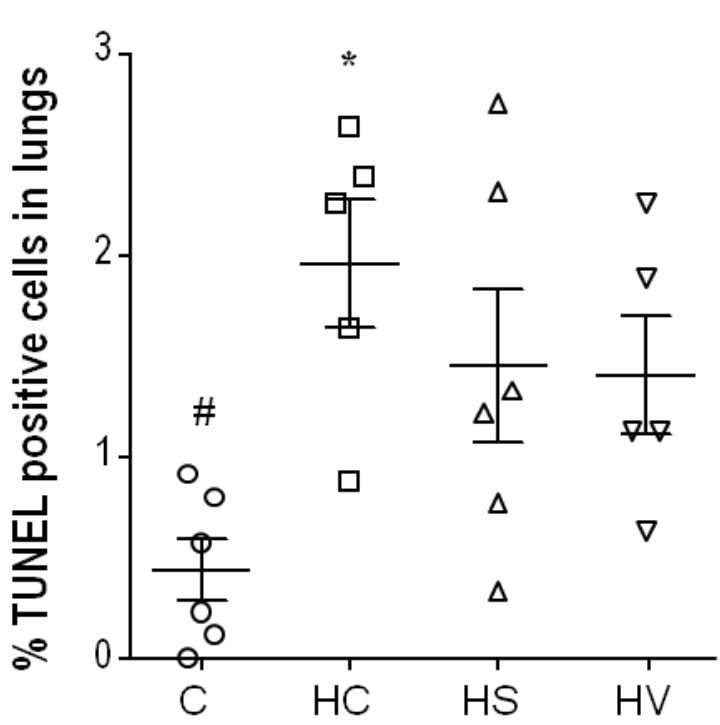

$\mathrm{B}$
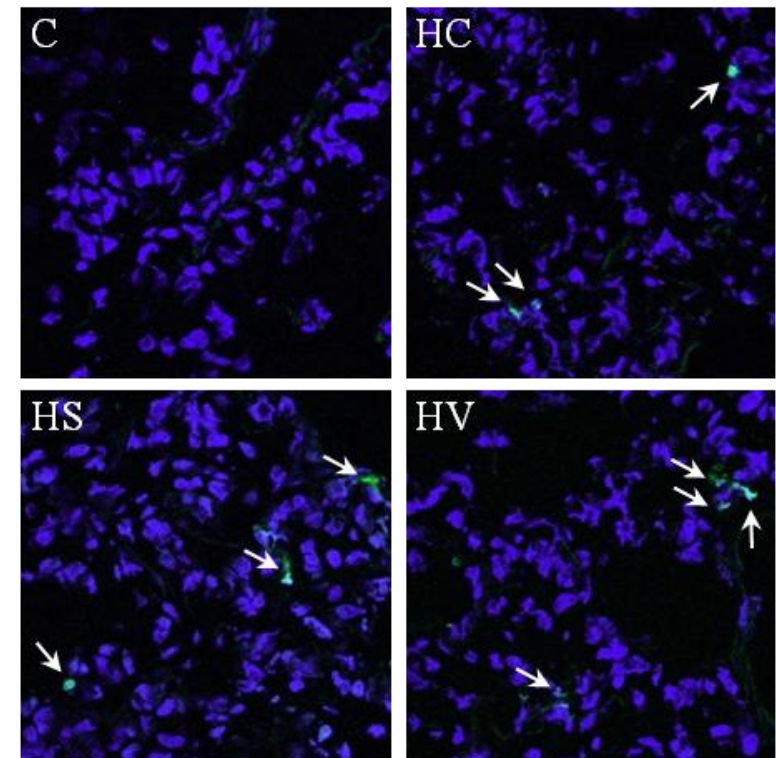

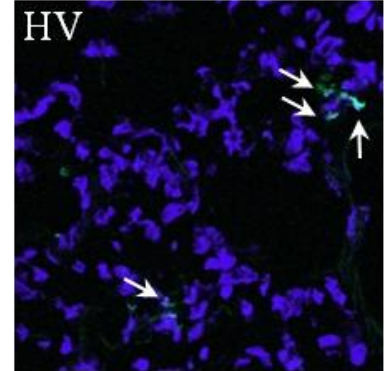

Figure 14. Percentages of TUNEL-positive nuclei counted in lung cryosections (panel A) collected from rats exposed to room air (Group C) subjected to hyperoxia without any additional treatment (Group HC) and hyperoxic rats treated either with sildenafil (Group HS) or VIP (Group HV). *: $p<0.05$ vs. Group C, ${ }^{\#}:$ p $<0.05$ vs. Group HC. Representative images for TUNEL in cryosections from the studied groups are shown in panel $\mathbf{B}$. Arrows indicate TUNEL-positive nuclei (green).

Exposure to hyperoxia induced a statistically significant increase in the percentage of positive nuclei in Group $\mathrm{HC}$ relative to that in Group $\mathrm{C}(\mathrm{p}<0.01)$. No evidence of statistically significant differences was observed in the sildenafil- or VIP-treated rats as concern the apoptosis in the lung cells in comparison with either the untreated hyperoxic or to the normoxic animals, although there were strong tendencies to increases in the relative numbers of TUNEL-positive nuclei in these groups.

\subsection{Results of the clinical study}

\subsubsection{Basal lung functional and mechanical parameters in asthmatic children}

The children had normal basal lung function parameters with a mean percentage predicted value for $\mathrm{FEV}_{1}$ of $104 \%$ (range $93-136 \%$ ) and a mean respiratory resistance between 4 and $24 \mathrm{~Hz}\left(\mathrm{R}_{4-24}\right)$ of $91 \%$ (range $\left.74-105 \%\right)$. 


\subsubsection{Detection of BHR}
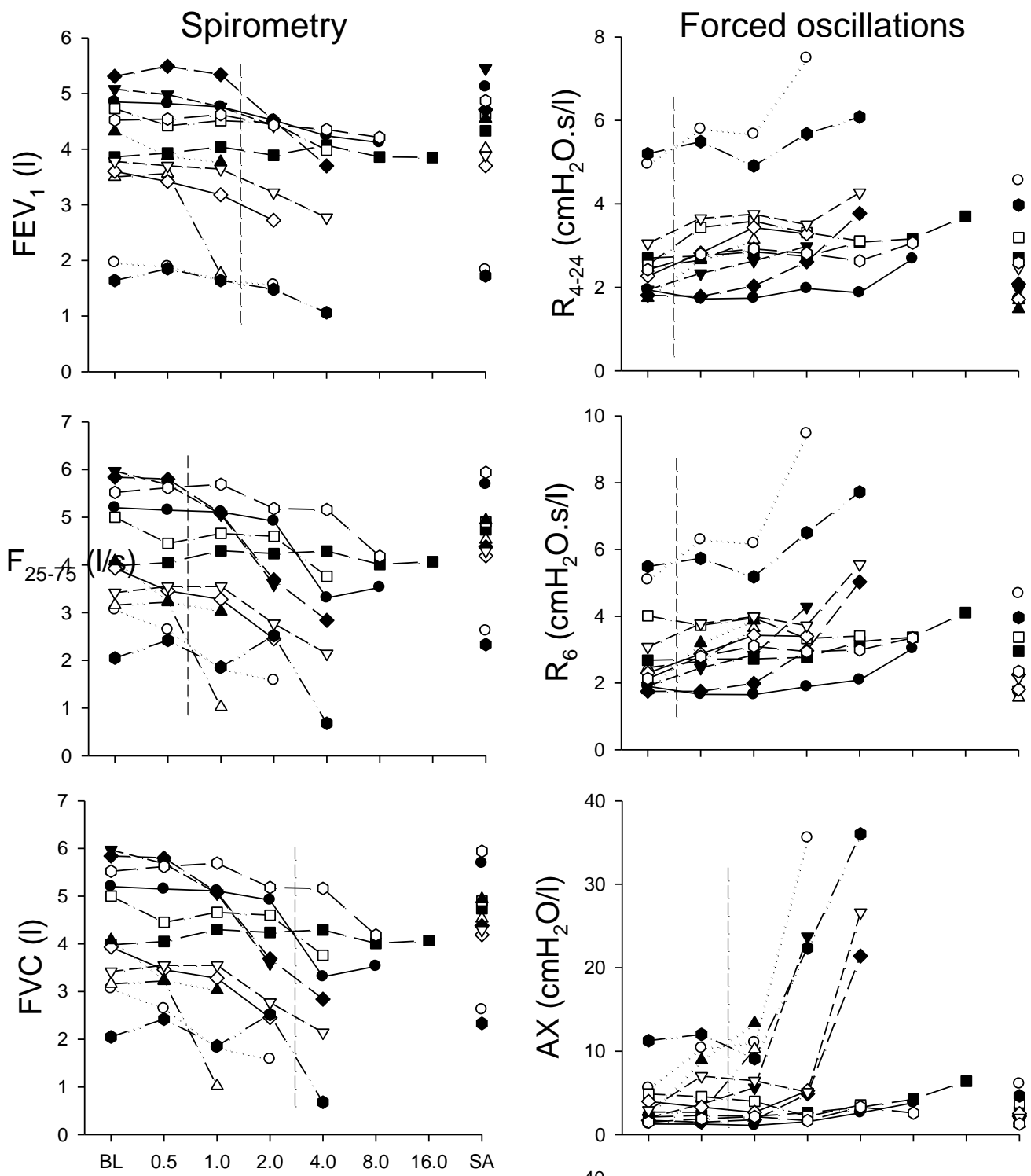

Figure 15. Lung function parameters obtained with spirometry (left) or forced oscillations (right) in individual asthmatic children under the baseline condition (BL), following inhalations of increasing doses of His (0.5-16 $\mathrm{mg} / \mathrm{ml}$ ) and after inhalation of salbutamol (SA). Vertical dashed lines indicate the limits of statistical significance.

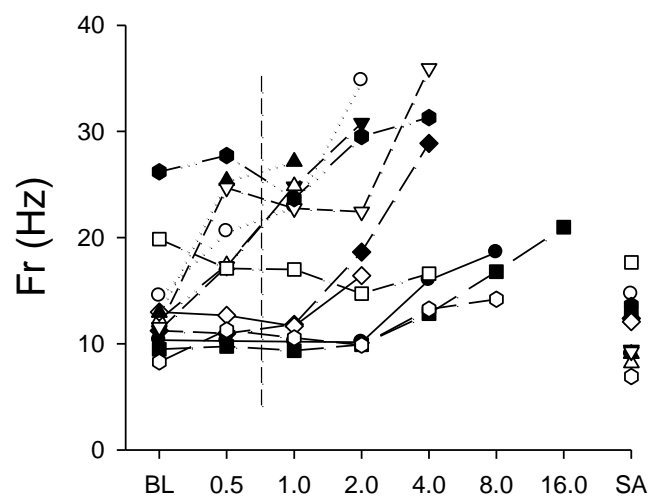


Changes observed in the spirometric and FOT parameters following His challenges are depicted in Fig. 15. Increasing doses of aerosolized His caused statistically significant decreases in the lung volume/flow indices determined by spirometry $\left(\mathrm{p}<0.001\right.$ for $\mathrm{FEV}_{1}$ and $\mathrm{FEF}_{25-75} ; \mathrm{p}<0.05$ for $\mathrm{FVC}$ ). The parameters extracted from the real and imaginary parts of the Zrs spectra exhibited dose-dependent elevations after His provocation $\left(\mathrm{p}<0.001\right.$ for $R_{4-24}, R_{6}$ and Fr, $\mathrm{p}<0.01$ for $\mathrm{AX})$. The data analyses revealed that the changes in the parameters determined with the FOT were statistically detectable at lower doses of His (after $0.5 \mathrm{mg} / \mathrm{ml}$ in $\mathrm{R}_{4-24}, \mathrm{R}_{6}$ and $\mathrm{Fr}$; and after $2 \mathrm{mg} / \mathrm{ml}$ in $\mathrm{AX}$ ) than those obtained by spirometry (after 1 $\mathrm{mg} / \mathrm{ml}$ in $\mathrm{FEV}_{1}, \mathrm{FVC}$ and $\mathrm{FEF}_{25-75}$ ). The lung function parameters obtained with spirometry after Sal inhalation were not significantly different from those measured at the beginning of the study, but the administration of Sal led to significant decreases in $R_{6}(p<0.01)$ and $A X$ $(\mathrm{p}<0.05)$, indicating that the decreases in the airway tone by the $\beta_{2}$ agonist may be reflected in the FOT indices.

Figure 16. summarizes the changes in the spirometric and FOT parameters during the MCh challenge protocol. Inhalation of saline following the baseline recordings did not cause significant changes in any of the lung function parameters $(\mathrm{p}=0.47,0.34,0.75,0.98,0.84$, 0.94 and 0.55 for $\mathrm{FEV}_{1}, \mathrm{FEF}_{25-75}, \mathrm{FVC}, \mathrm{R}_{4-24}, \mathrm{R} 6, \mathrm{AX}$ and $\mathrm{Fr}$, respectively). Inhalation of increasing doses of $\mathrm{MCh}$ resulted in dose-dependent decreases in $\mathrm{FEV}_{1}, \mathrm{FEF}_{25-75}$ ( $\mathrm{p}<0.001$ for both) and FVC $(\mathrm{p}<0.01)$. All parameters obtained with the FOT displayed dose-dependent significant increases following MCh inhalation $(\mathrm{p}<0.001$ for all). The changes in the spirometric indices became statistically significant after a MCh dose of $1.0 \mathrm{mg} / \mathrm{ml}$. Inhalation of even the smallest concentration of MCh $(0.5 \mathrm{mg} / \mathrm{ml})$ was sufficient to cause statistically detectable increases in the FOT parameters $R_{4-24}, R_{6}$ and Fr, while significant increases in AX were observed after a MCh dose of $1 \mathrm{mg} / \mathrm{ml}$. Inhalation of Sal after these bronchial provocations totally abolished the bronchoconstrictor effects of MCh. Similarly as for His, the resistance parameters obtained with the FOT revealed significant decreases in the airway tone after Sal inhalations $\left(\mathrm{p}=0.002\right.$ for $\mathrm{R}_{4-24}, \mathrm{p}=0.006$ for $\mathrm{R}_{6}$ ), while these changes were not reflected in the spirometric indices. 

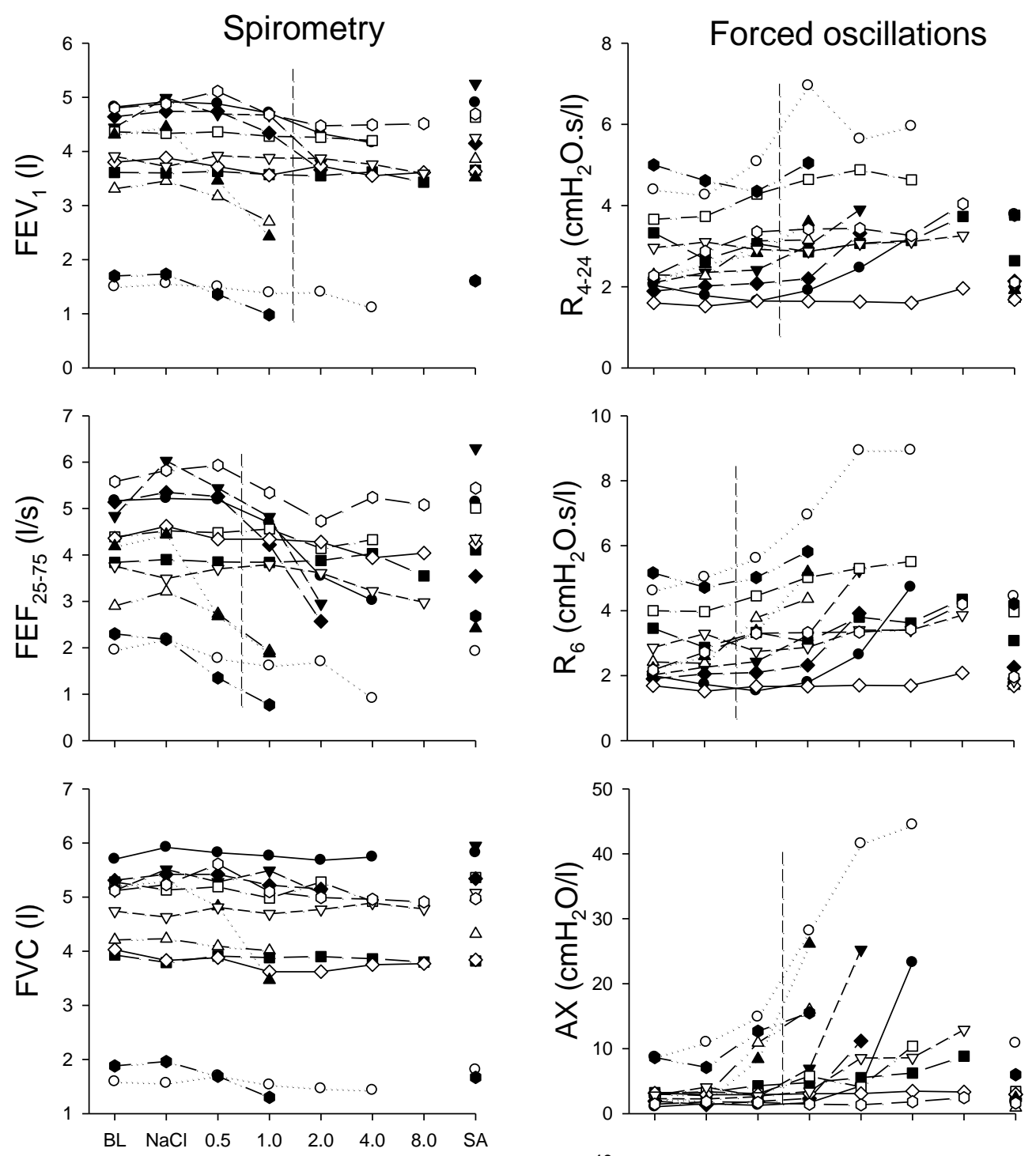

Figure 16. Lung function parameters obtained with spirometry (left) or forced oscillations (right) in individual asthmatic children under the baseline condition (BL), following inhalations of normal saline $(\mathrm{NaCl})$ and increasing doses of $\mathrm{MCh}(0.5-8.0 \mathrm{mg} / \mathrm{ml})$, and after inhalation of salbutamol (SA). Vertical dashed lines indicate the limits of statistical significance.

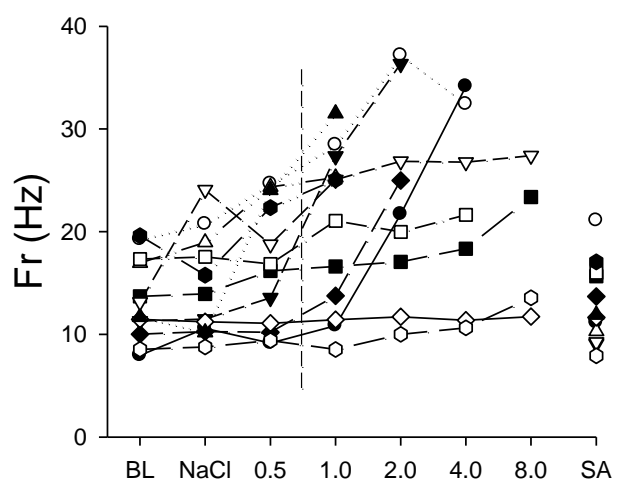




\subsubsection{Comparison of the parameters obtained with spirometry and FOT}

\subsubsection{Relationships between the parameters detected}

The $\mathrm{FEV}_{1}$ values obtained with spirometry and the resistance values in the medium frequency range $(4-24 \mathrm{~Hz})$ obtained with the FOT are primarily determined by the geometry of the central conducting airways. Conversely, the contributions of the small airways appear in the
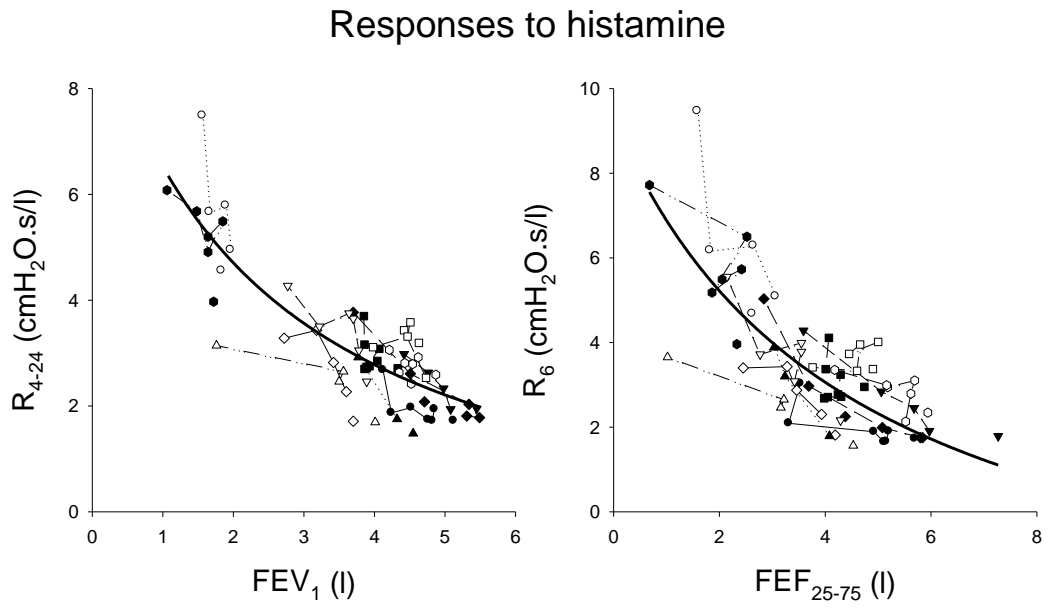

Responses to methacholine
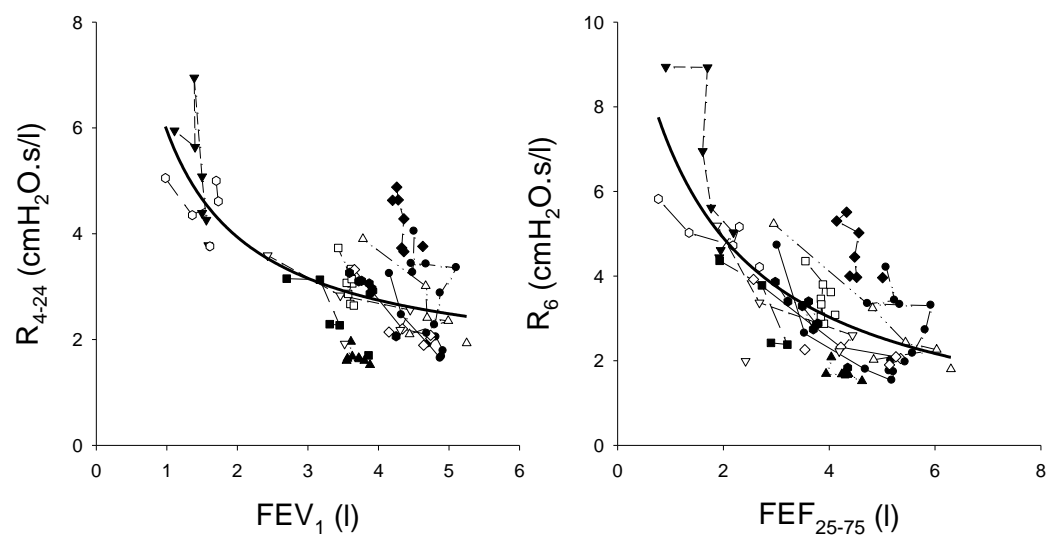

Figure 17. Correlations observed between spirometric and resistance parameters obtained with forced oscillations following aerosolized His (top) or MCh (bottom) challenges in individual asthmatic children. spirometric $\mathrm{FEF}_{25-75}$ and the low-frequency resistance values, such as $R_{6}(22,47)$. Accordingly, we characterize the associations between these corresponding spirometric and FOT indices following the His and MCh challenges in Fig. 17. Following His challenges, strong and statistically significant correlations were observed between $\mathrm{FEV}_{1}$ and $\mathrm{R}_{4-24}$ $\left(\mathrm{R}^{2}=0.6, \quad \mathrm{p}<0.0001\right) \quad$ and between $\mathrm{FEF}_{25-75}$ and $\mathrm{R}_{6}$ $\left(\mathrm{R}^{2}=0.47, \mathrm{p}<0.0001\right)$. The correlations between these parameters following $\mathrm{MCh}$ challenges were somewhat weaker, but their associations were still close and highly significant $\left(\mathrm{R}^{2}=0.48, \mathrm{p}=0.0001\right.$ between $\mathrm{FEV}_{1}$ and $\mathrm{R}_{4-24}$ and $\mathrm{R}^{2}=0.5, \mathrm{p}<0.0001$ between $\mathrm{FEF}_{25-75}$ and $\mathrm{R}_{6}$ ). 


\subsubsection{Variabilities}

Data on the short- and long-term variabilities in the spirometric and FOT parameters are demonstrated in Table 1.

\begin{tabular}{|c|c|c|c|}
\hline & & $\begin{array}{c}\text { Percentage short-term } \\
\text { variability }\end{array}$ & $\begin{array}{c}\text { Percentage long-term } \\
\text { variability }\end{array}$ \\
\hline 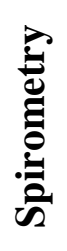 & $\begin{array}{l}\mathrm{FEV}_{1} \\
\mathrm{FEF}_{25-75} \\
\text { FVC }\end{array}$ & $\begin{array}{l}4.3 \\
7.1 \\
4.4\end{array}$ & $\begin{array}{r}9.3 \\
\\
15.3 \\
8.2\end{array}$ \\
\hline 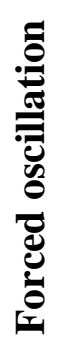 & $\begin{array}{l}\mathrm{R}_{4-24} \\
\mathrm{R}_{6} \\
\mathrm{AX} \\
\mathrm{Fr}\end{array}$ & $\begin{array}{c}10.3(6.1) \\
11.3(6.2) \\
25.6(17.0) \\
16.7(9.2)\end{array}$ & $\begin{array}{l}13.8 \\
12.2 \\
31.9 \\
25.7\end{array}$ \\
\hline
\end{tabular}

Table 1. Percentages of short- and long-term variability of the lung function parameters determined with spirometry or FOT in the main study group of 12 children. Values in parentheses: values obtained in 8 additional children where the FOT was performed without spirometry. Variability was defined as the standard deviation of the percentage changes between the data obtained in the first and second tests.

The smallest variabilities were found for $\mathrm{FEV}_{1}$ and $\mathrm{FVC}$, those for $\mathrm{FEF}_{25-75}, \mathrm{R}_{4-24}$ and $\mathrm{R}_{6}$ were higher, and the highest were observed for AX and Fr in the children who participated in both the FOT and spirometry. Substantial decreases in the short-term variability were observed for the FOT parameters in the 8 additional children where the FOT data were collected without spirometry.

Since the variability in the FOT parameters was greater than that in the spirometric indices, we examined the magnitude of the changes in the resistance parameters where the His and MCh provocation tests became positive according to the ATS/ERS guidelines (a 20\% decrease in $\mathrm{FEV}_{1}$ or the appearance of clinical symptoms). These data are displayed in Table 2. When a positive response was detected during the bronchial challenge tests, the changes in $\mathrm{R}_{4-24}$ were about twice as high as those in $\mathrm{FEV}_{1}$ for both of the constrictor agonists studied, while the elevations in $\mathrm{R}_{6}$ were even more pronounced. 


\begin{tabular}{|c|c|c|c|c|c|c|}
\hline & \multicolumn{3}{|c|}{ Histamine } & \multicolumn{3}{|c|}{ Methacholine } \\
\hline & $\mathbf{R}_{4-24}$ & $\mathbf{R}_{6}$ & Response & $\mathbf{R}_{4-24}$ & $\mathbf{R}_{6}$ & Response \\
\hline 1 & 38.1 & 59.4 & W & 82.0 & 172.8 & W \\
\hline 2 & 48.4 & 80.9 & SW & 80.9 & 77.6 & SW \\
\hline 3 & 53.6 & 124.1 & $\mathrm{~W}$ & 56.9 & 110.4 & SW \\
\hline 4 & 16.1 & 24.9 & SW & 38.7 & 80.1 & SW \\
\hline 5 & 37.0 & 53.4 & SW & 39.7 & 51.6 & SW \\
\hline 6 & 41.5 & -1.5 & $\mathrm{~W}$ & 30.8 & 38.8 & W \\
\hline 7 & 64.9 & 107.8 & SW & 53.6 & 76.1 & SW \\
\hline 8 & 46.8 & 48.3 & SW & 28.9 & 36.8 & SW \\
\hline 9 & 66.9 & 116.8 & SW & 7.1 & 20.0 & SW \\
\hline 10 & 25.8 & 46.7 & SW & 5.2 & 17.3 & W \\
\hline 11 & 12.3 & 27.3 & SW & -5.3 & 5.94 & SW \\
\hline 12 & 20.7 & 40.4 & $\mathrm{~W}$ & 40.8 & 54.4 & W \\
\hline 13 & 5.9 & 5.5 & SW & -2.7 & 19.8 & SW \\
\hline 14 & 16.3 & 31.0 & SW & 30.8 & 62.4 & SW \\
\hline 15 & 27.7 & 23.6 & $\mathrm{~W}$ & 2.9 & 11.3 & W \\
\hline 16 & 34.8 & 11.1 & SW & 24.1 & 41.0 & SW \\
\hline 17 & 38.6 & 58.0 & SW & 11.4 & 8.1 & SW \\
\hline 18 & 23.4 & 23.1 & W & 12.8 & 9.9 & SW \\
\hline 19 & 7.0 & 23.2 & SW & 10.7 & 28.3 & SW \\
\hline 20 & 15.5 & 40.9 & W & 46.9 & 43.4 & SW \\
\hline Mean & 32.1 & 48.9 & & 27.6 & 49.7 & \\
\hline
\end{tabular}

Table 2. Percentage changes in the resistance parameters where the His and MCh provocation tests became positive according to the ATS/ERS guidelines (a 20\% decrease in FEV1 or the appearance of clinical symptoms). SW: positive response (20\% decrease in FEV1 and the appearance of wheeze); W: wheeze, clinical symptoms appeared 


\subsubsection{SD indices}

The SD indices for the changes in the lung function parameters following the His and $\mathrm{MCh}$ challenges (determined with spirometry and the FOT) are presented in Fig. 18. Data are shown for the lower part of the dose-response curve, where measurements were made for the majority of the children (i.e. prior to a $20 \%$ decrease in $\mathrm{FEV}_{1}$ or the appearance of clinical symptoms). The sensitivity of the FOT parameter $\mathrm{R}_{4-24}$ was greatest following both His and

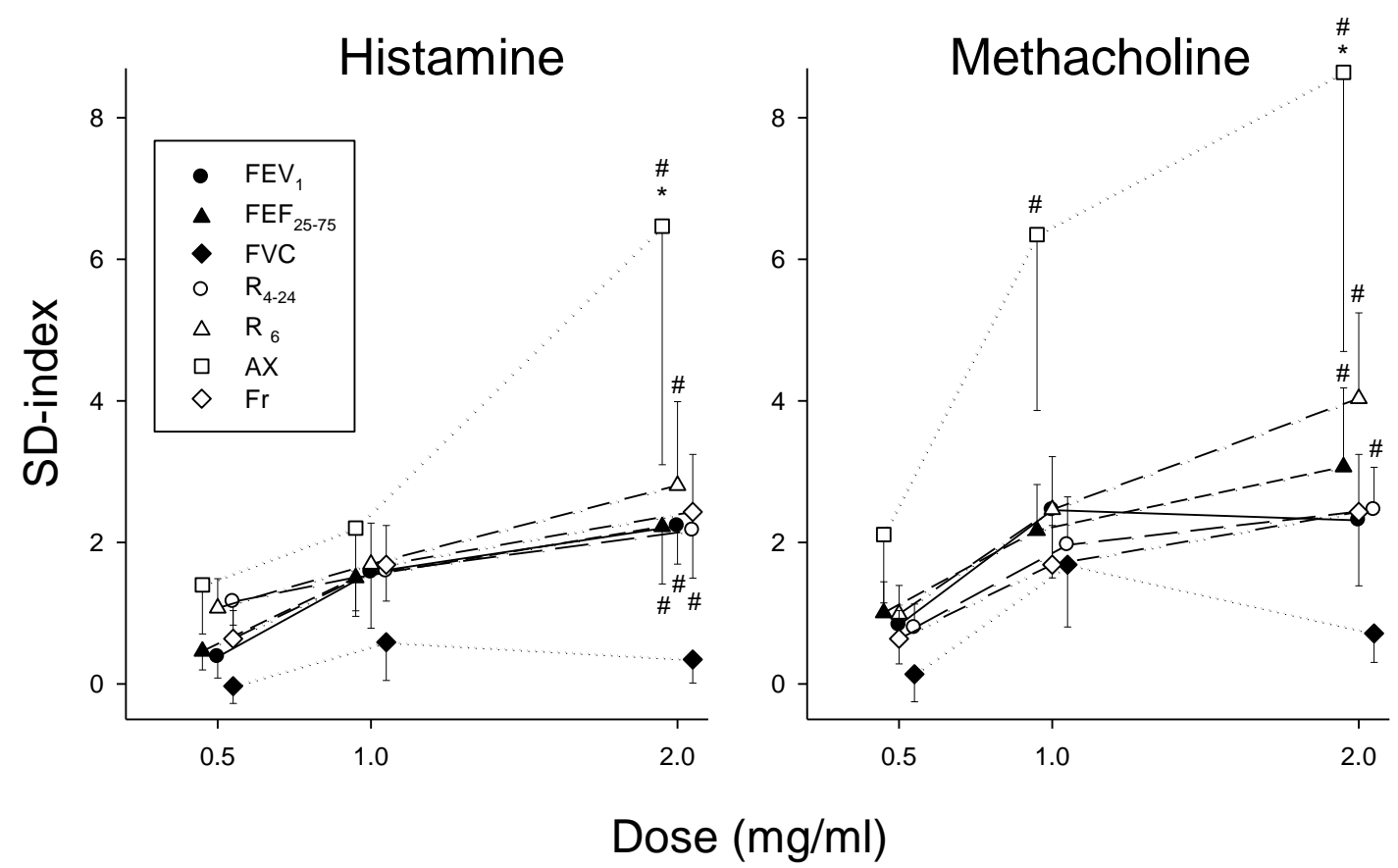

Figure 18. SD index of the lung function parameters obtained with spirometry (filled symbols) and forced oscillations (open symbols) following His or MCh challenges. *: p<0.05 vs. FEV1 within a dose, \#: $\mathrm{p}<0.05$ vs. zero level within a parameter.

MCh challenges. $\mathrm{R}_{6}$ and $\mathrm{FEF}_{25-75}$ exhibited similarly high sensitivities in the detection of Hisor MCh-induced airway narrowing. The parameters $\mathrm{AX}, \mathrm{Fr}, \mathrm{FEV}_{1}$ or $\mathrm{FEF}_{25-75}$ also demonstrated bronchoconstriction after His and MCh challenges, but only after the second dose of the constrictor agonists. 


\section{DISCUSSION}

Airway susceptibilities involving BHR are posing an increasing worldwide challenge for health professionals. The studies included in the present thesis focus on the environmental factors involved in the pathogenesis of BHR in animal models. Airway irritations leading to chronic inflammation may result from the inhalation of airborne particles and/or an altered $\mathrm{O}_{2}$ content of the inspired gas mixture. Treatment of BHR related to asthma has been well established by inhibiting the inflammation and by affecting the receptors responsible for the regulation of the airway tone. However, treatment strategies for hyperoxia-induced lung damage that may also induce BHR have not been completely characterized. Thus, interest has emerged in protection against the adverse pulmonary effects of $\mathrm{O}_{2}$ toxicity. Since the first symptoms of asthma are revealed before school age, a clinical protocol was designed to detect BHR in asthmatic children by using a novel measurement technique that can be applied in pre-schoolers.

\subsection{Animal models}

\subsubsection{Lung mechanics in animal models}

\subsubsection{Effects of RSD on basal lung function and lung hyperresponsiveness}

Despite the high RSD concentration (peak/minimum concentration in the exposure chamber: $\sim 1 / 7 \mathrm{mg} / \mathrm{m}^{3}$ ) and the evidence that it accessed the lower respiratory tract, no clinically significant adverse changes in the baseline airway or respiratory tissue mechanics were detected (Fig. 5.). The tendency to higher $\mathrm{G}$ and $\mathrm{H}$ in the animals in the RSD group may be a consequence of the mild inflammation demonstrated by the lung histology (Fig. 11.). The development of airway inflammation is in accord with previous findings on animals exposed to high concentrations of inhalable particles originating from carbon black $(45,53)$, ultrafine titania (66), urban air pollution $(17,33)$, and fine particulate matter arising from the destruction of the World Trade Center (26). Since merely mild airway inflammation has no major effects on the basal lung function $(17,65,71,84)$, the lack of difference between the two groups is consistent with the previous results. 
In agreement with previous findings that inhaled particulate matter induced asthma-like symptoms $(17,42,45,56,63,84,92)$, the chronic airway inflammation that occurred following RSD inhalation led to the development of BHR, which was manifested in significantly elevated responses to $\mathrm{MCh}$ (Fig. 7.) and subsequent decreases in $\mathrm{ED}_{100}$. As concerns the mechanism of the emergence of BHR, the involvement of macrophages can be anticipated from the histological findings (Fig. 9 and 11), since the role of alveolar macrophages in the development of an inflammation response in the small airways was evidenced previously $(56,67)$. Acute inflammation is probably caused by the phagocytosis of inhaled particles by alveolar macrophages and the release of inflammatory mediators from these cells. This injury response already appears within a few hours after inhalation and is particle size-dependent: the most destructive particles are the ultrafine ones $(<50 \mathrm{~nm})$, which are able to pass into the phagocytes (57). Since a substantial proportion of the particles in our study were in this size range, the involvement of this mechanism is expected. Chronic dust inhalation drives the influx of macrophages and other inflammatory cells, and these factors may lead to the progress of chronic lung diseases such as asthma $(2,17)$, emphysema, bronchiolitis (27) or fibrosis (67).

\subsubsection{Respiratory function and lung responsiveness after hyperoxia exposure}

In accordance with earlier results when immature rats were exposed to $\mathrm{O}_{2}$ for a short time (34), the basal Raw was not affected by hyperoxia exposure (Fig. 6.); this is also in line with the notion that Raw is determined primarily by the geometry of the central conducting airways, which remained unaffected $(28,72,85)$. An airway obstruction was detected in earlier studies when exposure to $\mathrm{O}_{2}$ was applied for a prolonged period (e.g. 4 weeks), which was sufficient for airway remodeling to develop (89).

The 72-h exposure to hyperoxia resulted in increases in the basal values of both viscoelastic tissue parameters (Fig. 6; G.BW and $\mathrm{H} \cdot \mathrm{BW}$ ), which accords with the results of previous studies where a decreased compliance was found after the application of $\mathrm{O}_{2}$ toxicity $(5,28$, 87, 89). Since the hyperoxia-induced increases in $\mathrm{G} \cdot \mathrm{BW}$ and $\mathrm{H} \cdot \mathrm{BW}$ were proportional, the enhancement of ventilation heterogeneities was not likely to have played a role in these findings (55). It seems more probable that perivascular and interstitial edema formation is responsible for these proportional elevations, this being substantiated by the histological 
findings (Fig. 13B) and the elevated protein level in the BALF (Fig. 10C). Nevertheless, other processes may also have been involved in the increase in $\mathrm{H} \cdot \mathrm{BW}$, since an elevation in elastance was also observed in the VIP-treated rats, despite the lack of manifest edema. Such processes may be related to hyperventilation throughout the exposure, striving to compensate the hyperoxia and causing hypertrophy of the intercostal muscles, leading to stiffening of the entire respiratory system.

Our findings demonstrate the development of lung hyperresponsiveness as early as $72 \mathrm{~h}$ after the onset of hyperoxia, manifested in a decreased $\mathrm{ED}_{50}$ value (Fig. 8A), in accordance with the results of the few previous studies where bronchoprovocation tests were performed (14, $34,87)$. It is noteworthy that this functional abnormality is already present despite the lack of remodeling of the bronchial wall at this early stage of $\mathrm{O}_{2}$ toxicity (85). Both sildenafil and VIP compensated and even overcompensated the enhanced lung responsiveness by stimulating endogenous NO production in the lungs. The excessive NO level may explain the diminished airway responsiveness by exerting the relaxation potential of the bronchial smooth muscle, which then leads to a decreased response relative to that in naïve animals. Since exposure to hyperoxia causes adverse alterations in the lungs at functional, structural and molecular levels, we characterized whether the prevention of functional abnormalities by stimulating the NO pathway is due to maintenance of the normal lung structure and biochemical profile.

\subsubsection{Mechanisms underlying BHR following hyperoxia exposure}

\subsubsection{Inflammation}

It is generally considered that inflammation and the influx of leukocytes play major roles in severe hyperoxia-induced lung injury (51). Leukocyte infiltration involving mainly macrophages and neutrophil granulocytes $(62,70,81)$ leads to a demonstrable accumulation in the alveolar space even after an exposure to hyperoxia of only $12 \mathrm{~h}$ (62). We found similar results in our model (Fig. 10). Since the inflammation is of great importance in the development of hyperoxia-induced lung damage, and as the inflammatory cells appear in the first few hours of hyperoxia exposure, early inhibition of the inflammatory response might prevent the lung injury. A further consequence of hyperoxia-induced cell damage is the loss of integrity of the alveolar-capillary barrier, resulting in an alveolar leak, which then causes 
increased exudation in the alveolar spaces $(7,81)$ and an increased protein level in the BALF (Fig. 10C). VIP was previously shown to protect alveolar epithelial cells against hyperoxia via the activation of the signal transducers and activator of transcription $3(3,4)$ and the overexpression of several survival genes (50). This results in capillary leakage retardation and a decreased neutrophil influx (Fig. 10A,B) into the lung. These findings may be attributed to the preserved NO activity, which can maintain the normal clearance of edema fluid in the lungs (74). Thus, treatment with sildenafil or VIP offers effective protection against the deleterious inflammatory events in the lungs by inhibiting PMN cell infiltration into the alveolar compartment and reducing the consecutive tissue destruction and pulmonary edema caused by hyperoxia. Overall, lung inflammation with low levels of bronchodilatory NO production, and alveolar destruction with a subsequent decrease in mechanical support to the small airways, are responsible for the enhancement in lung responsiveness.

\subsubsection{Lung morphology}

Recent results suggested the importance of the vascular endothelial growth factor (VEGF) in normal lung development: inhibition of VEGF led to abnormal alveolarization in neonatal rats, while VEGF therapy during hyperoxia maintained the normal alveolarization $(76,80)$. Furthermore, a decreased VEGF level in hyperoxia may contribute to insufficient NO production and, vice versa, a disturbance of the NO/cGMP pathway also exerts a negative effect on the VEGF activity (70). In our hyperoxia model, the 72-h exposure to $\mathrm{O}_{2}$ was sufficiently long for an abnormal alveolar structure to be observed in the developing lungs (Fig. 12). Compensation of the decreased NO activity, either through stimulation of the cGMP-dependent effects by using sildenafil to activate VEGF (70), or through enhancement of the NO production by VIP treatment was able to preserve the normal lung development despite maintenance of the hyperoxic environment (Fig. 12). MLI measurement confirmed that enlarged alveolar spaces were observed only in the non-treated $\mathrm{O}_{2}$-exposed animals; in the other groups, the MLI data were normal. This finding points to a preserved physiological alveolar structure (Fig. 13A).

\subsubsection{Changes in lung volume}

The changes in lung architecture were also reflected in the hyperoxia-induced EELV elevation in Group HC (Fig. 8A). In this emphysematous condition, air is trapped in the 
enlarged alveolar spaces at end-expiration and the gas content of the chest is increased. Moreover, the small airways are likely to display a tendency to collapse during expiration due to their structural impairment, and their function may be further compromised by the decreased elastic support of the damaged lung parenchyma, which would be less able to keep the small airways open. Since the sildenafil and VIP treatments prevented the adverse alterations in the alveolar structure, the EELV must have remained normal in these animals.

\subsubsection{Alveolo-capillary disruption}

Elevated amounts of ROS are known to cause alterations in DNA and proteins and are the major contributors to alveolar cell death in hyperoxia $(7,13)$. Alveolar cell death is an early event in hyperoxia-induced lung injury $(7,44)$. In agreement with the literature finding, the number of apoptotic/necrotic cells in the rat lungs was elevated following exposure to hyperoxia for $72 \mathrm{~h}$ (Fig. 14). However, there was no evidence that sildenafil or VIP could prevent apoptosis and necrosis (Fig. 14), suggesting that these treatments are unable to counteract the early ROS injuries, which are the initial mechanisms in the influx of inflammatory cells.

\subsection{Detection of BHR in children}

Since the introduction of the FOT by Dubois et al. in 1956 (18) and its extension towards the application of a wide frequency range of pseudorandom pressure excitation (46), the popularity of this lung mechanical measurement technique has increased, particularly as concerns examinations on patients with a limited ability to cooperate $(12,19,22-24,29,30$, $43,48,49,58,68,77,88,90,94)$. This beneficial profile of the FOT allows the characterization of lung function abnormalities in children with various respiratory diseases, such as cystic fibrosis $(23,24,49,77,88)$, neonatal chronic lung disease $(88,90)$, wheezy bronchitis $(68,88,94,95)$ or asthma $(12,29,43,64,88)$. Furthermore, the FOT has been used successfully to characterize bronchodilator responsiveness $(58,68,88)$ and to detect lung function changes following the inhalation of a bronchoconstrictor agonist in children $(29,43$, 94, 95). However we are aware of only a few previous studies in which the sensitivities of the FOT and spirometry were compared with regard to the detection of BHR in asthmatic children $(12,19,48)$, when the bronchial challenges were performed in accordance with the ATS guidelines (16). Even those earlier studies lack a comprehensive analysis of the 
sensitivities of the lung function parameters with consideration of the differences in variability of the techniques applied. Since spirometry is a routine procedure in lung function laboratories for the detection of BHR in the diagnosis of asthma, demonstration of the similar ability of the FOT is of major importance, since this technique can be carried out reliably in a much younger age group (as low as 2 years of age $(43,64)$ ). Nevertheless, children of school age were enrolled in the present study, in order to allow a comparison with spirometry.

\subsubsection{Relationships between the parameters obtained with the FOT and spirometry}

Strong and highly significant correlations were observed between the corresponding FOT and spirometric parameters relating to the larger $\left(\mathrm{FEV}_{1}\right.$ vs. $\left.\mathrm{R}_{4-24}\right)$ and smaller airways $\left(\mathrm{FEF}_{25-75} \mathrm{vs}\right.$. $\mathrm{R}_{6}$ ), which suggests that airway narrowing is faithfully reflected by both techniques (Fig. 17.). Nevertheless, the correlation analysis does not take into account the variability of the measured parameters, which is of great importance in a comparison of the ability of a lung function test to measure bronchoconstriction with subsequent promise to detect BHR. Previous studies have established that lung function parameters obtained by measurement techniques utilized during tidal breathing exhibit somewhat greater variability than those based on forced expiration (23). In accordance with that finding, we experienced greater short- and long-term variabilities for the FOT parameters than those measured with spirometry. This implies that greater magnitudes of changes can be regarded as positive responses in the FOT parameters (Table 2), which corresponds to previous observations (10, $29,94)$ and recommendations for higher acceptance limits of clinically important changes (10).

\subsubsection{SD indicies}

In order to take the greater magnitudes of the changes in the FOT parameters into account, the alterations in the lung function indices following the His and $\mathrm{MCh}$ challenges were also expressed in SD indicies (Fig. 18). This analysis revealed comparable SD indicies for the lung function parameters determined with the FOT and spirometry in the detection of airway narrowing following both the His and the MCh challenges. However, there was a tendency to a greater sensitivity of the FOT parameters relating to the low-frequency part of the Zrs spectra, which was particularly evident for AX. Since AX is extracted from the low-frequency reactance, it primarily reflects changes in the elasticity of the total respiratory system. It 
therefore seems likely that, besides inducing a constriction of the conducting airways manifested in elevated forced expiratory lung volumes and resistance parameters, the inhalation of the bronchoconstrictor agonists also led to a stiffening of the respiratory tissues. The most probable mechanism responsible for such a change in the respiratory elasticity is the loss of lung volume via the development of air trapping, due to the uneven deposition of the bronchoprovocation agonists, which was earlier clearly demonstrated following challenges with aerosolized His $(60,75)$. The lack of a significant decrease in FVC despite this loss of lung volume may be related to the forced deep inspiration to the total lung capacity prior to the expiration, which has been demonstrated to be likely to reopen the compromised lung regions (60).

\subsubsection{Effects of deep inspiration on the lung fuction}

As concerns the greater variabilities in the parameters determined with the FOT than those with spirometry, the sequence of the tests in the present experimental setting warrants consideration. Since the FOT requires normal quiet breathing only, it has no influence on the spirometric outcome. This sequence of the tests ensured the minimal interaction between the two lung function tests. Nevertheless, the deep inspiration and subsequent forced expiration maneuvers necessary for spirometry may affect the lung mechanics, which may be manifested even 5 min later in the FOT recordings. In addition to the potential diminution of the lung functional changes that results from the deep inspirations homogenizing the lung periphery (60), these forced breathing maneuvers may also widen the short-term variability of the FOT parameters obtained in the present study, which then ultimately affect the SD index extracted from the Zrs spectra, and hence the sensitivity of the tests. To test this hypothesis, we recruited 8 asthmatic children of school age on whom two sets of baseline FOT recordings were performed $5 \mathrm{~min}$ apart, without spirometry between them. The SD index decreased substantially (Table 1), suggesting that the sensitivity of the FOT test for the detection of BHR can be potentially doubled if the measurements are performed without additional lung function tests requiring special breathing maneuvers. It is noteworthy that, even with the apparently increased variabilities in the FOT indices, the resistance parameter $\mathrm{R}_{4-24}$ was the most sensitive in the detection of BHR, since the SD index of this parameter exhibited significant increases after the first dose of both His and MCh. 


\section{SUMMARY AND CONCLUSIONS}

We investigated the influence of environmental factors on the development of BHR in inbred animals, which excluded the effects of various genetic factors. We demonstrated the development of pulmonary inflammation and subsequent BHR following airway irritations in animal model studies. We also demonstrated the feasibility of detection of BHR in children of school age by using a technique that requires minimal patient cooperation. In all studies included in the present thesis, the basal airway mechanics was unaffected be the altered environment, while the elevated constrictor response of the airway smooth muscle following the application of bronchial challenges was proved by measuring airway properties with the FOT. Specifically, the findings of the present thesis contributed to the following particular research topics:

- The effects of RSD produced from an on-site sample in the Ajka region on the pulmonary system were assessed in an animal model by performing basal lung function measurements, with the assessment of changes in lung responsiveness and also histopathological analyses. When rats were chronically exposed to a high concentration of RSD, the fine powder particles reached the lower respiratory tract, but the alterations in the basal airway and respiratory tissue mechanics were not significant. The mild inflammation that developed around the pulmonary vessels and in the alveolar wall was associated with a mild BHR. Since these mild respiratory symptoms emerged following exposure to extremely high concentrations, our results may suggest that the short-term health hazard as regards the pulmonary system in healthy human adults exposed to RSD inhalation is not greater than that due to urban dust at a comparable concentration.

- In our short-term hyperoxia exposure model, duration of $72 \mathrm{~h}$ was sufficient to induce adverse molecular, morphological and functional changes in the lungs. Although no evidence was found that sildenafil and VIP treatments prevented the initial apoptotic changes in the lungs, both treatments were able to maintain the normal alveolar structure, inhibit the development of edema and inflammation, and prevent the consequential lung function deterioration by enhancing the activity of NO-mediated pathways involved in the lung damage following hyperoxia. Our findings therefore 
point to the potential benefit of sildenafil or VIP treatment in the critical acute phase of hyperoxic lung damage, and such treatment should be considered as one of the possible strategies designed to prevent the irreversible functional and structural changes in the developing lungs.

Since the detection of BHR poses an increasing clinical challenge in patients with limited abilities to cooperate, a clinical study was designed to determine the efficiency of the FOT in the detection of BHR following bronchoprovocation tests in asthmatic children. Our clinical findings suggest that

- the resistance and reactance parameters determined with the FOT revealed airway constriction at smaller doses of the agonists than those needed in standard spirometry;

- with regard to the greater variability in the FOT parameters when the FOT is performed concomitantly with spirometry, the two lung function measurement methods have similar sensitivities in the assessment of BHR;

- if the FOT is performed alone, the short-term variability of the resistance parameters decreases markedly and approaches that observed for the spirometric indices.

In summary, the studies included in the present thesis contribute to a better understanding of the BHR that develops in an altered environment by pointing to the complex involvement of inflammatory and cellular mechanisms leading to structural and functional abnormalities. Our clinical study reveals that the use of the FOT may impose less stress on the tested children and may lead to a decrease in the age at which BHR can be detected, so that asthma can subsequently be diagnosed in the preschool age range. 


\section{ACKNOWLEDGEMENTS}

First and foremost, I would like to thank my supervisors.

I thank Zoltán Novák who introduced me to clinical research and provided expertise, support and guidance throughout my studies and experimental work. Thank you for the incessant encouragement, especially before my first presentation, which has had a profound effect on my personal and academic career.

I would also like to express my gratitude to Ferenc Peták for his constant support and mentoring, especially during my experimental work. His excellent guidance has been essential in the development of my research career. Without your belief and advice I would never have begun my PhD studies.

I am also very grateful to Walid Habre for being my host supervisor during my year in Geneva. Thank you for the opportunity to work within your laboratory and for the trust, independence, invaluable advice, training and support you have provided me.

I wish to express my thanks to Ferenc Bari, head of my home institute (Department of Medical Physics and Informatics) for his support, trust, understanding (and for the pressure you put on me with your recurrent questions).

Thanks to Mária Balla for her indefatigable help with my experimental work, and for demonstrating exemplary patience during the very long weekends that we have spent together in the pulmonary function laboratory.

A special thanks goes to Xavier Belin for his unique technical support in the animal research projects we have undertaken together in Geneva, and for the never ending days we spent underground without seeing the sun.

I further express my deep gratitude to my friends from Geneva; Fabiola, Iliona, Camille and Yves. They were always with me in the challenging moments during and following my stay. Thank you very much for making my year in Geneva unforgettable and enjoyable. 
I would like to express my thanks to my friends and collegaues for the nice moments and the pleasant time spent at work in your company. Thanks to Marietta, Magdi, Anna, Darren, Zsuzsi, Kati, Juli and also to Bence for your motivation and humour.

I also wish to thank my parents, sister and brother who have always provided exceptional motivation over the years. Thank you for your love, trust and opportunities you have given me in life.

I wish to express my grateful thanks to Zoltán Hantos not only for his professional help, advice and support but also for his invaluable friendship. Zoli, thank you very much for looking after me, and for your help and support in all circumstances. As my gratitude is far too personal I prefer to express it to you in the company with a couple of beers.

Last but by far not least, I would like to thank Csaba for his patience, support, and love; even in the most difficult moments. Without you, these years would have been more complicated and less enjoyable. Your particular sense of humor sweetened my days and always provided me with an optimistic attitude. Köszönöm szépen!

$$
* * *
$$

The work described in this thesis has been supported by grants from the European Respiratory Society (Long-Term Research Fellowship 172-2011), the Hungarian Scientific Research Fund grants OTKA K81-179 and the TÁMOP 4.2.2.A-11/1/KONV-2012-0052. and 4.2.4-A/2-111-2012-0001 


\section{REFERENCES}

1. Anaid S, Petkov V, Baykuscheva-Gentscheva T, Hoeger H, Painsipp E, Holzer P, and Mosgoeller W. Involvement of endothelial NO in the dilator effect of VIP on rat isolated pulmonary artery. Regul pept 139: 102-108, 2007.

2. Andersen ZJ, Loft S, Ketzel M, Stage M, Scheike T, Hermansen MN, and Bisgaard H. Ambient air pollution triggers wheezing symptoms in infants. Thorax 63: 710-716, 2008.

3. Ao X, Fang F, and Xu F. Role of vasoactive intestinal peptide in hyperoxia-induced injury of primary type II alveolar epithelial cells. Indian J Ped 78: 535-539, 2011.

4. Ao X, Fang F, and Xu F. Vasoactive intestinal peptide protects alveolar epithelial cells against hyperoxia via promoting the activation of STAT3. Regul pept 168: 1-4, 2011.

5. Arkovitz MS, Garcia VF, Szabo C, McConnell K, Bove K, and Wispe JR. Decreased pulmonary compliance is an early indicator of pulmonary oxygen injury. $J$ Surg Res 67: 193-198, 1997.

6. Balasubramaniam V, Tang JR, Maxey A, Plopper CG, and Abman SH. Mild hypoxia impairs alveolarization in the endothelial nitric oxide synthase-deficient mouse. Am J Physiol Lung Cell Mol Physiol 284: L964-971, 2003.

7. Barazzone C, Horowitz S, Donati YR, Rodriguez I, and Piguet PF. Oxygen toxicity in mouse lung: pathways to cell death. Am J Respir Cel Mol Biol 19: 573-581, 1998.

8. Bateman ED, Hurd SS, Barnes PJ, Bousquet J, Drazen JM, FitzGerald M, Gibson P, Ohta K, O'Byrne P, Pedersen SE, Pizzichini E, Sullivan SD, Wenzel SE, and Zar HJ. Global strategy for asthma management and prevention: GINA executive summary. Eur Respir J 31: 143-178, 2008. 
9. Berger RM, Beghetti M, Humpl T, Raskob GE, Ivy DD, Jing ZC, Bonnet D, Schulze-Neick I, and Barst RJ. Clinical features of paediatric pulmonary hypertension: a registry study. Lancet 379: 537-546, 2012.

10. Beydon N, Davis SD, Lombardi E, Allen JL, Arets HG, Aurora P, Bisgaard H, Davis GM, Ducharme FM, Eigen H, Gappa M, Gaultier C, Gustafsson PM, Hall GL, Hantos Z, Healy MJ, Jones MH, Klug B, Lodrup Carlsen KC, McKenzie SA, Marchal F, Mayer OH, Merkus PJ, Morris MG, Oostveen E, Pillow JJ, Seddon PC, Silverman M, Sly PD, Stocks J, Tepper RS, Vilozni D, and Wilson NM. An official American Thoracic Society/European Respiratory Society statement: pulmonary function testing in preschool children. Am J Respir Crit Care Med 175: 1304-1345, 2007.

11. Bhandari $\mathbf{V}$. The role of nitric oxide in hyperoxia-induced injury to the developing lung. Front Biosci 8: e361-369, 2003.

12. Bisgaard H, and Klug B. Lung function measurement in awake young children. Eur Respir J 8: 2067-2075, 1995.

13. Brueckl C, Kaestle S, Kerem A, Habazettl H, Krombach F, Kuppe H, and Kuebler WM. Hyperoxia-induced reactive oxygen species formation in pulmonary capillary endothelial cells in situ. Am J Respir Cel Mol Biol 34: 453-463, 2006.

14. Burghardt JS, Boros V, Biggs DF, and Olson DM. Lipid mediators in oxygeninduced airway remodeling and hyperresponsiveness in newborn rats. Am J Respir Crit Care Med 154: 837-842, 1996.

15. Cockcroft DW. Direct challenge tests: Airway hyperresponsiveness in asthma: its measurement and clinical significance. Chest 138: 18S-24S., 2010

16. Crapo RO, Casaburi R, Coates AL, Enright PL, Hankinson JL, Irvin CG, MacIntyre NR, McKay RT, Wanger JS, Anderson SD, Cockcroft DW, Fish JE, and Sterk PJ. Guidelines for methacholine and exercise challenge testing-1999. This official statement of the American Thoracic Society was adopted by the ATS Board of Directors, July 1999. Am J Respir Crit Care Med 161: 309-329, 2000. 
17. Dong CC, Yin XJ, Ma JY, Millecchia L, Wu ZX, Barger MW, Roberts JR, Antonini JM, Dey RD, and Ma JK. Effect of diesel exhaust particles on allergic reactions and airway responsiveness in ovalbumin-sensitized brown Norway rats. Toxicol Sci 88: 202-212, 2005.

18. Dubois AB, Brody AW, Lewis DH, and Burgess BF, Jr. Oscillation mechanics of lungs and chest in man. $J$ Appl Physiol 8: 587-594, 1956.

19. Duiverman EJ, Neijens HJ, Van der Snee-van Smaalen M, and Kerrebijn KF. Comparison of forced oscillometry and forced expirations for measuring dose-related responses to inhaled methacholine in asthmatic children. Bull Eur Physiopathol Respir 22: 433-436, 1986.

20. Farrow KN, Lee KJ, Perez M, Schriewer JM, Wedgwood S, Lakshminrusimha S, Smith CL, Steinhorn RH, and Schumacker PT. Brief hyperoxia increases mitochondrial oxidation and increases phosphodiesterase 5 activity in fetal pulmonary artery smooth muscle cells. Antioxid Redox Signal 17: 460-470, 2012.

21. Fredberg JJ, and Stamenovic D. On the imperfect elasticity of lung tissue. J Appl Physiol 67: 2408-2419, 1989.

22. Frey U. Forced oscillation technique in infants and young children. Paediatr Respir Rev 6: 246-254, 2005.

23. Gangell CL, Hall GL, Stick SM, and Sly PD. Lung function testing in preschoolaged children with cystic fibrosis in the clinical setting. Pediatr Pulmonol 45: 419433, 2010.

24. Gangell CL, Horak F, Jr., Patterson HJ, Sly PD, Stick SM, and Hall GL. Respiratory impedance in children with cystic fibrosis using forced oscillations in clinic. Eur Respir J 30: 892-897, 2007.

25. Gaston B, Drazen JM, Loscalzo J, and Stamler JS. The biology of nitrogen oxides in the airways. Am J Respir Crit Care Med 149: 538-551, 1994.

26. Gavett SH, Haykal-Coates N, Highfill JW, Ledbetter AD, Chen LC, Cohen MD, Harkema JR, Wagner JG, and Costa DL. World Trade Center fine particulate 
matter causes respiratory tract hyperresponsiveness in mice. Environ Health Perspect 111: 981-991, 2003.

27. Girod CE, and King TE, Jr. COPD: a dust-induced disease? Chest 128: 3055-3064, 2005 .

28. Habre W, Petak F, Ruchonnet-Metrailler I, Donati Y, Tolsa JF, Lele E, Albu G, Beghetti M, and Barazzone-Argiroffo C. The role of endothelin-1 in hyperoxiainduced lung injury in mice. Respir Res 7: 45, 2006.

29. Hall GL, Gangell C, Fukushima T, Horak F, Jr., Patterson H, Stick SM, Sly PD, and Franklin PJ. Application of a shortened inhaled adenosine-5'-monophosphate challenge in young children using the forced oscillation technique. Chest 136: 184$189,2009$.

30. Hall GL, Sly PD, Fukushima T, Kusel MM, Franklin PJ, Horak F, Jr., Patterson H, Gangell C, and Stick SM. Respiratory function in healthy young children using forced oscillations. Thorax 62: 521-526, 2007.

31. Hantos Z, Daróczy B, Suki B, Nagy S, Fredberg JJ. Input impedance and peripheral inhomogeneity of dog lungs. J Appl Physiol 72:168-78., 1992.

32. Hantos Z, Daroczy B, Csendes T, Suki B, and Nagy S. Modeling of low-frequency pulmonary impedance in dogs. J Appl Physiol 68: 849-860, 1990.

33. Harkema JR, Keeler G, Wagner J, Morishita M, Timm E, Hotchkiss J, Marsik F, Dvonch T, Kaminski N, and Barr E. Effects of concentrated ambient particles on normal and hypersecretory airways in rats. Res Rep Health Eff Inst 1-68; discussion 69-79, 2004.

34. Hershenson MB, Aghili S, Punjabi N, Hernandez C, Ray DW, Garland A, Glagov S, and Solway J. Hyperoxia-induced airway hyperresponsiveness and remodeling in immature rats. Am J Physiol 262: L263-269, 1992.

35. Hershenson MB, Wylam ME, Punjabi N, Umans JG, Schumacker PT, Mitchell RW, and Solway J. Exposure of immature rats to hyperoxia increases tracheal smooth muscle stress generation in vitro. J Appl Physiol 76: 743-749, 1994. 
36. Izbicki G, Chavko R, Banauch GI, Weiden MD, Berger KI, Aldrich TK, Hall C, Kelly KJ, and Prezant DJ. World Trade Center "sarcoid-like" granulomatous pulmonary disease in New York City Fire Department rescue workers. Chest 131: 1414-1423, 2007.

37. Janosi TZ, Adamicza A, Zosky GR, Asztalos T, Sly PD, and Hantos Z. Plethysmographic estimation of thoracic gas volume in apneic mice. J Appl Physiol 101: 454-459, 2006.

38. Jobe AH, and Bancalari E. Bronchopulmonary dysplasia. Am J Respir Crit Care Med 163: 1723-1729, 2001.

39. Jobe AJ. The new BPD: an arrest of lung development. Pediatric research 46: 641643, 1999.

40. Kaplan E, Bar-Yishay E, Prais D, Klinger G, Mei-Zahav M, Mussaffi H, Steuer G, Hananya S, Matyashuk Y, Gabarra N, Sirota L, and Blau H. Encouraging pulmonary outcome for surviving, neurologically intact, extremely premature infants in the postsurfactant era. Chest 142: 725-733, 2012.

41. Kermarrec N, Zunic P, Beloucif S, Benessiano J, Drouet L, and Payen D. Impact of inhaled nitric oxide on platelet aggregation and fibrinolysis in rats with endotoxic lung injury. Role of cyclic guanosine 5'-monophosphate. Am J Respir Crit Care Med 158: 833-839, 1998.

42. Kilburn KH. Particles causing lung disease. Environ Health Perspect 55: 97-109, 1984.

43. Klug B, and Bisgaard H. Measurement of lung function in awake 2-4-year-old asthmatic children during methacholine challenge and acute asthma: a comparison of the impulse oscillation technique, the interrupter technique, and transcutaneous measurement of oxygen versus whole-body plethysmography. Pediatr Pulmonol 21: 290-300, 1996.

44. Ladha F, Bonnet S, Eaton F, Hashimoto K, Korbutt G, and Thebaud B. Sildenafil improves alveolar growth and pulmonary hypertension in hyperoxia-induced lung injury. Am J Respir Crit Care Med 172: 750-756, 2005. 
45. Lambert AL, Mangum JB, DeLorme MP, and Everitt JI. Ultrafine carbon black particles enhance respiratory syncytial virus-induced airway reactivity, pulmonary inflammation, and chemokine expression. Toxicol Sci 72: 339-346, 2003.

46. Landser FJ, Nagles J, Demedts M, Billiet L, and van de Woestijne KP. A new method to determine frequency characteristics of the respiratory system. J Appl Physiol 41: 101-106, 1976.

47. Lebecque $\mathbf{P}$, Kiakulanda $\mathbf{P}$, and Coates AL. Spirometry in the asthmatic child: is FEF25-75 a more sensitive test than FEV1/FVC? Pediatr Pulmonol 16: 19-22, 1993.

48. Lebecque P, Spier S, Lapierre JG, Lamarre A, Zinman R, and Coates AL. Histamine challenge test in children using forced oscillation to measure total respiratory resistance. Chest 92: 313-318, 1987.

49. Lebecque P, and Stanescu D. Respiratory resistance by the forced oscillation technique in asthmatic children and cystic fibrosis patients. Eur Respir J 10: 891-895, 1997.

50. Lee PJ, Camhi SL, Chin BY, Alam J, and Choi AM. AP-1 and STAT mediate hyperoxia-induced gene transcription of heme oxygenase-1. Am J Physiol Lung Cell Mol Physiol 279: L175-182, 2000.

51. Lee PJ, and Choi AM. Pathways of cell signaling in hyperoxia. Free Radic Biol Med 35: 341-350, 2003.

52. Lee TJ. Nitric oxide and the cerebral vascular function. J Biomel Sci 7: 16-26, 2000.

53. Li XY, Gilmour PS, Donaldson K, and MacNee W. Free radical activity and proinflammatory effects of particulate air pollution (PM10) in vivo and in vitro. Thorax 51: 1216-1222, 1996.

54. Lopez E, Boucherat O, Franco-Montoya ML, Bourbon JR, Delacourt C, and Jarreau PH. Nitric oxide donor restores lung growth factor and receptor expression in hyperoxia-exposed rat pups. Am J Respir Cel Mol Biol 34: 738-745, 2006.

55. Lutchen KR, Hantos Z, Petak F, Adamicza A, and Suki B. Airway inhomogeneities contribute to apparent lung tissue mechanics during constriction. $J$ Appl Physiol 80: 1841-1849, 1996. 
56. Maatta J, Lehto M, Leino M, Tillander S, Haapakoski R, Majuri ML, Wolff H, Rautio S, Welling I, Husgafvel-Pursiainen K, Savolainen K, and Alenius $\mathbf{H}$. Mechanisms of particle-induced pulmonary inflammation in a mouse model: exposure to wood dust. Toxicol Sci 93: 96-104, 2006.

57. Mantecca P, Farina F, Moschini E, Gallinotti D, Gualtieri M, Rohr A, Sancini G, Palestini P, and Camatini M. Comparative acute lung inflammation induced by atmospheric PM and size-fractionated tire particles. Toxicol Lett 198: 244-254, 2010.

58. Mazurek HK, Marchal F, Derelle J, Hatahet R, Moneret-Vautrin D, and Monin P. Specificity and sensitivity of respiratory impedance in assessing reversibility of airway obstruction in children. Chest 107: 996-1002, 1995.

59. Miller MR, Hankinson J, Brusasco V, Burgos F, Casaburi R, Coates A, Crapo R, Enright P, van der Grinten CP, Gustafsson P, Jensen R, Johnson DC, MacIntyre N, McKay R, Navajas D, Pedersen OF, Pellegrino R, Viegi G, and Wanger J. Standardisation of spirometry. Eur Respir J 26: 319-338, 2005.

60. Monfraix S, Bayat S, Porra L, Berruyer G, Nemoz C, Thomlinson W, Suortti P, and Sovijarvi AR. Quantitative measurement of regional lung gas volume by synchrotron radiation computed tomography. Phys Med Biol 50: 1-11, 2005.

61. Mourani PM, Ivy DD, Gao D, and Abman SH. Pulmonary vascular effects of inhaled nitric oxide and oxygen tension in bronchopulmonary dysplasia. Am J Respir Crit Care Med 170: 1006-1013, 2004.

62. Nagato AC, Bezerra FS, Lanzetti M, Lopes AA, Silva MA, Porto LC, and Valenca SS. Time course of inflammation, oxidative stress and tissue damage induced by hyperoxia in mouse lungs. Int J Exp Pathol 93: 269-278, 2012.

63. Nel AE, Diaz-Sanchez D, and Li N. The role of particulate pollutants in pulmonary inflammation and asthma: evidence for the involvement of organic chemicals and oxidative stress. Curr Opin Pulm Med 7: 20-26, 2001.

64. Nielsen KG, and Bisgaard $\mathbf{H}$. Lung function response to cold air challenge in asthmatic and healthy children of 2-5 years of age. Am J Respir Crit Care Med 161: 1805-1809, 2000. 
65. Novak Z, Petak F, Banfi A, Toth-Szuki V, Barati L, Kosa L, Bari F, and Szekely E. An improved technique for repeated bronchoalveolar lavage and lung mechanics measurements in individual rats. Respir Physiol Neurobiol 154: 467-477, 2006.

66. Oberdorster G. Pulmonary effects of inhaled ultrafine particles. Int Arch Occup Environ Health 74: 1-8, 2001.

67. Oberdorster G, Ferin J, Gelein R, Soderholm SC, and Finkelstein J. Role of the alveolar macrophage in lung injury: studies with ultrafine particles. Environ Health Perspect 97: 193-199, 1992.

68. Oostveen E, Dom S, Desager K, Hagendorens M, De Backer W, and Weyler J. Lung function and bronchodilator response in 4-year-old children with different wheezing phenotypes. Eur Respir J 35: 865-872, 2010.

69. Oostveen E, MacLeod D, Lorino H, Farre R, Hantos Z, Desager K, and Marchal F. The forced oscillation technique in clinical practice: methodology, recommendations and future developments. Eur Respir J 22: 1026-1041, 2003.

70. Park HS, Park JW, Kim JH, Choi CW, Lee HJ, Kim BI, and Chun YS. Sildenafil Alleviates Bronchopulmonary Dysplasia in Neonatal Rats by Activating the HypoxiaInducible Factor Signaling Pathway. Am J Respir Cel Mol Biol 2012.

71. Petak F, Banfi A, Toth-Szuki V, Barati L, Bari F, Szekely E, and Novak Z. Airway responsiveness and bronchoalveolar lavage fluid profiling in individual rats: effects of different ovalbumin exposures. Respir Physiol Neurobiol 170: 76-82, 2010.

72. Petak F, Habre W, Donati YR, Hantos Z, and Barazzone-Argiroffo C. Hyperoxiainduced changes in mouse lung mechanics: forced oscillations vs. barometric plethysmography. J Appl Physiol 90: 2221-2230, 2001.

73. Petak F, Hantos Z, Adamicza A, Asztalos T, and Sly PD. Methacholine-induced bronchoconstriction in rats: Effects of intravenous vs. aerosol delivery. $J$ Appl Physiol 82: 1479-1487, 1997.

74. Pittet JF, Wiener-Kronish JP, McElroy MC, Folkesson HG, and Matthay MA. Stimulation of lung epithelial liquid clearance by endogenous release of catecholamines in septic shock in anesthetized rats. J Clin Invest 94: 663-671, 1994. 
75. Popa V, Chandnani PC, and Reardon M. The relationship between conductance and functional residual capacity during drug-induced bronchoconstriction. Chest 97: 831839, 1990.

76. Randell SH, Mercer RR, and Young SL. Neonatal hyperoxia alters the pulmonary alveolar and capillary structure of 40-day-old rats. Am J Pathol 136: 1259-1266, 1990.

77. Ren CL, Brucker JL, Rovitelli AK, and Bordeaux KA. Changes in lung function measured by spirometry and the forced oscillation technique in cystic fibrosis patients undergoing treatment for respiratory tract exacerbation. Pediatr Pulmonol 41: 345349, 2006.

78. Rowland R, and Newman CG. Pulmonary complications of oxygen therapy. J Clin Pathol 22: 192-198, 1969.

79. Sears MR, Greene JM, Willan AR, Wiecek EM, Taylor DR, Flannery EM, Cowan JO, Herbison GP, Silva PA, and Poulton R. A longitudinal, populationbased, cohort study of childhood asthma followed to adulthood. $N$ Engl J Med 349: 1414-1422, 2003.

80. Shaffer SG, O'Neill D, Bradt SK, and Thibeault DW. Chronic vascular pulmonary dysplasia associated with neonatal hyperoxia exposure in the rat. Ped res 21: 14-20, 1987.

81. Shasby DM, Fox RB, Harada RN, and Repine JE. Reduction of the edema of acute hyperoxic lung injury by granulocyte depletion. J Appl Physiol 52: 1237-1244, 1982.

82. Solway J, and Hershenson MB. Structural and functional abnormalities of the airways of hyperoxia-exposed immature rats. Chest 107: 89S-93S, 1995.

83. Stenger MR, Rose MJ, Joshi MS, Rogers LK, Chicoine LG, Bauer JA, and Nelin LD. Inhaled nitric oxide prevents 3-nitrotyrosine formation in the lungs of neonatal mice exposed to $>95 \%$ oxygen. Lung 188: 217-227, 2010.

84. Stevens T, Cho SH, Linak WP, and Gilmour MI. Differential potentiation of allergic lung disease in mice exposed to chemically distinct diesel samples. Toxicol Sci 107: 522-534, 2009. 
85. Szarek JL, Ramsay HL, Andringa A, and Miller ML. Time course of airway hyperresponsiveness and remodeling induced by hyperoxia in rats. Am J Physiol 269: L227-233, 1995.

86. Szeinuk J, Padilla M, and de la Hoz RE. Potential for diffuse parenchymal lung disease after exposures at World Trade Center Disaster site. Mt Sinai J Med 75: 101$107,2008$.

87. Takeda K, Okamoto M, de Langhe S, Dill E, Armstrong M, Reisdorf N, Irwin D, Koster M, Wilder J, Stenmark KR, West J, Klemm D, Gelfand EW, NozikGrayck E, and Majka SM. Peroxisome proliferator-activated receptor-g agonist treatment increases septation and angiogenesis and decreases airway hyperresponsiveness in a model of experimental neonatal chronic lung disease. Anatl Rec 292: 1045-1061, 2009.

88. Thamrin C, Gangell CL, Udomittipong K, Kusel MM, Patterson H, Fukushima T, Schultz A, Hall GL, Stick SM, and Sly PD. Assessment of bronchodilator responsiveness in preschool children using forced oscillations. Thorax 62: 814-819, 2007.

89. Tibboel J, Joza S, Reiss I, Jongste JC, and Post M. Amelioration of hyperoxiainduced lung injury using a sphingolipid-based intervention. Eur Respir J 2012.

90. Udomittipong K, Sly PD, Patterson HJ, Gangell CL, Stick SM, and Hall GL. Forced oscillations in the clinical setting in young children with neonatal lung disease. Eur Respir J 31: 1292-1299, 2008.

91. Van de Woestijne KP editor. A modification of the forced oscillation technique. Oxford, UK: Pergamon, 1981, p. 655-660.

92. Wang T, Moreno-Vinasco L, Huang Y, Lang GD, Linares JD, Goonewardena SN, Grabavoy A, Samet JM, Geyh AS, Breysse PN, Lussier YA, Natarajan V, and Garcia JG. Murine lung responses to ambient particulate matter: genomic analysis and influence on airway hyperresponsiveness. Environ Health Perspect 116: 1500-1508, 2008. 
93. Weichelt U, Cay R, Schmitz T, Strauss E, Sifringer M, Buhrer C, and Endesfelder S. Prevention of hyperoxia-mediated pulmonary inflammation in neonatal rats by caffeine. Eur Respir J 2012.

94. Wilson NM, Bridge P, Phagoo SB, and Silverman M. The measurement of methacholine responsiveness in 5 year old children: three methods compared. Eur Respir J 8: 364-370, 1995.

95. Wilson NM, Bridge P, and Silverman M. Bronchial responsiveness and symptoms in 5-6 year old children: a comparison of a direct and indirect challenge. Thorax 50: 339-345, 1995. 
Czovek D, Novak Z, Somlai C, Asztalos T, Tiszlavicz L, Bozoki Z, Ajtai T, Utry N, Filep A, Bari F, Petak F:

Respiratory consequences of red sludge dust inhalation in rats.

Toxicology Letters 209:(2) pp. 113-120. (2012) 


\title{
Respiratory consequences of red sludge dust inhalation in rats
}

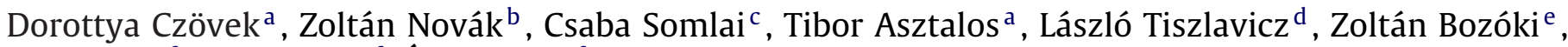 \\ Tibor Ajtai ${ }^{\mathrm{f}}$, Noémi Utry ${ }^{\mathrm{f}}$, Ágnes Filep ${ }^{\mathrm{f}}$, Ferenc Bari ${ }^{\mathrm{a}}$, Ferenc Peták ${ }^{\mathrm{a}, *}$ \\ a Department of Medical Physics and Informatics, University of Szeged, H-6720 Szeged, Korányi fasor 9, Hungary \\ ${ }^{\mathrm{b}}$ Department of Pediatrics, University of Szeged, H-6720 Szeged, Korányi fasor 14-15, Hungary \\ ${ }^{\mathrm{c}}$ Department of Medical Chemistry, University of Szeged, H-6720 Szeged, Dóm tér 8, Hungary \\ d Department of Pathology, University of Szeged, H-6720 Szeged, Állomás u. 2, Hungary \\ e Research Group on Laser Physics of the Hungarian Academy of Sciences, H-6720 Szeged, Dóm tér 9, Hungary \\ ${ }^{\mathrm{f}}$ Department of Optics and Quantum Electronics, University of Szeged, H-6720 Szeged, Dóm tér 9, Hungary
}

\section{A R T I C L E I N F O}

\section{Article history:}

Received 21 August 2011

Received in revised form 24 October 2011

Accepted 14 December 2011

Available online 22 December 2011

\section{Keywords:}

Alumina plant

Lung function

Fugitive dust

Airway resistance

Lung compliance

Bronchial hyper-reactivity

\begin{abstract}
A B S T R A C T
The environmental disaster following flooding by red sludge in the Ajka region in Hungary poses a serious public health threat with particular concern regarding the potentially adverse respiratory effects of the inhalation of red sludge dust (RSD). The respiratory consequences of the inhalation of RSD obtained from field samples were investigated in rats. Rats were either exposed to RSD at a high concentration ( 2 weeks, $8 \mathrm{~h} /$ day), or kept in room air. After the exposures, the airway resistance $\left(R_{\mathrm{aw}}\right)$ and the respiratory tissues mechanics were measured under baseline condition, and following methacholine $(\mathrm{MCh})$ challenges with the aim of establishing airway hyper-responsiveness ( $\mathrm{AH}$ ). Histopathology was performed to assess lung morphologic alterations. The physical properties and the chemical composition of the RSD were also characterized. The size distribution, chemical composition and topology of the RSD particles applied in our experiments were similar to those observed at the site of the disaster. The inhalation of RSD did not alter the basal respiratory mechanics, whereas it led to greater MCh-induced responses in $R_{\mathrm{aw}}$, demonstrating the progression of mild AH. Histopathological investigations revealed fine, granular particles in the alveolar macrophages, as evidence that RSD had reached the lower respiratory tract and induced mild inflammation around the alveoli and the pulmonary vasculature. The mild respiratory symptoms that developed following short-term exposure of healthy individuals to high concentrations of airborne RSD do not appear to pose a greater respiratory hazard than the inhalation of urban dust at a comparable concentration.
\end{abstract}

(C) 2011 Elsevier Ireland Ltd. All rights reserved.

\section{Introduction}

The pond dam of a red sludge reservoir of an alumina plant near Ajka, in the west of Hungary, burst on October 4, 2010. The $600,000-700,000 \mathrm{~m}^{3}$ of toxic red sludge that streamed out from the damaged flooded 3 towns and affected 4 other residential areas, in some places in a depth of up to $2 \mathrm{~m}$, and rapidly covered an agricultural area of about $40 \mathrm{~km}^{2}$ (http://redsludge.bm.hu, 2011. Official Website of the Hungarian Government). This catastrophe, as one of the worst environmental disasters in Europe, caused the death of 10 persons, and hundreds of others suffered major injuries, mainly burns from direct contact with the highly alkaline $(\mathrm{pH} \sim 13)$ material (Gelencser et al., 2011).

Even after the immediate critical phase of the sludge pill had passed, the potential hazards posed by constituents of the red

\footnotetext{
* Corresponding author. Tel.: +36 62 545077; fax: +36 62545077 .

E-mail address: petak@dmi.szote.u-szeged.hu (F. Peták).
}

sludge continue to raise severe public health concerns (Ruyters et al., 2011). Health professionals agree that the most important health risk is related to inhalation of the dust formed when the red sludge dries and its particles are swept into the atmosphere by the wind. Since the air may also be contaminated with red sludge dust (RSD) if the common dry storage method is used for the deposition of this byproduct, this environmental threat may also involve workers or inhabitants in regions neighboring plants where alumina is produced from bauxite by the Bayer process.

Despite the potential health hazards posed by the inhalation of RSD, the likelihood of its adverse affects in the respiratory system have previously been assessed only by examining the chemical and physical properties of red sludge particles (Gelencser et al., 2011). These measurements indicated that the particle size of the RSD examined was larger than the critical size capable of reaching the alveolar compartment. Nevertheless, the fugitive dust particles may still reach and subsequently irritate the epithelium in both the central and peripheral airways (Dong et al., 2005; Fernvik et al., 2002; Kilburn, 1984; Li et al., 1997). Accordingly, an investigation 


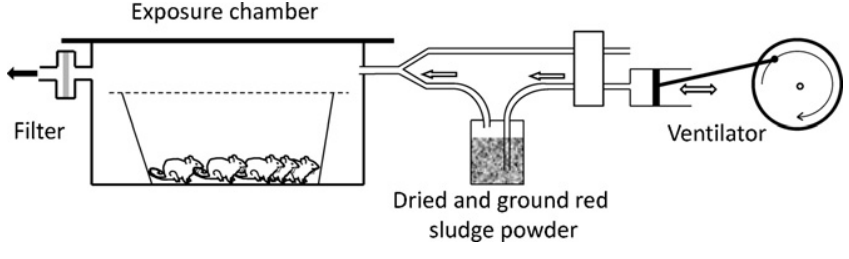

Fig. 1. Experimental setup for RSD exposure.

is warranted in which the effects of prolonged exposure to RSD are examined in an animal model; such results may contribute greatly to clarification of the potential respiratory complications.

The primary aim of the present study, therefore, was a systematic investigation of the consequences of prolonged RSD inhalation on the airway and respiratory tissue mechanics in rats. Consideration was given to potential histopathological alterations in the lungs. Since the airway irritation following the inhalation of ambient particulate matter contributes to an increased prevalence and exacerbations of asthma (Dong et al., 2005; Kilburn, 1984; Lambert et al., 2003; Nel et al., 2001; Wang et al., 2008), we also set out to explore whether RSD exposure leads to airway hyper-responsiveness $(\mathrm{AH})$, which is the hallmark feature of asthma.

\section{Materials and methods}

\subsection{Exposure to RSD}

The experimental protocol was approved by the Experimental Ethics Committee of the University of Szeged (I-74-17/2010) and the Animal Health and Welfare Office of the local authorities in Hungary. Certified red sludge samples were obtained from the local office of the National Directorate General for Disaster Management in Devecser 10 days after the disaster. The red sludge was dried in an oven at $60^{\circ} \mathrm{C}$ for $24 \mathrm{~h}$ and the resulting dry material was mechanically ground to form a powder containing fine particles able to furnish a cloud of dust in an airflow. The particle size distribution was determined (see below). The resulting RSD was then placed in a sealed glass container with two tubes passing through its lid (Fig. 1). The internal end of one of these tubes was immersed in the RSD and the other end was attached to the inspiratory port of a small animal ventilator (model 683, Harvard Apparatus Co. Inc., South Natick, MA, USA). The internal end of the other tube was kept above the RSD while the other end was connected to the inlet of the exposure chamber. This system cyclically raises a cloud of dust in the RSD container during the inspiratory phases of the ventilator. The airborne flow of RSD by wind was mimicked by shaking the glass container containing the RSD for 20-30 s every 60-90 min, which intensified the access of particles to the inspiratory port and subsequently increased the RSD concentration in the exposure chamber. Since the ventilator frequency was maintained at 50 strokes/min with the stroke volume set at $30 \mathrm{ml}$ during exposure, this apparatus ensured the supply of fresh ambient gas into the exposure chamber, which contained a maximum of 5 animals at a time. The exposure chamber was connected to the atmosphere via a disposable bacterial filter in order to avoid contamination of the room air with RSD particles.

Two groups of male Wistar rats were studied (weight range 350-455 g). The animals in the RSD group were exposed to RSD in the exposure chamber for $8 \mathrm{~h}$ a day for 2 weeks $(N=10)$. The animals in the control group were kept in another chamber with identical dimensions and underwent the same procedure except that they were allowed to breathe dust-free room air $(N=11)$. The rats in both groups had access to food and water ad libitum throughout the entire exposure period.

\subsection{Assessment of RSD concentration}

To determine the concentration of respirable particulate matter $(<10 \mu \mathrm{m}$ aerodynamic diameter; $\mathrm{PM}_{10}$ ), the tapered element oscillating microbalance (TEOM) technique (Series 1400a, Rupprecht and Patashnick Co. Inc., Albany, NY, USA) was used. This instrument allows quasi-continuous monitoring of the mass of $\mathrm{PM}_{10}$ accumulating on a filter mounted on an oscillating balance inside the measurement apparatus (Kinghama et al., 2006). Changes in the frequency of oscillation reflecting the mass of material accumulating on the filter are detected in quasi-realtime and converted by a microprocessor into an equivalent PM mass concentration every few seconds with a 10-min running average. The TEOM air stream was heated to $40^{\circ} \mathrm{C}$ to prevent the condensation of water vapor on the collected samples, the non-water semivolatile mass loss being kept at a minimum (Aberkane et al., 2004).

\subsection{Measurement of RSD particle size distribution}

\subsubsection{Measurements below $300 \mathrm{~nm}$}

A scanning mobility particle sizer (SMPS) consisting of a differential mobility analyzer (Model \#5.400, with Classifier "Vienna"-Type DMA) and a condensation particle counter (Model \#5.500, Grimm Aerosol Technik, Ainring, Germany) was used to measure the particle size distribution below $300 \mathrm{~nm}$. The sheath and aerosol flow rates were set to 3.0 and $0.3 \mathrm{l} / \mathrm{min}$, respectively, which allowed measurements of particles with electrical mobility diameters between 5.5 and $350 \mathrm{~nm}$.

\subsubsection{Measurements above $300 \mathrm{~nm}$}

An optical particle counter (Model 1.109, Grimm Aerosol Technik, Ainring, Germany) was used for real-time characterization in the particle size range above $300 \mathrm{~nm}$ (Heim et al., 2008). This device uses a 683-nm laser diode to illuminate the beam containing the particles, and a wide-angle collector optic is used to detect the subsequent light pulses with a photodiode. The optical arrangement (mean scattering angle $90^{\circ}$ ) collects the scattered light with a parabolic mirror $\left(120^{\circ}\right)$ on one side and an additional $18^{\circ}$ on the opposing side. The wide-angle optic increases the total amount of scattered light detected by the photosensor close to the Rayleigh scattering domain. This improves the signal to noise ratio, which leads to a decrease in the minimum particle size that can be detected (specified by the manufacturer as $205 \mathrm{~nm}$ ). The optical counter readings were corrected by a method suggested previously (Gelencser et al., 2011).

\subsection{Determination of RSD topology and composition}

RSD was collected on double-sided adhesive carbon tape, and the topology and approximate composition were subsequently examined with a scanning electron microscope (Hitachi-S4700, $20 \mathrm{kV}$ acceleration voltage) at various magnifications (1000-25,000 $\times$ ). Energy-dispersive X-ray spectroscopy (EDX) data were obtained with a Röntec QX2 energy-disperser microanalytical system (Röntec GmbH, Berlin, Germany) from various parts of the sample for elemental composition identification.

\subsection{Measurement of airway and respiratory tissue mechanics in rats}

Airway and tissue mechanics was characterized by measuring the forced oscillatory input impedance of the respiratory system $\left(Z_{\mathrm{rs}}\right)$, as detailed previously (Novak et al., 2006; Petak et al., 1997). Briefly, the respirator was stopped at end-expiration, and the tracheal cannula was connected to a loudspeaker-in-box system during the resulting 6-s apneic period. The loudspeaker generated a small-amplitude pseudorandom forcing signal in the frequency range $0.5-21 \mathrm{~Hz}$. The excitation signal was led through a polyethylene wave-tube $(L=100 \mathrm{~cm}$, ID $=2 \mathrm{~mm})$; lateral pressures were measured at both ends of the tube with two identical pressure transducers (model 33NA002D, ICSensors, Milpitas, CA, USA), and $Z_{\mathrm{rs}}$ was determined as the load impedance of the wave-tube (Van de Woestijne et al., 1981). The airway and tissue parameters were estimated separately by fitting a model to the $Z_{\mathrm{rs}}$ spectra via minimization of the relative differences between the measured and modeled impedance values. The model contained a frequency-independent airway resistance $\left(R_{\mathrm{aw}}\right)$ and inertance $\left(I_{\mathrm{aw}}\right)$ in series with a constant-phase tissue compartment (Hantos et al., 1992 ) characterized by the coefficients of tissue damping $(G)$ and elastance $(H)$. The parameter $R_{\mathrm{aw}}$ characterize the resistance of the treacheobonchial tree against airflow, while $I_{\mathrm{aw}}$ is related to acceleration and deceleration of air in the bronchi; tissue parameters $\mathrm{G}$ and $\mathrm{H}$ reflect dissipative (resistive) and energy storage (elastic) properties of the respiratory tissues (Hantos et al., 1992). Respiratory tissue hysteresivity $(\eta)$ reflecting the coupling between energy dissipation and storage within the respiratory tissues was calculated as $G / H$ (Fredberg and Stamenovic, 1989). The impedance of the tracheal cannula and the connecting tubing was measured after the experiments; the $R_{\mathrm{aw}}$ and $I_{\mathrm{aw}}$ values were corrected by subtracting the instrumental resistance and inertance values from them.

\subsection{Experimental protocol}

On the days of the experiments, anesthesia was induced in both groups of rats with an ip injection of $5 \%$ chloral hydrate at a dose of $400 \mathrm{mg} / \mathrm{kg}$, which ensures adequate anesthesia for 50-60 min (Novak et al., 2006). Endotracheal intubation was performed with a method developed for small rodents (Brown et al., 1999) with the rat suspended at an angle of $45^{\circ}$ by its two front upper teeth, and transillumination of the trachea just below the vocal cords was achieved by using a 150-W halogen light source (Nicon Volpi Cold Light Illuminator, Nikon Instruments Inc., Tokyo, Japan) connected to a flexible fiber optic arm. During this direct visualization, a 7.0-cm-long (ID $1.5 \mathrm{~mm}$, OD $2.0 \mathrm{~mm}$ ) polyethylene catheter was inserted into the trachea via the oral cavity with the help of a Draeger baby laryngoscope. The rat was then removed from the Plexiglas support, placed in a supine position on a heating pad, and the distal end of the tracheal cannula was attached to a small-animal ventilator (Model 683 Harvard Apparatus, South Natick, MA, USA). The rats were mechanically ventilated with room air with frequency set to 70 breaths $/ \mathrm{min}$ and $7 \mathrm{ml} / \mathrm{kg}$ tidal volume. The tail vein was cannulated with a 24-gauge cannula (Vygonüle V 24G), and muscle relaxation was achieved by administering pancuronium bromide $(0.2 \mathrm{mg} / \mathrm{kg}$ iv $)$.

When the animal had reached a steady-state condition (5-10 min after the starting of mechanical ventilation), the volume history was standardized by 
administering a hyperinflation via occlusion of the expiratory port of the ventilator. Three technically acceptable $Z_{\mathrm{rs}}$ recordings were then collected to establish the baseline respiratory mechanical parameters. An iv bolus of methacholine (MCh) at a dose of $2 \mu \mathrm{g} / \mathrm{kg}$ was next administered into the tail vein, and $Z_{\mathrm{rs}}$ was recorded $20 \mathrm{~s}, 1 \mathrm{~min}$ and $2 \mathrm{~min}$ after the injection. Previous experiments revealed that the peak response occurs at $20 \mathrm{~s}$ after the MCh injection, and the effect is diminished 2 min later (Novak et al., 2006). Following this transient constriction the animal was allowed to recover, and further iv MCh challenges were given with elevation of the $\mathrm{MCh}$ dose to 4, 8 and $16 \mu \mathrm{g} / \mathrm{kg}$. The peak increases in the mechanical parameters were observed $20 \mathrm{~s}$ after the MCh injection; these increases were related to those obtained from the average of the three baseline $Z_{\mathrm{rs}}$ recordings.

\subsection{Lung histopathological examinations}

After completion of the bronchoprovocation tests, the rats were euthanized with an iv injection of $10 \% \mathrm{KCl}$. The chest was opened by midline sternotomy, and the lungs were filled with $4 \%$ buffered formalin by applying a hydrostatic pressure of $20 \mathrm{~cm} \mathrm{H}_{2} \mathrm{O}$. The lungs and heart were then removed in one block and placed into $4 \%$ buffered formalin until processing.

Representative lung tissue sections (from the mid portion of both lungs) were embedded in paraffin blocks. Transhilar horizontal sections (perpendicular to the longitudinal axes of the lung from the hilum) were embedded in paraffin. Two $5-\mu \mathrm{m}$ sections were prepared in each lung specimen and were stained with hematoxylin-eosin. All slides were examined by the same investigator in a blind fashion and random sequence. A lung injury score was used to quantify the changes in lung morphometry observed under a light microscope. The degree of microscopic injury was scored with regard to the following variables: blood congestion (hyperemia), infiltration of perivascular and perialveolar inflammatory cells (lymphocytes, plasma cells and macrophages), and the presence of bronchus-associated lymphoid tissue (BALT) or its hyperplasia. The severity of injury was graded as follows for each of the four variables: no injury (None), injury involving up to one-third of the field (Mild), injury involving up to two-thirds of the field (Moderate) and diffuse injury throughout the field (Severe).

\subsection{Statistical analyses}

Scatters in the parameters were expressed in SE values. The MCh dose causing a $100 \%$ increase in $R_{\mathrm{aw}}\left(\mathrm{ED}_{100}\right)$ was calculated by linear interpolation of the doseresponse curves from the individual animals. The Kolmogorov-Smirnov test was used to test data for normality. The $t$-test was utilized to estimate the effects of RSD exposure on the basal respiratory mechanical parameters and on the $\mathrm{ED}_{100}$ values. Two-way repeated measures analysis of variance (ANOVA) was used with the variables RSD exposure and MCh dose to establish the effects of RSD on the lung responsiveness. The Student-Newman-Keuls multiple comparison procedure was employed to compare the respiratory mechanical parameters under different conditions. Since the histological data were not distributed normally, the Wilcoxon signed rank test was used to compare these findings between the protocol groups. The statistical tests were performed with a SigmaPlot software package (version 11, Systat Software Inc., Chicago, IL, USA). In each test, a significance level of $p<0.05$ was applied.

\section{Results}

A typical change in the concentration of RSD in the exposure chamber is illustrated in Fig. 2. Mimicking a gust of wind by shaking the RSD container caused a rapid increase in the amount of RSD in the air in the exposure chamber, which reached a peak concentration of $\sim 7 \mathrm{mg} / \mathrm{m}^{3}$. The concentration of RSD then gradually decreased, with the minimum amount of RSD approaching $\sim 1 \mathrm{mg} / \mathrm{m}^{3}$. The mean RSD concentration during exposures was $3.3 \mathrm{mg} / \mathrm{m}^{3}$.

The RSD particle size distribution before and immediately after the win-mimicking maneuver and the average for a complete exposure period are depicted in Fig. 3. The peak of the log-normal distribution during the overall exposure period was at $150 \mathrm{~nm}$, with a detectable amount of particles observed in the range $20 \mathrm{~nm}$ to $5 \mu \mathrm{m}$. There was a temporary shift to higher particle sizes after the win-mimicking maneuver, but a smaller particle dominated the RSD thereafter.

The analyses of the chemical composition of the RSD aggregates revealed the predominance of oxygen $(55.4 \pm 2.8 \%)$ in all 5 samples analyzed. Among the remaining chemical elements, Fe was present in the greatest quantity $(20.1 \pm 4.9 \%)$, followed by $\mathrm{Al}(8.6 \pm 3.4 \%)$, $\mathrm{Ca}(6.0 \pm 3.2 \%), \mathrm{Si}(3.9 \pm 1.1 \%), \mathrm{Ti}(3.7 \pm 1.4 \%), \mathrm{K}(2.1 \pm 0.7 \%)$ and $\mathrm{Mg}$

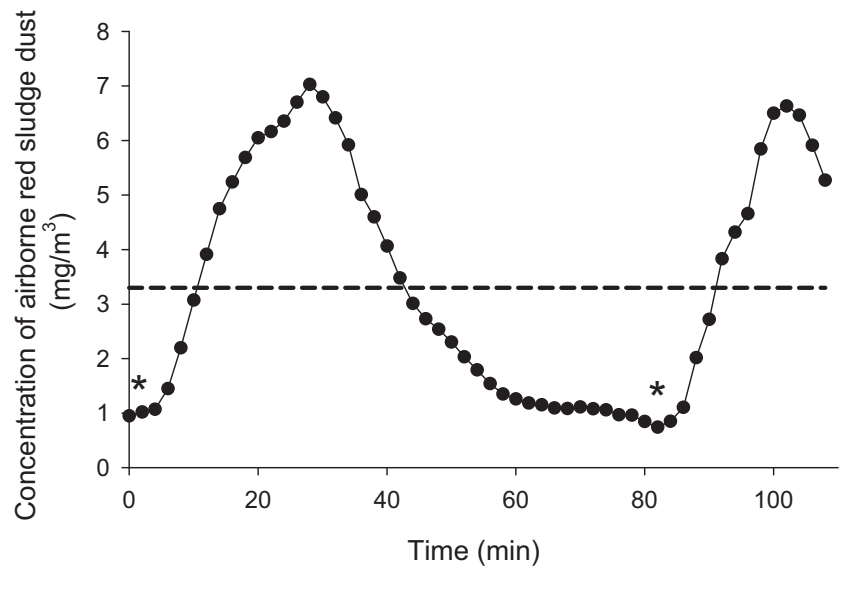

*: maneuver mimicking a gust of wind

Fig. 2. Changes in RSD concentration during exposure. Cyclic increases in the concentration were induced by shaking of the glass container containing the powder (denoted with ${ }^{*}$ ), which mimicked the wind-borne carriage of the red sludge particles.

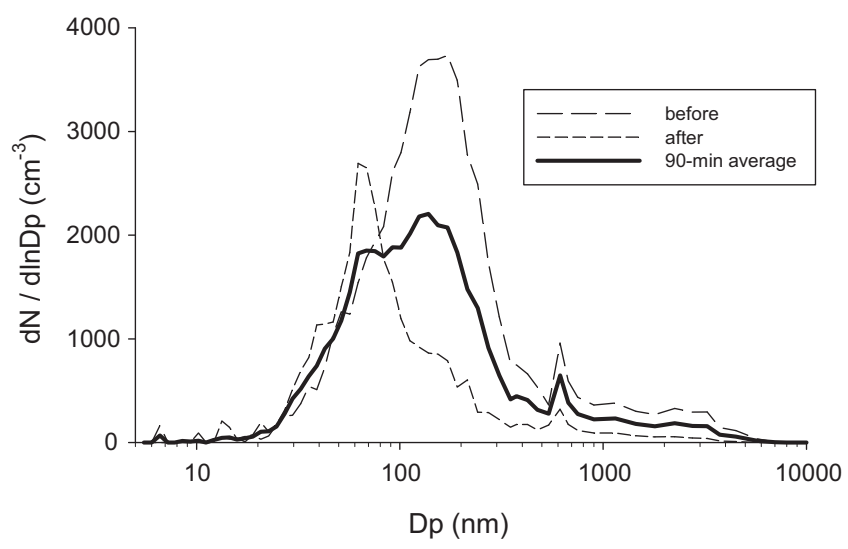

Fig. 3. RSD particle size distribution before and immediately after the winmimicking maneuver, and the average for the overall exposure period.

$(0.19 \pm 0.16 \%)$ (Fig. 4). The electron microscopic images of representative individual RSD particles are to be seen in Fig. 5. The particles were generally irregularly shaped with a coarse surface that might facilitate the adhesion of these particles on the airway epithelium.

Fig. 6 illustrates the baseline values of the airway and respiratory tissue mechanical parameters for the rats in both groups. RSD exposure did not lead to any significant change in $R_{\mathrm{aw}}(p=0.65)$ or $\eta(p=0.90)$. There was a tendency for $G$ and $H$ to increase in the rats exposed to RSD, but these differences did not reach the level of statistical significance ( $p=0.071$ and $p=0.10$, respectively).

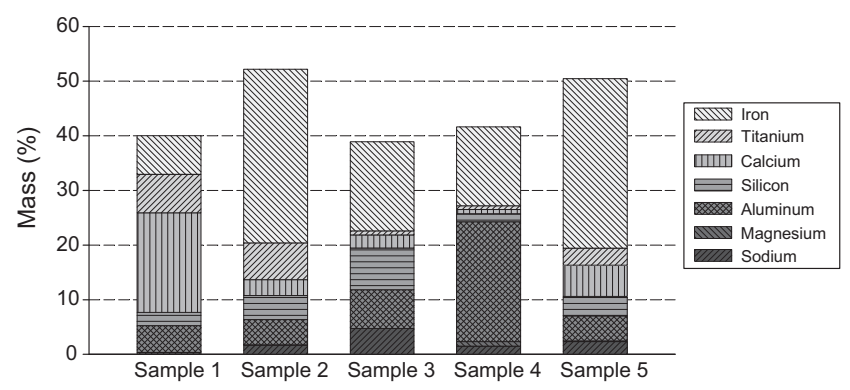

Fig. 4. Chemical compositions of 5 samples of RSD aggregates. 

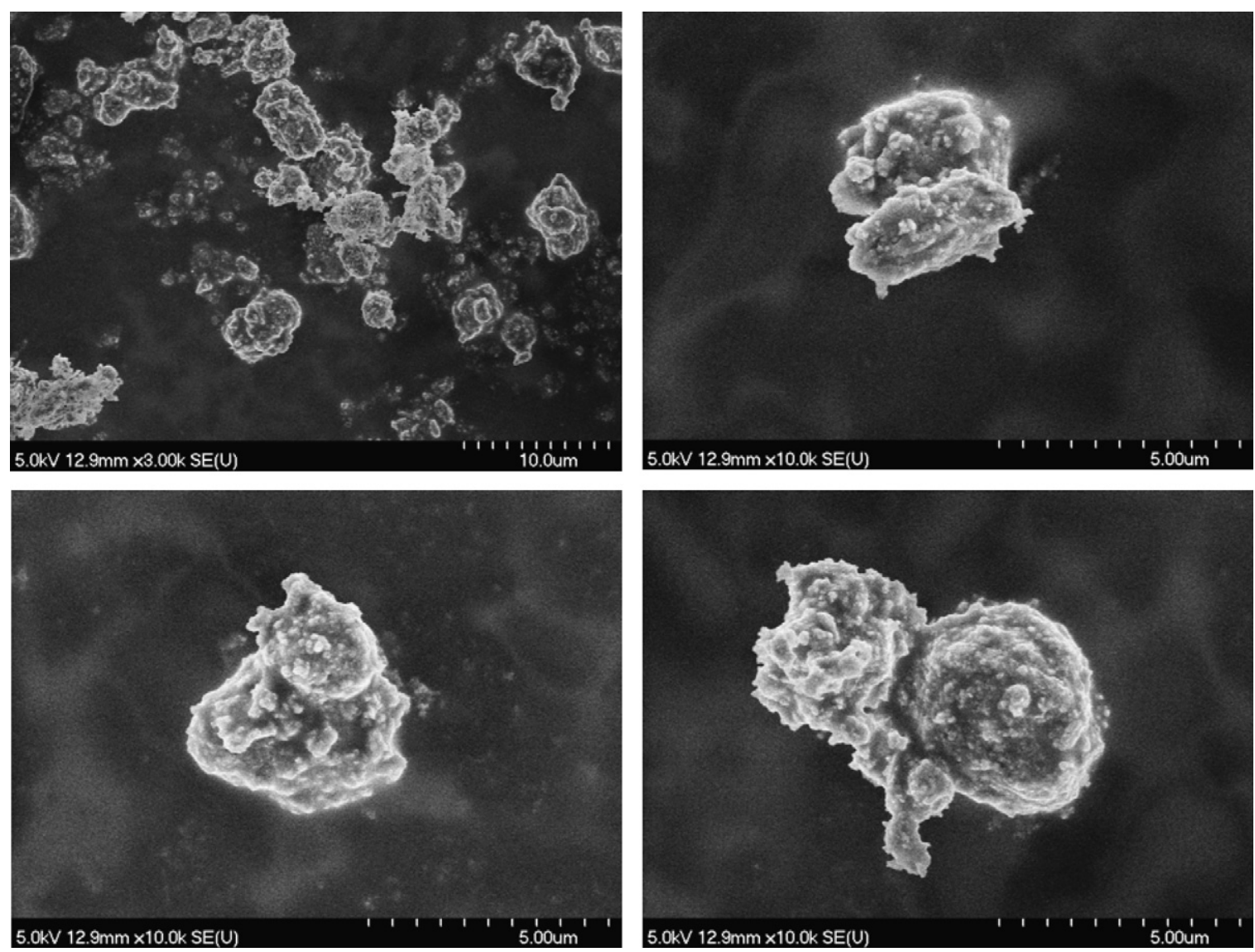

Fig. 5. Electron microscopic images demonstrating the topology of 4 representative RSD aggregates.

The changes in the airway and tissue parameters in the control and RSD-exposed animals following the MCh challenges are demonstrated in Fig. 7. MCh caused marked dose-dependent increases in $R_{\mathrm{aw}}, G$ and $\eta(p<0.001)$, while the increases in $H$ were less pronounced, but still statistically highly significant $(p<0.001)$. The significant interactions revealed between MCh and RSD by twoway ANOVA ( $p=0.005)$ indicated that RSD inhalation affected the magnitude of the MCh-induced increases in $R_{\mathrm{aw}}$, i.e. AH developed in the RSD group. The presence of AH following RSD inhalation was also reflected in the significantly lower $\mathrm{ED}_{100}$ values in the RSD group than in controls $(5.3 \pm 0.2$ vs. $7.5 \pm 0.9 \mu \mathrm{g} / \mathrm{kg}$, respectively, $p=0.041$ ).

Representative histological sections in lungs obtained from rats in both groups are demonstrated in Fig. 8. Inhalation of RSD led to perivascular infiltration (in decreasing sequence of particle amount in lymphocytes, plasma cells, eosinophils, mastocytes and neutrophils) and perialveolar infiltration (in decreasing sequence in macrophages, lymphocytes and plasma cells) of inflammatory cells.
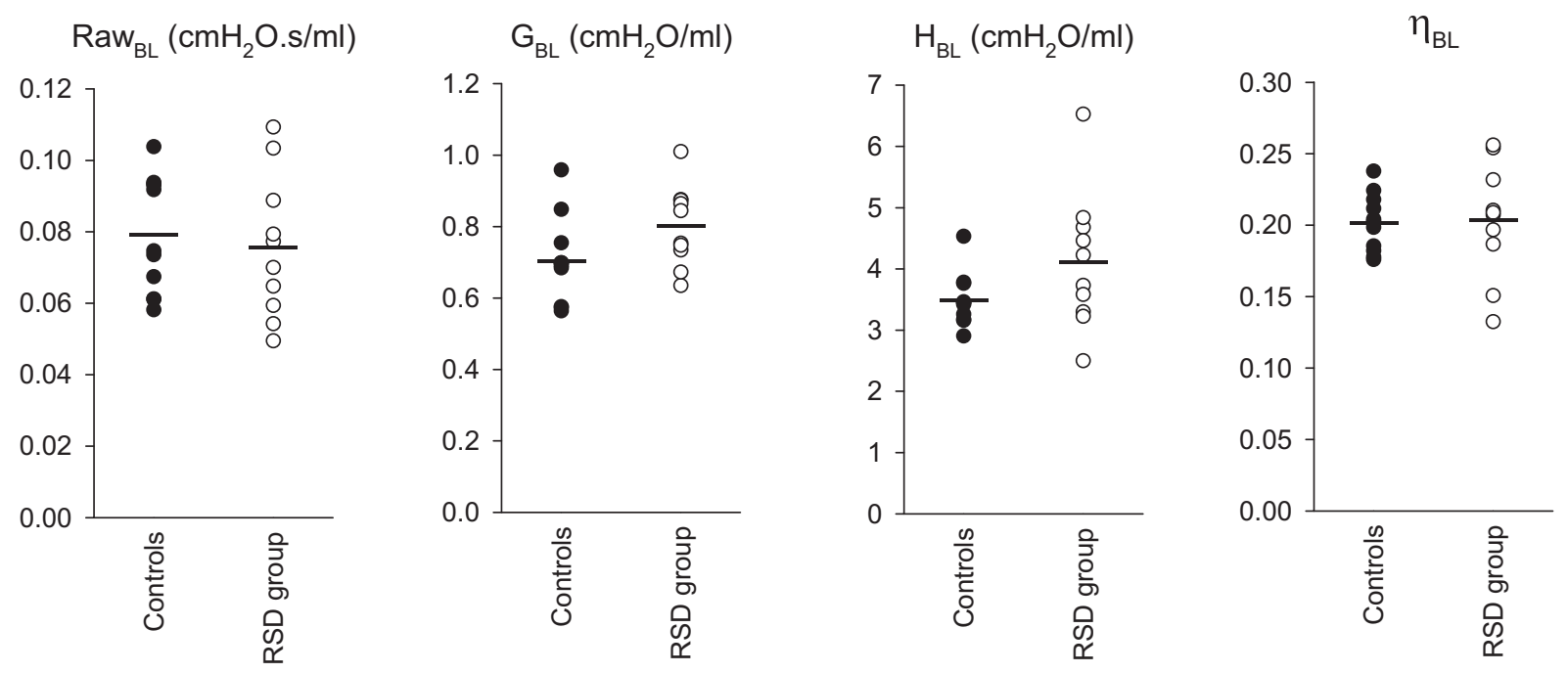

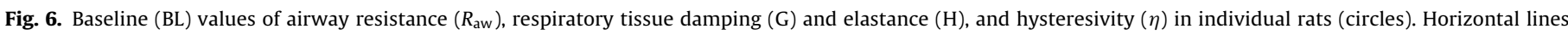
denote the group means. 

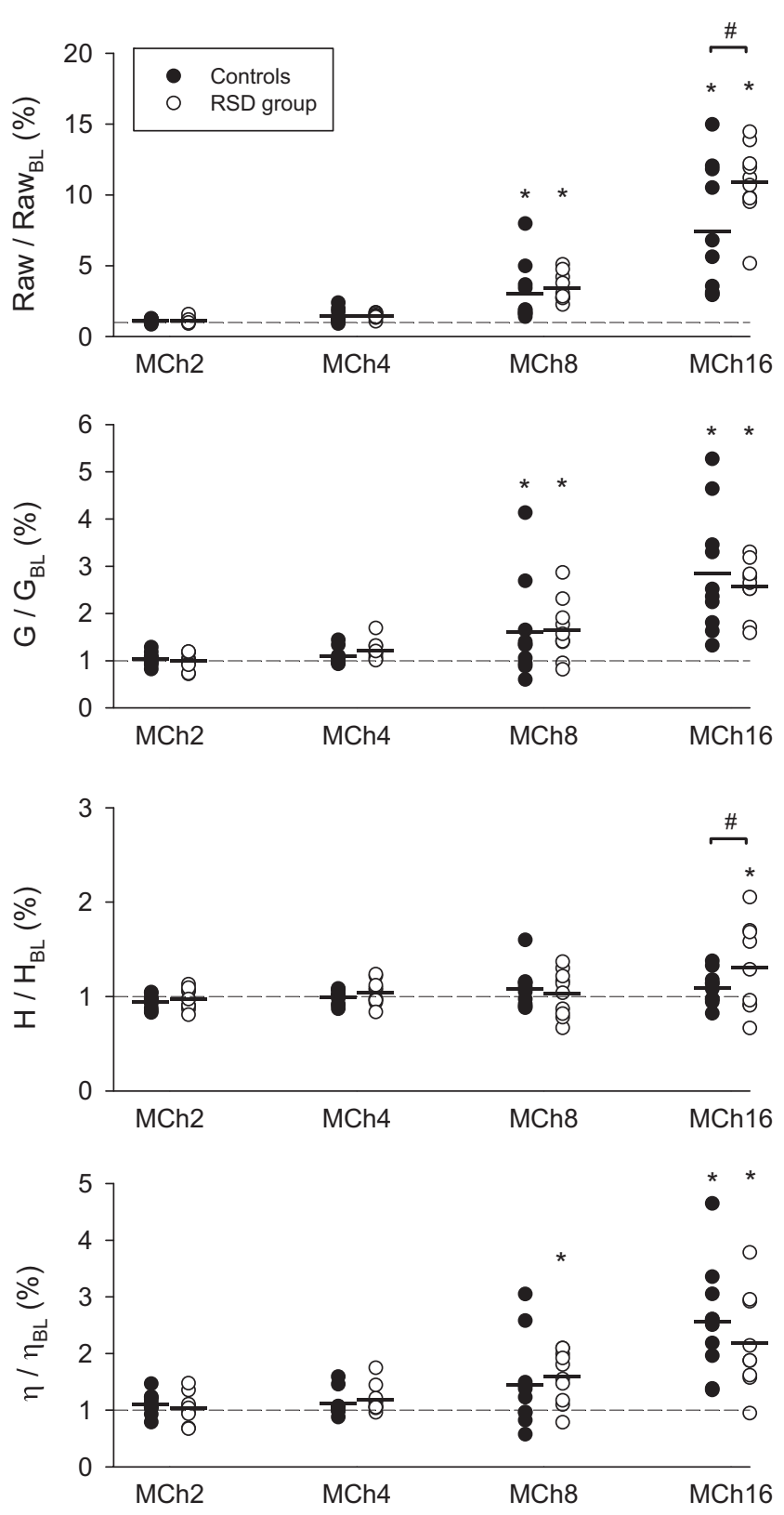

Fig. 7. Airway and respiratory tissue parameters measured after MCh challenges relative to the baseline (BL) values in the control rats (closed circles) and in rats exposed to RSD (open circles). Horizontal lines denote the group mean values. *: $p<0.05 v s$. the baseline; \#: $p<0.05$ between the groups.

In the alveolar areas which exhibited an inflammatory response, RSD particles were recovered as fine, granular and pigmented cytoplasmatic inclusions in the alveolar macrophages.

Fig. 9 depicts the histological findings. Prolonged exposure to RSD induced the development of mild hyperemia $(p=0.03)$ and the mild-to-moderate infiltration of inflammatory cells into the perivascular $(p=0.003)$ or perialveolar $(p<0.001)$ areas. No difference in BALT hyperplasia was observed between the two groups $(p=0.43)$.

\section{Discussion}

The present study examined the respiratory consequences of prolonged inhalation of RSD extracted from on-site sampling of toxic red sludge following the environmental disaster near Ajka (western Hungary). The exposure of rats to RSD in high concentrations caused no detectable changes in the basal airway and respiratory tissue parameters, whereas this irritation led to the development of mild $\mathrm{AH}$. Histological investigations revealed that this adverse respiratory consequence of the RSD was associated with a mild-to-moderate inflammatory response around the pulmonary blood vessels and in the alveolar walls.

\subsection{Physical properties and chemical composition of the RSD exposure model}

Since the exposure of the rats to RSD was performed under laboratory conditions following drying and mechanical grinding of an authorized red sludge sample collected at the site of the disaster, the relationship of the concentration, the physical properties and the chemical composition of our RSD powder to the on-site field samples of the ambient particles warrant consideration.

As concerns the concentration of the RSD particles in the exposure chamber, the mass of airborne particles varied cyclically between 1 and $7 \mathrm{mg} / \mathrm{m}^{3}$ (Fig. 2). This pattern, mimicking wind gusts in the area affected by the disaster, resulted in a mean floating mass concentration of RSD $\left(3.3 \mathrm{mg} / \mathrm{m}^{3}\right)$ that was about two orders of magnitude greater than the levels observed around the devastated area in the months following the accident (http://www.kvvm.hu/olm/index.php, 2011. Ministry of Rural Development, Hungary). Considering the limited time available for the exposures of the animals, we deliberately made the concentration high enough for mild-to-moderate respiratory symptoms to appear, and to achieve a total RSD dose exposure similar to what might be expected for the people living continuously in the affected areas for a period of some years.

Since the particle size fundamentally affects its deposition in the respiratory system, another important aspect of our experiments was the size distribution airborne particles. The critical diameter for particles to reach the lower respiratory tract by inhalation in humans is about $10 \mu \mathrm{m}$ (Oberdorster, 2001; Salma et al., 2001). Since almost all of the RSD particles in our investigation were smaller than this limit, this exposure was appropriate for study of the respiratory consequences of RSD inhalation (Fig. 3). This was evidenced by the lung histology, which revealed particles as cytoplasmatic inclusions in the alveolar macrophages (Fig. 8). The size distribution obtained in the present study differs from data published earlier on resuspended red dust samples (Gelencser et al., 2011), where somewhat greater particles were detected. This difference could be explained by methodological differences in RSD preparation, since the resuspended red sludge samples in that previous field study were collected from agricultural soil and contained larger particles less likely to become airborne. We exposed rats to particles made airborne by applying a positive pressure airflow stream to previously dried powder in a chamber. In order to verify our results, we made independent in situ measurements on airborne material with the same instrumentation at Devecser, where we likewise detected a negligible amount of particles with diameters $>500 \mathrm{~nm}$. Our applied approach, therefore, appears to give a better simulation to the situation when the wet red sludge is dried by the sun and the resulting fine dry dust particles are blown by wind gusts into the air, reaching heights relevant to the exposure of humans to inhalable dust $(\sim 2 \mathrm{~m})$.

The topology and composition of the RSD used in the present exposures agreed well with those obtained previously by analyzing on-site field samples (Gelencser et al., 2011). Topological examination confirmed that the RSD particles had irregular shapes with a coarse surface (Fig. 5), which is likely to promote the adhesion of such particles on the lower respiratory tract. The main components were the elements present in the bauxite and remaining following the Bayer process (e.g. Fe, Ti and $\mathrm{Mg}$ ), while other less frequent 

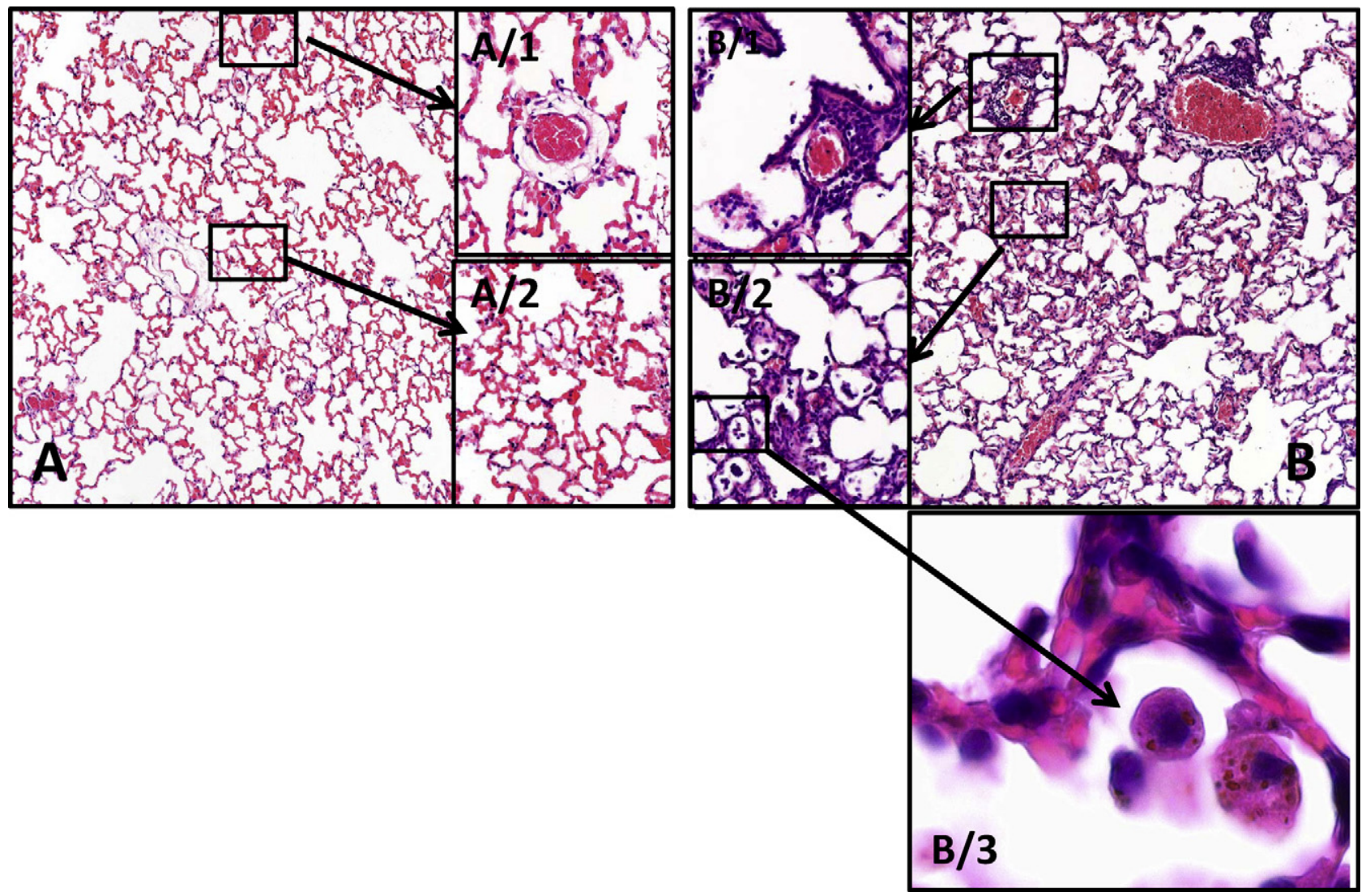

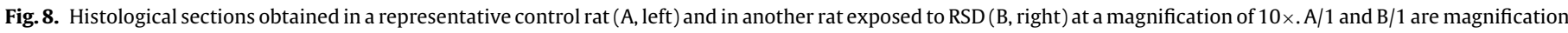

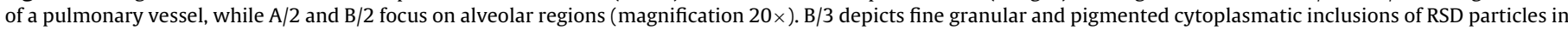
macrophages.

components (e.g. Si and Ca) originated from the soil soaked by the red sludge (Fig. 4).

\subsection{Effects of RSD on basal lung function}

Despite the high RSD concentration and the evidence that it accessed the lower respiratory tract, no clinically significant adverse changes in the baseline airway or respiratory tissue mechanics were detected in the present study (Fig. 6). The tendency to higher $G$ and $H$ in the animals in the RSD group may be a consequence of the mild inflammation demonstrated by the lung histology (Fig. 9). The development of airway inflammation agrees with previous findings on animals exposed to high concentrations of inhalable particles originating from carbon black (Lambert et al., 2003; Li et al., 1996), ultrafine $\mathrm{TiO}_{2}$ (Oberdorster, 2001), urban air pollution (Dong et al., 2005; Harkema et al., 2004), and fine particulate matter arising from the destruction of the World Trade Center (Gavett et al., 2003). Since merely mild airway inflammation has no major effects on the basal lung function (Dong et al., 2005; Novak et al., 2006; Petak et al., 2010; Stevens et al., 2009), the lack of difference between the two groups is consistent with the previous results.

\subsection{Airway inflammation and responsiveness following RSD inhalation}

In agreement with previous findings that inhaled particulate matter induced asthma-like symptoms (Dong et al., 2005; Kilburn, 1984; Lambert et al., 2003; Maatta et al., 2006; Nel et al., 2001; Stevens et al., 2009; Wang et al., 2008), the airway inflammation that occurred following RSD inhalation in the present study led to the development of $\mathrm{AH}$, which was manifested in significantly elevated responses to $\mathrm{MCh}$ (Fig. 7) and subsequent decreases in $\mathrm{ED}_{100}$. As concerns the mechanism of the emergence of $\mathrm{AH}$, the involvement of macrophages can be anticipated from the histological findings (Fig. 8), since the role of alveolar macrophages in the development of an inflammation response in the small airways was evidenced previously (Maatta et al., 2006; Oberdorster et al., 1992). Acute inflammation is probably caused by the phagocytosis of inhaled particles by alveolar macrophages and the release of inflammatory mediators from these cells. This injury response already appears within a few hours after inhalation and is particle size-dependent: the most destructive particles are the ultrafine ones $(<50 \mathrm{~nm})$, which are able to pass into the phagocytes (Mantecca et al., 2010). Since a substantial proportion of the particles in our study were in this size range, the involvement of this mechanism is expected. Chronic dust inhalation drives the influx of macrophages and other inflammatory cells, and these factors may lead to the progress of chronic lung diseases such as asthma (Andersen et al., 2008; Dong et al., 2005), emphysema, bronchiolitis (Girod and King, 2005) or fibrosis (Oberdorster et al., 1992).

\subsection{Limitations}

The present study investigated the short-term pulmonary consequences of exposure to a high dose of RSD in healthy adult rats, an adequate model of long-term RSD inhalation in adult individuals with normal lungs. However, it must be borne in mind that susceptibility of the lungs to exogenous stimuli may be enhanced by many factors, such as a persistent lung disease (Harkema et al., 2004; Lambert et al., 2003; Martins et al., 2011), respiratory infection (Zanobetti et al., 2000) and age, with an increased risk of 

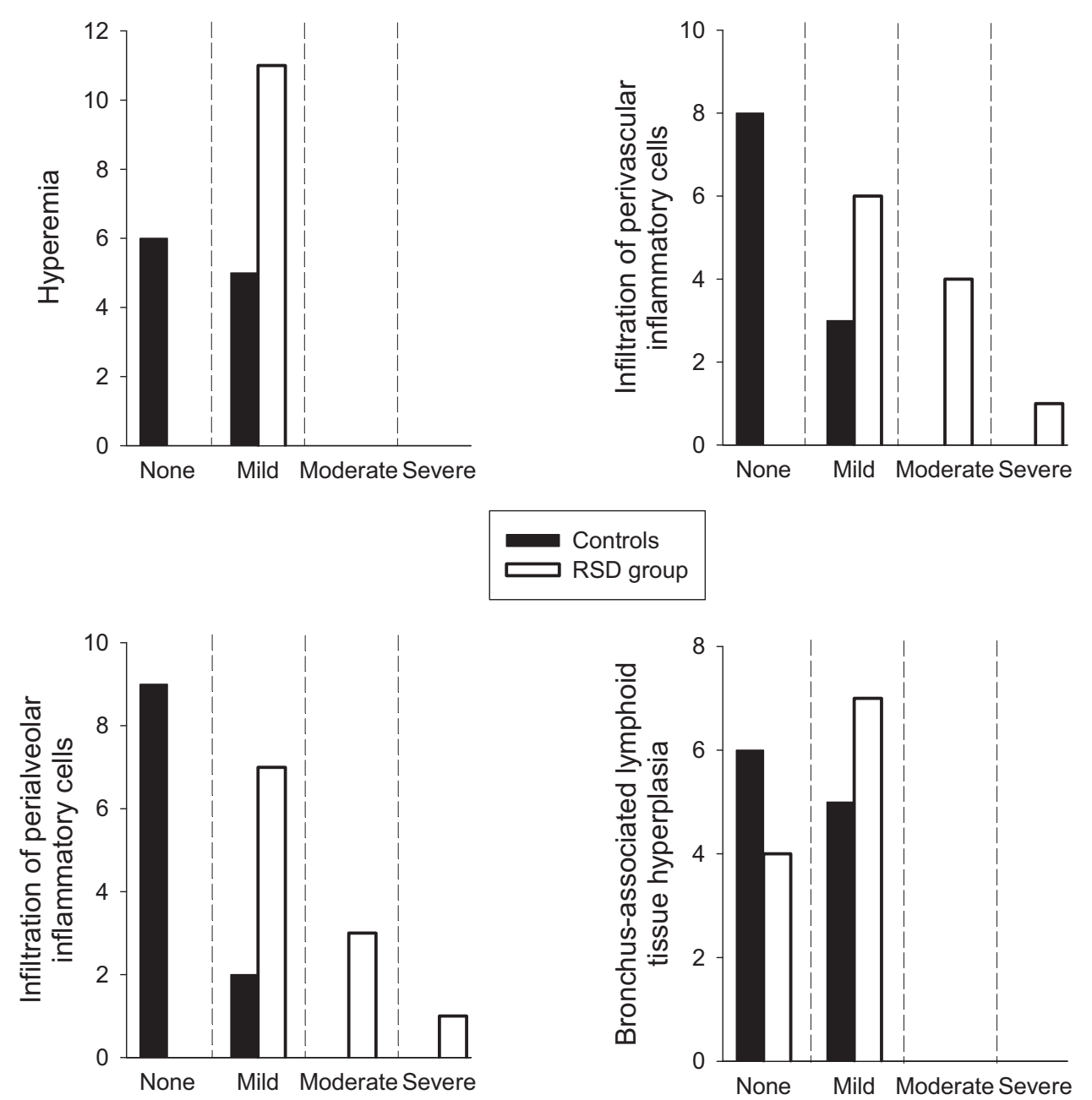

Fig. 9. Numbers of control (closed bars) and RSD-treated rats (open bars) with different severity scores based on the histopathological evaluations.

pulmonary complications in response to particulate air pollution in both the pediatric (Martins et al., 2011) and the elderly (Laskin et al., 2010) population. The detrimental effects of RSD exposure on the pulmonary system may therefore be exaggerated when such factors are present, they must form the subject of further investigations. Another important feature in the present study is the limited time allowed for the potential manifestation of pulmonary diseases. While the development of inflammation was demonstrated by the histopathological results, its potential longterm consequences were not been covered. Previous studies have indicated that the inhalation of various dust particles may involve long-term adverse pulmonary effects that may promote the development of COPD (Girod and King, 2005), sarcoid-like pulmonary disease (Izbicki et al., 2007) and diffuse parenchymal lung disease (Szeinuk et al., 2008); accordingly, these slowly progressing lung diseases demand further studies with longer time-frames.

\section{Conclusions}

Fine airborne particles of the dried red sludge following an environmental disaster near Ajka in 2010 and around regions near dry storage reservoirs have given rise to serious public health concerns, with a particular fear of respiratory complications. We examined the effects of RSD produced from an on-site sample in the Ajka region on the pulmonary system by performing basal lung function measurements, with the assessment of changes in lung responsiveness and also histopathological analyses. When rats were exposed to a high concentration of RSD, the fine powder particles reached the lower respiratory tract, but the alterations in the basal airway and respiratory tissue mechanics were not significant. The mild inflammation that developed around the pulmonary vessels and in the alveolar wall was associated with a mild bronchial hyper-reactivity. Since these mild respiratory symptoms emerged following exposure to extremely high concentrations, our results may suggest that the short-term health hazard as regards the pulmonary system in healthy human adults exposed to RSD inhalation is not greater than that due to urban dust at a comparable concentration.

\section{Conflict of interest}

The authors declare that there is no conflict of interest.

\section{Acknowledgments}

Supported by Hungarian Basic Scientific Research Grant OTKA K81179 and CNK78549. Ferenc Petak is supported by a Bolyai János Research Fellowship. The authors are grateful for the advice of Katalin Varjú and for the excellent technical assistance of István Kopasz. The authors thank the Veszprém County Office of the National Directorate General for Disaster Management, Ministry of Internal Affairs, Hungary, for providing the official red sludge sample. 


\section{References}

Aberkane, T., Harvey, M., Webb, M., 2004. Annual ambient air quality monitoring report 2003. Environment Canterbury Technical Report No U04/58.

Andersen, Z.J., Loft, S., Ketzel, M., Stage, M., Scheike, T., Hermansen, M.N., Bisgaard, H., 2008. Ambient air pollution triggers wheezing symptoms in infants. Thorax 63, 710-716.

Brown, R.H., Walters, D.M., Greenberg, R.S., Mitzner, W., 1999. A method of endotracheal intubation and pulmonary functional assessment for repeated studies in mice. J. Appl. Physiol. 87, 2362-2365.

Dong, C.C., Yin, X.J., Ma, J.Y., Millecchia, L., Wu, Z.X., Barger, M.W., Roberts, J.R., Antonini, J.M., Dey, R.D., Ma, J.K., 2005. Effect of diesel exhaust particles on allergic reactions and airway responsiveness in ovalbumin-sensitized brown Norway rats. Toxicol. Sci. 88, 202-212.

Fernvik, E., Peltre, G., Senechal, H., Vargaftig, B.B., 2002. Effects of birch pollen and traffic particulate matter on Th2 cytokines, immunoglobulin E levels and bronchial hyper-responsiveness in mice. Clin. Exp. Allergy 32 $602-611$.

Fredberg, J.J., Stamenovic, D., 1989. On the imperfect elasticity of lung tissue. J. Appl. Physiol. 67, 2408-2419.

Gavett, S.H., Haykal-Coates, N., Highfill, J.W., Ledbetter, A.D., Chen, L.C., Cohen, M.D., Harkema, J.R., Wagner, J.G., Costa, D.L., 2003. World Trade Center fine particulate matter causes respiratory tract hyperresponsiveness in mice. Environ. Health Perspect. 111, 981-991.

Gelencser, A., Kovats, N., Turoczi, B., Rostasi, A., Hoffer, A., Imre, K., Nyiro-Kosa, I., Csakberenyi-Malasics, D., Toth, A., Czitrovszky, A., Nagy, A., Nagy, S., Acs, A., Kovacs, A., Ferincz, A., Hartyani, Z., Posfai, M., 2011. The red mud accident in Ajka (Hungary): characterization and potential health effects of fugitive dust. Environ. Sci. Technol. 45, 1608-1615.

Girod, C.E., King Jr., T.E., 2005. COPD: a dust-induced disease? Chest 128, 3055-3064.

Hantos, Z., Daroczy, B., Suki, B., Nagy, S., Fredberg, J.J., 1992. Input impedance and peripheral inhomogeneity of dog lungs. J. Appl. Physiol. 72, 168-178.

Harkema, J.R., Keeler, G., Wagner, J., Morishita, M., Timm, E., Hotchkiss, J., Marsik, F., Dvonch, T., Kaminski, N., Barr, E., 2004. Effects of concentrated ambient particles on normal and hypersecretory airways in rats. Res. Rep. Health Eff. Inst., 1-68 (discussion 69-79).

Heim, M., Mullins, B., Umhauer, H., Kasper, G., 2008. Performance evaluation of three optical particle counters with an efficient multimodal calibration method. Aerosol Sci. 39, 1019-1031.

Izbicki, G., Chavko, R., Banauch, G.I., Weiden, M.D., Berger, K.I., Aldrich, T.K., Hall, C., Kelly, K.J., Prezant, D.J., 2007. World Trade Center sarcoid-like granulomatous pulmonary disease in New York City Fire Department rescue workers. Chest 131, 1414-1423.

Kilburn, K.H., 1984. Particles causing lung disease. Environ. Health Perspect. 55, 97-109.

Kinghama, S., Duranda, M., Aberkaneb, T., Harrisona, J., Wilsona, J., Eptonc, M., 2006. Winter comparison of TEOM, MiniVol and DustTrak PM10 monitors in a woodsmoke environment. Atmos. Environ. 40, 338-347.

Lambert, A.L., Mangum, J.B., DeLorme, M.P., Everitt, J.I., 2003. Ultrafine carbon black particles enhance respiratory syncytial virus-induced airway reactivity, pulmonary inflammation, and chemokine expression. Toxicol. Sci. 72, 339-346.

Laskin, D.L., Mainelis, G., Turpin, B.J., Patel, K.J., Sunil, V.R., 2010. Pulmonary effects of inhaled diesel exhaust in young and old mice: a pilot project. Res. Rep. Health Eff. Inst., 3-31.

Li, X.Y., Gilmour, P.S., Donaldson, K., MacNee, W., 1996. Free radical activity and pro-inflammatory effects of particulate air pollution (PM10) in vivo and in vitro. Thorax 51, 1216-1222.
Li, X.Y., Gilmour, P.S., Donaldson, K., MacNee, W., 1997. In vivo and in vitro proinflammatory effects of particulate air pollution (PM10). Environ. Health Perspect. 105 (Suppl. 5), 1279-1283.

Maatta, J., Lehto, M., Leino, M., Tillander, S., Haapakoski, R., Majuri, M.L., Wolff, H. Rautio, S., Welling, I., Husgafvel-Pursiainen, K., Savolainen, K., Alenius, H., 2006. Mechanisms of particle-induced pulmonary inflammation in a mouse model: exposure to wood dust. Toxicol. Sci. 93, 96-104.

Mantecca, P., Farina, F., Moschini, E., Gallinotti, D., Gualtieri, M., Rohr, A., Sancini, G., Palestini, P., Camatini, M., 2010. Comparative acute lung inflammation induced by atmospheric PM and size-fractionated tire particles. Toxicol. Lett. 198, 244-254.

Martins, P.C., Valente, J., Papoila, A.L., Caires, I., Araujo-Martins, J., Mata, P., Lopes, M., Torres, S., Rosado-Pinto, J., Borrego, C., Annesi-Maesano, I., Neuparth, N., 2011. Airways changes related to air pollution exposure in wheezing children. Eur. Respir. J., Epub ahead of print.

Nel, A.E., Diaz-Sanchez, D., Li, N., 2001. The role of particulate pollutants in pulmonary inflammation and asthma: evidence for the involvement of organic chemicals and oxidative stress. Curr. Opin. Pulm. Med. 7, 20-26.

Novak, Z., Petak, F., Banfi, A., Toth-Szuki, V., Barati, L., Kosa, L., Bari, F., Szekely, E., 2006. An improved technique for repeated bronchoalveolar lavage and lung mechanics measurements in individual rats. Respir. Physiol. Neurobiol. 154, 467-477.

Oberdorster, G., 2001. Pulmonary effects of inhaled ultrafine particles. Int. Arch. Occup. Environ. Health 74, 1-8.

Oberdorster, G., Ferin, J., Gelein, R., Soderholm, S.C., Finkelstein, J., 1992. Role of the alveolar macrophage in lung injury: studies with ultrafine particles. Environ. Health Perspect. 97, 193-199.

Petak, F., Banfi, A., Toth-Szuki, V., Barati, L., Bari, F., Szekely, E., Novak, Z., 2010. Airway responsiveness and bronchoalveolar lavage fluid profiling in individual rats: effects of different ovalbumin exposures. Respir. Physiol. Neurobiol. 170, 76-82.

Petak, F., Hantos, Z., Adamicza, A., Asztalos, T., Sly, P.D., 1997. Methacholine-induced bronchoconstriction in rats: effects of intravenous vs. aerosol delivery. J. Appl. Physiol. 82, 1479-1487.

Ruyters, S., Mertens, J., Vassilieva, E., Dehandschutter, B., Poffijn, A., Smolders, E., 2011. The red mud accident in Ajka (Hungary): plant toxicity and trace metal bioavailability in red mud contaminated soil. Environ. Sci. Technol., Epub ahead of print.

Salma, I., Balásházy, I., Winkler-Heil, R., Hofmann, W., Záray, G., 2001. Effect of particle mass size distribution on the deposition of aerosols in the human respiratory system. J. Aerosol Sci. 33, 119-132.

Stevens, T., Cho, S.H., Linak, W.P., Gilmour, M.I., 2009. Differential potentiation of allergic lung disease in mice exposed to chemically distinct diesel samples. Toxicol. Sci. 107, 522-534.

Szeinuk, J., Padilla, M., de la Hoz, R.E., 2008. Potential for diffuse parenchymal lung disease after exposures at World Trade Center disaster site. Mt. Sinai J. Med. 75 101-107.

Van de Woestijne, K., Franken, H., Cauberghs, M., Landser, F., Clement, J., 1981. A modification of the forced oscillation technique. In: Hutas, I., Debreczeni, L.A. (Eds.), Advances in Physiological Sciences Respiration, Proceedings of the 28th International Congress of Physiological Sciences. Oxford, Pergamon, pp. 655-660.

Wang, T., Moreno-Vinasco, L., Huang, Y., Lang, G.D., Linares, J.D., Goonewardena, S.N., Grabavoy, A., Samet, J.M., Geyh, A.S., Breysse, P.N., Lussier, Y.A., Natarajan, V., Garcia,J.G., 2008. Murine lung responses to ambient particulate matter: genomic analysis and influence on airway hyperresponsiveness. Environ. Health Perspect. 116, 1500-1508.

Zanobetti, A., Schwartz, J., Gold, D., 2000. Are there sensitive subgroups for the effects of airborne particles? Environ. Health Perspect. 108, 841-845. 
Petak F, Czovek D, Novak Z:

Spirometry and forced oscillations in the detection of airway hyperreactivity in asthmatic children.

Pediatric Pulmonology 47:(10) pp. 956-965. (2012) 


\title{
Spirometry and Forced Oscillations in the Detection of Airway Hyperreactivity in Asthmatic Children
}

\author{
Ferenc Peták, $\mathrm{PhD},{ }^{1 *}$ Dorottya Czövek, $\mathrm{MD}^{2}$ and Zoltán Novák, $\mathrm{MD}, \mathrm{PhD}^{2}$ \\ Summary. Background: Provocation tests are routinely used to detect airway hyperreactivity \\ $(\mathrm{AH})$ in the diagnosis of asthma. We compared the sensitivities of the forced oscillation tech- \\ nique (FOT) and spirometry in the detection of $\mathrm{AH}$ in asthmatic children. Methods: FOT and \\ spirometry were performed in 20 asthmatic children (aged 5-18 years) following aerosolized \\ histamine and methacholine at an interval of 2 weeks. The respiratory system input impedance \\ was measured by FOT; the resistance at $6 \mathrm{~Hz}\left(\mathrm{R}_{6}\right)$, the average resistance between 4 and \\ $24 \mathrm{~Hz}$, the area under the reactance curve $(A X)$ and the resonant frequency were extracted \\ from these recordings. Spirometry was used to obtain forced expiratory volumes and flow \\ parameters. Results: Following provocation with the two agonists, the FOT detected the airway \\ response as early as spirometry. When the greater variability of the impedance parameters \\ was taken into account, the two methods were observed to have similar sensitivities. Among \\ the lung function parameters studied, $A X$ and $R_{6}$ were the most sensitive for the demonstration \\ of $\mathrm{AH}$. Conclusions: Our findings demonstrate that FOT is as suitable as spirometry for the \\ measurement of bronchoconstriction and thus it may be considered for the detection of $\mathrm{AH}$ in \\ asthmatic children. Since its application requires minimal cooperation, this approach imposes \\ less stress and may be particularly favorable in the diagnosis of asthma at a young age. \\ Pediatr Pulmonol. 2012; 47:956-965. ๑ 2012 Wiley Periodicals, Inc.
}

Key words: lung function; bronchoconstriction; airway resistance; histamine; methacholine.

Funding source: Hungarian Basic Scientific Research, Number: OTKA K81179, Bolyai Janos Research Fellowship, European Union, European Regional Fund.

\section{INTRODUCTION}

The airway hyperreactivity $(\mathrm{AH})$ during bronchoprovocation tests plays a key role in the diagnosis of asthma. ${ }^{1-4}$ The early diagnosis and adequate treatment of asthma in early childhood significantly improve the prognosis and the quality of life. ${ }^{5}$ In older children or adults, the $\mathrm{AH}$ can be detected indirectly by performing spirometry during airway challenges with an inhaled bronchoconstrictor agonist. However, the measurement of lung function and the subsequent detection of $\mathrm{AH}$ in young children are limited by their inability to perform the close cooperation necessary for spirometry.

The forced oscillation technique (FOT) has gained increasing attention for the measurement of pulmonary mechanics in children because this approach requires no special breathing maneuvers. ${ }^{6,7}$ Moreover, in contrast with spirometry, the FOT provides direct information on the mechanical properties of the airways and the respiratory tissues. These beneficial properties of the FOT have resulted in numerous previous studies in which the lung function was assessed in children with no respiratory disease,${ }^{8-10}$ or with various lung diseases such as cystic fibrosis, ${ }^{9,11-14}$ neonatal chronic lung disease, ${ }^{9,15}$ wheezy bronchitis, ${ }^{9,16-18}$ or asthma. ${ }^{1-3,9,10}$

(c) 2012 Wiley Periodicals, Inc.
Despite the potential of the FOT to detect early bronchoconstriction during different challenges, the sensitivity of this method has not been systematically evaluated with the gold standard of spirometry in asthmatic children. The aims of the present study were therefore (i) to compare the sensitivities of the FOT and spirometry during airway challenges involving the inhalation of different direct stimuli commonly used in clinical practice (histamine [His] and methacholine $[\mathrm{MCh}]$ ) and

\footnotetext{
${ }^{1}$ Department of Medical Physics and Informatics, University of Szeged, Hungary.

${ }^{2}$ Department of Pediatrics, University of Szeged, Hungary.

Conflict of interest: None
}

*Correspondence to: Ferenc Peták, PhD, Department of Medical Physics and Informatics, University of Szeged, Korányi fasor 9, H-6720 Szeged, Hungary. E-mail: petak@dmi.szote.u-szeged.hu, petakf@yahoo.com

Received 2 August 2011; Accepted 29 December 2011.

DOI 10.1002/ppul.22551

Published online 26 March 2012 in Wiley Online Library

(wileyonlinelibrary.com). 
(ii) to establish which FOT parameter and which provocation test is most appropriate for the detection of $\mathrm{AH}$ in asthmatic children.

\section{MATERIALS AND METHODS}

\section{Subjects}

Twenty asthmatic children ( 5 girls and 15 boys, age range 5-18 years) were enrolled into the study. The diagnosis of asthma, the degree of its severity, and the level of control were categorized according to the GINA (Global Initiative for Asthma) guidelines, ${ }^{19}$ based on the previous history of recurrent coughing, wheezing, shortness of breath (at rest or following exercise), and the symptomatic improvement following short-acting bronchodilator administration. Each child and/or their guardian completed the informed consent document, which was approved by the Clinical Ethics Committee of the University of Szeged (Ref No. WHO2803). Seventeen children did not receive any regular asthma medication during one month prior to the study; they used only inhaled salbutamol (Sal) occasionally, as needed (GINA level 1). Three children used inhaled corticosteroid (ICS) as maintenance (budesonide $200 \mu \mathrm{g}$ twice a day) and Sal (200 $\mu \mathrm{g}$ as needed) as rescue therapy (GINA level 2). All children were controlled during the study period. Only patients who did not need Sal during $8 \mathrm{hr}$ before the visit were included in the study.

\section{Forced Oscillations}

The FOT measurements were performed in accordance with the ERS guidelines. ${ }^{6}$ To measure the input impedance of the respiratory system (Zrs) during spontaneous breathing, a commercially available device (i2m, Chess Medica, Oostakker, Belgium) was applied. Briefly, a loudspeaker was used to generate the pseudorandom broad-band oscillatory pressure signals containing integer multiple frequencies between 4 and $48 \mathrm{~Hz}$. The forcing signal was applied to the child via a disposable bacterial filter and a mouthpiece (Type PBF-30, Piston Ltd., Budapest, Hungary). Zrs was obtained from 8 -sec measurements while the child performed normal breathing during the oscillatory measurements. The equipment was calibrated by measuring known impedances prior to the measurements. The additional impedance of the bacterial filter and mouthpiece was determined and the Zrs spectra were corrected for this equipment component.

During the 8-sec data recording periods, the children sat upright, wearing a noseclip, and breathing quietly through the mouthpiece. They were asked to support their cheeks with their palms during these maneuvers in order to minimize upper airway shunting. The $\mathrm{Zrs}$ recordings were accepted if the coherence functions between the pressure and flow signals were generally $>0.95$, no leak was noted around the mouthpiece, and no technical artifact occurred due to coughing, swallowing or glottis closure.

The changes in the resistive properties of the respiratory system were evaluated by calculating the average resistance between 4 and $24 \mathrm{~Hz}\left(\mathrm{R}_{4-24}\right)$ and by extracting the resistance and reactance at $6 \mathrm{~Hz}\left(\mathrm{R}_{6}\right.$ and $\mathrm{X}_{6}$; the lowest frequency at which the impedance was reliably measured). The elasticity of the respiratory system was assessed by calculating the sum of all negative values in the imaginary part of Zrs from $4 \mathrm{~Hz}$, which corresponds to the area above the reactance curve and the $x$-axis (AX). The resonance frequency of the respiratory system $\left(\mathrm{F}_{\text {res }}\right)$, that is, the frequency at which the reactance was zero, was determined by linear interpolation.

\section{Spirometry}

Spirometry was performed in accordance with the ATS/ERS recommendations..$^{20}$ Forced expiratory flowvolume curves were measured by means of a commercial spirometer (Type PDD-301/s, Piston Ltd., Budapest, Hungary) including a screen pneumotachograph equipped with a differential pressure transducer. The flow signal was integrated to obtain changes in lung volume during the forced expiratory maneuvers. The forced expiratory volume in the first second of expiration $\left(\mathrm{FEV}_{1}\right)$, the forced vital capacity $(\mathrm{FVC})$, and the forced expired flow between $25 \%$ and $75 \%$ of the volume expired $\left(\mathrm{FEF}_{25-75}\right)$ were extracted from the recordings. Three technically acceptable reproducible measurements were performed, and the highest values of the spirometric parameters were extracted from the maneuvers for the final analyses.

\section{Measurement Protocol and Bronchial Challenges}

On the first study day, three-to-five reproducible Zrs data epochs were recorded, which were followed by three consecutive technically acceptable forced expiratory maneuvers in order to establish the baseline values of the FOT and spirometric lung functional parameters. Since the FOT does not require any special breathing maneuvers, this technique was always performed first. The deep inspirations and forced expirations necessary for spirometry may affect FOT measurements. ${ }^{13,21}$ This sequence guaranteed the lack of influence of the assessments themselves on the measured values. Increasing doses of aerosolized (Voyage Mefar jet nebulizer, Italy) His (Sigma-Aldrich Ltd., Budapest, Hungary) was then administered (airflow $8 \mathrm{~L} / \mathrm{min}$, mass median aerodynamic diameter $1.9 \mu \mathrm{m}$, minimum output $0.3 \mathrm{ml} / \mathrm{min}$ ) to the children for 2 min via a face mask, in doubling doses ranging from 0.5 to $16 \mathrm{mg} / \mathrm{ml}$. A set of $\mathrm{Zrs}$ 
recordings was first collected, including measurements of three 8-sec data epochs at 10, 50, and $90 \mathrm{sec}$ after the end of the inhalation. This was followed by three forced expiratory maneuvers for spirometry at 2, 2.5, and 3 min after the completion of each dose. An interval of at least 5 min was allowed between two consecutive doses. The study was terminated before the highest dose of His, or if $\mathrm{FEV}_{1}$ decreased by more than $20 \%$ and/or clinical symptoms of wheeze or persistent cough were noted. ${ }^{22,23}$ To detect the reversibility of the bronchoconstriction, the challenge protocol was terminated in all children by administering $400 \mu \mathrm{g}$ inhaled Sal (Ventolin, GlaxoSmithKline, Greenford, UK) followed by the final assessment of Zrs and spirometry.

The children revisited the lung function laboratory 2 weeks later. The baseline FOT and spirometry were performed identically as detailed above. Aerosolized saline as the solvent of the agonists was then administered for $2 \mathrm{~min}$, and both the FOT and spirometry were repeated. The bronchoprovocation tests with increasing doses of MCh $(0.5-8 \mathrm{mg} / \mathrm{ml}$ for $2 \mathrm{~min})$ and the broncholysis with Sal were then repeated in the same manner as detailed above.

The deep inspirations and forced expirations necessary for spirometry may affect FOT measurements. ${ }^{13,21}$ Accordingly, to test whether the variability of the FOT parameters was altered when this lung function test was performed alone, another 8 asthmatic children similar to the main study population were studied (three girls and five boys, age range 6-16 years, weight range $27-74 \mathrm{~kg}$, height range $122-164 \mathrm{~cm}$ ). Two sets of Zrs recordings by the FOT were collected in these children at times 5 min apart.

\section{Statistical Analyses}

Short-term variability in the spirometric and FOT parameters was defined as the standard deviation of percentage changes between measurements before and after $\mathrm{NaCl}$ inhalations, while long-term variability was determined by calculating the standard deviation of percentage changes between the two baseline values at the two visits. The $Z$ score for each parameter was calculated as the difference between the post-test and the basal value divided by the standard deviation of the expected value of the change (i.e., the short-term variability). This $Z$ score is the number of standard deviations by which a lung function parameter responded to the constrictor agonists as compared with inhalation of the solvent. Responses were considered statistically significant when the $Z$ scores for each parameter were outside the -1.96 and +1.96 critical levels. The $Z$-test comparing two proportions was applied to detect statistical significance between the lung function parameters. To express group means and deviations, the values are reported as means \pm SE. The Kolmogorov-Smirnov test was used to test data for normality. The changes in the group means of the FOT and spirometric $Z$ score parameters were assessed by using one-way ANOVA tests on repeated measures. The relationships between the continuous variables (i.e., the FOT and spirometry indices) were examined by means of Pearson correlation tests. Pairwise comparisons were performed by using the Student-Newman-Keuls multiple comparison procedures. Statistical significance was accepted at the level $P<0.05$.

\section{RESULTS}

The children had normal basal lung function parameters, with a mean percentage predicted value for $\mathrm{FEV}_{1}$ of $106 \%$ (range $93-136 \%$ ) and a mean $Z$ score of 0.54 (ranging between -1.0 and +1.43 ). The mean FVC was $105 \%(67-121 \%)$, with a $Z$ score of 0.48 (ranging between -1.3 and +1.75 ). $\mathrm{FEF}_{25-75}$ was also normal, with a mean percentage predicted value of $106 \%$ (77$124 \%$ ) and a mean $Z$ score of 0.62 (ranging between -2.05 and +3.04$).{ }^{24}$ The mean respiratory resistance between 4 and $24 \mathrm{~Hz}\left(\mathrm{R}_{4-24}\right)$ was $91 \%$ of the percentage predicted (range $74-105 \%$ ).

Data on the short- and long-term variabilities in the spirometric and FOT parameters are demonstrated in Table 1. The smallest variabilities were found for $\mathrm{FEV}_{1}$ and FVC, those for $\mathrm{FEF}_{25-75}, \mathrm{R}_{4-24} \mathrm{R}_{6}$ were higher, and the highest were observed for $\mathrm{X}_{6} \mathrm{AX}$ and $\mathrm{Fr}$ in the children who participated in both the FOT and spirometry. Substantial decreases in the short-term variability were observed for the FOT parameters in the eight additional

TABLE 1-Percentages of Short- and Long-Term Variability of the Lung Function Parameters Determined With Spirometry or Forced Oscillations in the Main Study Group of 20 Children (5 Girls and 15 Boys, Age Range 5-18 Years)

\begin{tabular}{lcc}
\hline & $\begin{array}{c}\text { Percentage short-term } \\
\text { variability }\end{array}$ & $\begin{array}{c}\text { Percentage long-term } \\
\text { variability }\end{array}$ \\
\hline Spirometry & & \\
FEV $_{1}$ & 4.3 & 9.3 \\
FEF $_{25-75}$ & 7.1 & 15.3 \\
FVC $_{\text {Forced oscillation }}$ & 4.4 & 8.2 \\
$\mathrm{R}_{4-24}$ & $10.3(6.1)$ & 13.8 \\
$\mathrm{R}_{6}$ & $11.3(6.2)$ & 12.2 \\
$\mathrm{X}_{6}$ & $15.41(7.2)$ & 18.7 \\
$\mathrm{AX}$ & $25.6(17.0)$ & 31.9 \\
Fr & $16.7(9.2)$ & 25.7 \\
\hline
\end{tabular}

Values in parentheses: values obtained in eight additional children where the FOT was performed without spirometry (three girls and five boys, age range 6-16 years). Variability was defined as the standard deviation of the percentage changes between the data obtained in the first and second tests. 

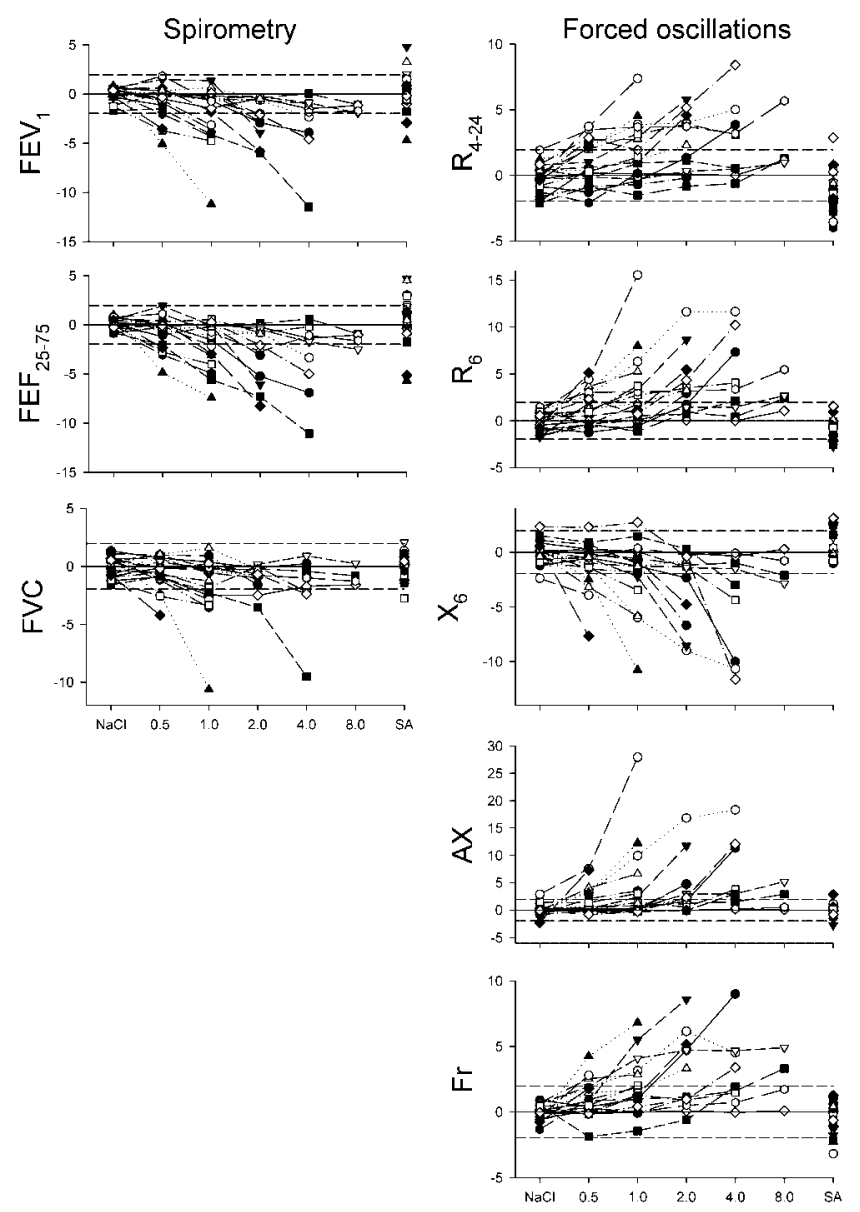

Fig. 1. The $Z$ scores of the lung function parameters obtained with spirometry (left) or forced oscillations (right) in individual asthmatic children under the baseline condition (BL), following inhalations of normal saline $(\mathrm{NaCl})$ and increasing doses of methacholine $(0.5-8.0 \mathrm{mg} / \mathrm{ml})$, and after inhalation of salbutamol (SA). Horizontal dashed lines indicate the limits of statistical significance ( $Z$ score 1.96).

children where the FOT data were collected without spirometry.

Figure 1 illustrates the $Z$ scores for the spirometric and FOT parameters during the MCh challenge protocol. Inhalation of saline following the baseline recordings did not cause significant changes in any of the lung function parameters $(P=0.47,0.34,0.75,0.98$, $0.84,0.78,0.94$, and 0.55 for $\mathrm{FEV}_{1}, \mathrm{FEF}_{25-75}$, FVC, $\mathrm{R}_{4-24}, \mathrm{R}_{6}, \mathrm{X}_{6}, \mathrm{AX}$, and Fr, respectively). Inhalation of increasing doses of MCh resulted in dose-dependent decreases in $\mathrm{FEV}_{1}, \mathrm{FEF}_{25-75}(P<0.001$ for both $)$ and FVC $(P=0.002)$. All parameters obtained with the FOT displayed dose-dependent significant increases following MCh inhalation $(P<0.001$ for all). Inhalation of Sal after these bronchial provocations totally abolished the bronchoconstrictor effects of MCh. Similar to His, the resistance parameters obtained by FOT were able to detect significant decreases in the airway tone after Sal inhalations $\left(P=0.002\right.$ for $\mathrm{R}_{4-24}, P=0.006$ for $\mathrm{R}_{6}$ ), while these changes were not reflected in the spirometric indices. Statistical results on these findings are presented in Table 2. The final concentration of MCh caused significant changes in the spirometric and forced oscillatory indices in the majority of the children; $Z$-tests revealed no significant difference between forced expiratory flow parameters $\left(\mathrm{FEV}_{1}\right.$ and $\left.\mathrm{FEF}_{25-75}\right)$ and lung function indices obtained by forced oscillations.

The $Z$ scores of the spirometric and FOT parameters during His challenges are depicted in Figure 2. Increasing doses of aerosolized His caused statistically significant decreases in the lung volume/flow indices determined by spirometry $\left(P<0.001\right.$ for $\mathrm{FEV}_{1}$ and $\mathrm{FEF}_{25-75} ; P=0.011$ for $\left.\mathrm{FVC}\right)$. The parameters extracted from the real and imaginary parts of the Zrs spectra exhibited dose-dependent elevations after His provocation $\left(P<0.001\right.$ for $\mathrm{R}_{4-24}, \mathrm{R}_{6}$ and $\mathrm{Fr}, P=0.005$ for $\mathrm{X}_{6}$ and $\mathrm{AX})$. The lung function parameters obtained with spirometry after Sal inhalation were not significantly different from those measured at the beginning of the study, but administration of Sal led to significant decreases in $\mathrm{R}_{6}(P<0.005), \mathrm{X}_{6}(P<0.005)$, and $\mathrm{AX}(P<0.05)$, indicating that the decreases in the airway tone by the $\beta_{2}$ agonist may be reflected in the FOT indices. Table 3 containes the results of the Z-test on the data in Figure 2. The majority of the children responded to His at the final concentration; $Z$-tests revealed no significant difference between the forced expiratory flow parameters $\left(\mathrm{FEV}_{1}\right.$ and $\left.\mathrm{FEF}_{25-75}\right)$ and the resistance parameters obtained by forced oscillations.

TABLE 2- $P$ Values Resulting From the Z-Tests Comparing Two Proportions for the Lung Function Parameters Obtained With Spirometry and Forced Oscillations During the Methacholine Challenges

\begin{tabular}{|c|c|c|c|c|c|}
\hline & $\mathrm{R}_{4-24}(13 / 7)$ & $\mathrm{R}_{6}(17 / 3)$ & $\mathrm{X}_{6}(16 / 4)$ & $\mathrm{AX}(16 / 4)$ & Fr $(13 / 7)$ \\
\hline $\mathrm{FEV}_{1}(14 / 6)$ & 0.73 & 0.26 & 0.46 & 0.46 & 0.73 \\
\hline $\mathrm{FEF}_{25-75}(14 / 6)$ & 0.73 & 0.26 & 0.46 & 0.46 & 0.73 \\
\hline $\operatorname{FVC~}(8 / 12)$ & 0.11 & 0.003 & 0.01 & 0.01 & 0.11 \\
\hline
\end{tabular}

Values in parentheses: number of children with significant change to the highest dose of histamine (defined as the $Z$ score for each parameter exceeding the critical levels of -1.96 or +1.96 ) over the number of children with no significant change. 

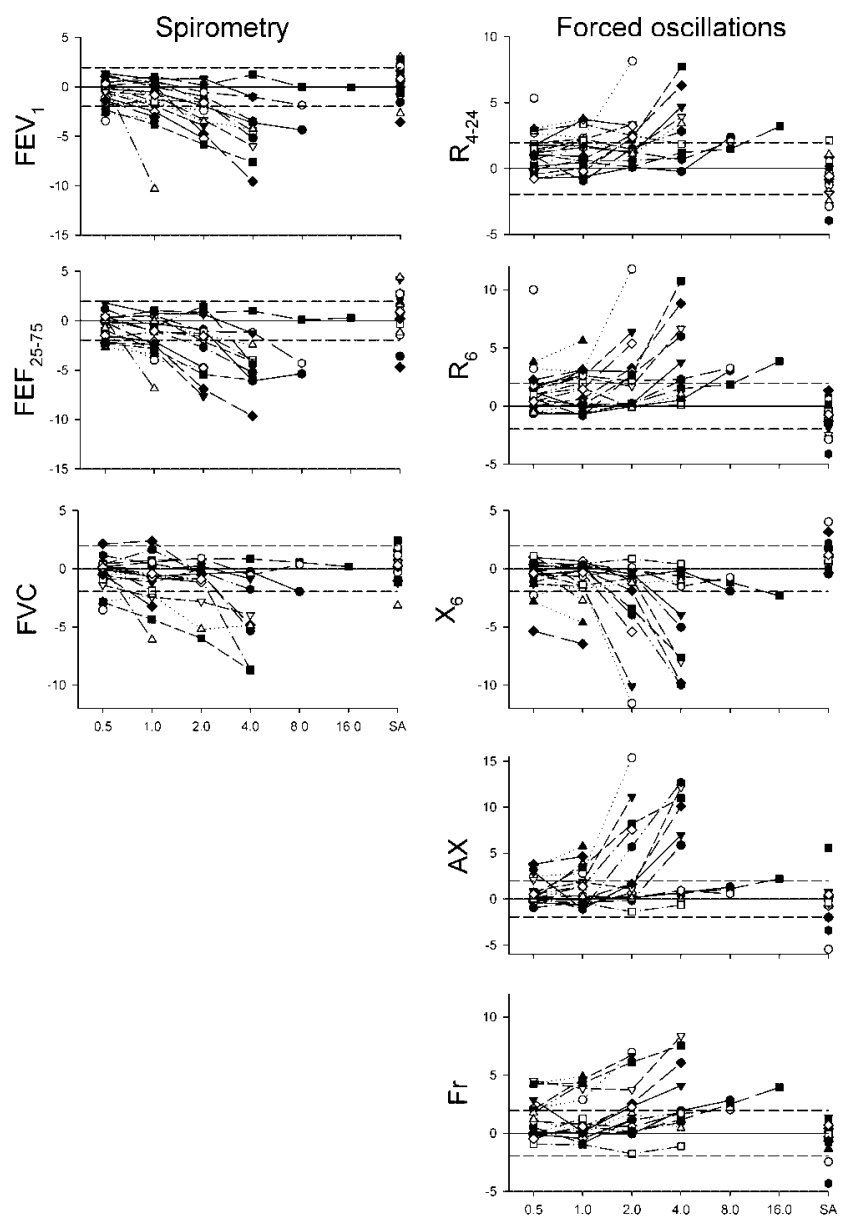

Fig. 2. The $Z$ scores of the lung function parameters obtained with spirometry (left) or forced oscillations (right) in individual asthmatic children under the baseline condition (BL), following inhalations of increasing doses of histamine $(0.5-16 \mathrm{mg} /$ $\mathrm{ml}$ ) and after inhalation of salbutamol (SA). Horizontal dashed lines indicate the limits of statistical significance ( $Z$ score 1.96).

To compare the sensitivities of spirometry and the FOT in the detection of airway narrowing, the absolute values of the $Z$ scores for the lung function parameters during the His and MCh challenges (determined with spirometry and the FOT) are presented in Figure 3. Data are shown for the lower part of the dose-response

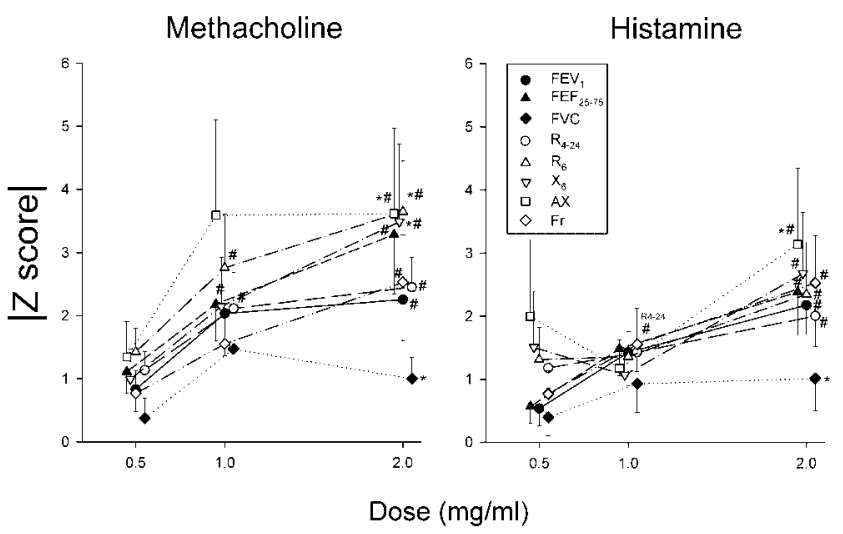

Fig. 3. The absolute $Z$ scores for the lung function parameters obtained with spirometry (filled symbols) and forced oscillations (open symbols) following histamine or methacholine challenges. ${ }^{*} \boldsymbol{P}<0.05$ versus FEV1 within a dose, ${ }^{\#} \boldsymbol{P}<0.05$ versus zero level within a parameter.

curve, where measurements were made for the majority of the children (i.e., prior to a $20 \%$ decrease in $\mathrm{FEV}_{1}$ or the appearance of clinical symptoms). The sensitivities of the FOT parameters related to the low-frequency part of the Zrs spectra were among the greatest during both His and MCh challenges. $\mathrm{R}_{6}$ and $\mathrm{FEF}_{25-75}$ exhibited similarly high sensitivities in the detection of His- or MCh-induced airway narrowing. The parameters $X_{6}$, $\mathrm{AX}, \mathrm{Fr}, \mathrm{FEV}_{1}$, or $\mathrm{FEF}_{25-75}$ were also able to detect bronchoconstriction after His and MCh challenges, but only after the second doses of the constrictor agonists.

Since the variability in the FOT parameters was greater than that in the spirometric indices, we examined the magnitude of the changes in the resistance parameters where the His and MCh provocation tests became positive according to the ATS/ERS guidelines (a $20 \%$ decrease in $\mathrm{FEV}_{1}$ or the appearance of clinical symptoms). These data are displayed in Table 4 . When a positive response was detected during the bronchial challenge tests, the changes in $\mathrm{R}_{4-24}$ were about twice as high as those in the $\mathrm{FEV}_{1}$ for both of the constrictor agonists studied, while the elevations in $R_{6}$ were even more pronounced.

The $\mathrm{FEV}_{1}$ values obtained with spirometry and the resistance values in the medium frequency range

TABLE 3- $P$ Values Resulting From the Z-Tests Comparing Two Proportions for the Lung Function Parameters Obtained With Spirometry and Forced Oscillations During the Histamine Challenges

\begin{tabular}{|c|c|c|c|c|c|}
\hline & $\mathrm{R}_{4-24}(17 / 3)$ & $\mathrm{R}_{6}(18 / 2)$ & $X_{6}(14 / 6)$ & $\mathrm{AX}(13 / 7)$ & Fr $(12 / 8)$ \\
\hline $\mathrm{FEV}_{1}(18 / 2)$ & 0.63 & 1 & 0.42 & 0.058 & 0.028 \\
\hline $\mathrm{FEF}_{25-75}(16 / 4)$ & 0.67 & 0.38 & 0.32 & 0.29 & 0.17 \\
\hline $\operatorname{FVC~}(8 / 12)$ & 0.003 & 0.001 & 0.09 & 0.11 & 0.21 \\
\hline
\end{tabular}

Values in parentheses: number of children with significant change to the highest dose of histamine (defined as the $Z$ scores for each parameter exceeding the critical levels of -1.96 or +1.96 ) over the number of children with no significant change. 
TABLE 4-Percentage Changes in the Resistance Parameters Where the Histamine and Methacholine Provocation Tests Became Positive According to the ATS/ERS Guidelines (a $20 \%$ Decrease in $\mathrm{FEV}_{1}$ or the Appearance of Clinical Symptoms)

\begin{tabular}{|c|c|c|c|c|c|c|}
\hline & \multicolumn{3}{|c|}{ Histamine } & \multicolumn{3}{|c|}{ Methacholine } \\
\hline & $\mathrm{R}_{4-24}$ & $\mathrm{R}_{6}$ & Response & $\mathrm{R}_{4-24}$ & $\mathrm{R}_{6}$ & Response \\
\hline 1 & 38.1 & 59.4 & W & 82.0 & 172.8 & $\mathrm{~W}$ \\
\hline 2 & 48.4 & 80.9 & SW & 80.9 & 77.6 & SW \\
\hline 3 & 53.6 & 124.1 & $\mathrm{~W}$ & 56.9 & 110.4 & SW \\
\hline 4 & 16.1 & 24.9 & SW & 38.7 & 80.1 & SW \\
\hline 5 & 37.0 & 53.4 & SW & 39.7 & 51.6 & SW \\
\hline 6 & 41.5 & -1.5 & W & 30.8 & 38.8 & $\mathrm{~W}$ \\
\hline 7 & 64.9 & 107.8 & SW & 53.6 & 76.1 & SW \\
\hline 8 & 46.8 & 48.3 & SW & 28.9 & 36.8 & SW \\
\hline 9 & 66.9 & 116.8 & SW & 7.1 & 20.0 & SW \\
\hline 10 & 25.8 & 46.7 & SW & 5.2 & 17.3 & $\mathrm{~W}$ \\
\hline 11 & 12.3 & 27.3 & SW & -5.3 & 5.94 & SW \\
\hline 12 & 20.7 & 40.4 & W & 40.8 & 54.4 & $\mathrm{~W}$ \\
\hline 13 & 5.9 & 5.5 & SW & -2.7 & 19.8 & SW \\
\hline 14 & 16.3 & 31.0 & SW & 30.8 & 62.4 & SW \\
\hline 15 & 27.7 & 23.6 & W & 2.9 & 11.3 & W \\
\hline 16 & 34.8 & 11.1 & SW & 24.1 & 41.0 & SW \\
\hline 17 & 38.6 & 58.0 & SW & 11.4 & 8.1 & SW \\
\hline 18 & 23.4 & 23.1 & W & 12.8 & 9.9 & SW \\
\hline 19 & 7.0 & 23.2 & SW & 10.7 & 28.3 & SW \\
\hline 20 & 15.5 & 40.9 & W & 46.9 & 43.4 & SW \\
\hline Mean & 32.1 & 48.9 & & 27.6 & 49.7 & \\
\hline SE & 4.1 & 8.7 & & 5.4 & 10.1 & \\
\hline
\end{tabular}

SW, positive response (20\% decrease in $\mathrm{FEV}_{1}$ and the appearance of wheeze); W, wheeze, clinical symptoms appeared.

(4-24 Hz) obtained with the FOT are primarily determined by the geometry and the mechanical properties of the central conducting airways. Conversely, the contributions of the small airways appear in the spirometric $\mathrm{FEF}_{25-75}$ and the low-frequency resistance values, such as $\mathrm{R}_{6}{ }^{7,25}$ Accordingly, we characterize the associations between these corresponding spirometric and FOT indices during the His and MCh challenges in Figure 4. During His challenges, strong and statistically significant correlations were observed between $\mathrm{FEV}_{1}$ and $\mathrm{R}_{4-24}\left(\mathrm{R}^{2}=0.6, P<0.0001\right)$ and between $\mathrm{FEF}_{25-75}$ and $\mathrm{R}_{6}\left(\mathrm{R}^{2}=0.47, P<0.0001\right)$. The correlations between these parameters during $\mathrm{MCh}$ challenges were somewhat weaker but their associations were still close and highly significant $\left(\mathrm{R}^{2}=0.48, P=0.0001\right.$ between $\mathrm{FEV}_{1}$ and $\mathrm{R}_{4-24}$ and $\mathrm{R}^{2}=0.5, P<0.0001$ between $\mathrm{FEF}_{25-75}$ and $\mathrm{R}_{6}$ ).

\section{DISCUSSION}

The results of the present study demonstrated concomitant changes in the lung function parameters determined with spirometry and the FOT during different bronchial challenges in asthmatic children, with significant correlations between the corresponding parameters. Inhalation of increasing doses of His or MCh caused bronchoconstriction, which was detected similarly from both the spirometric and the FOT parameters. Expressing the changes in $Z$ scores, which take into account the different variabilities in the lung function parameters, revealed that the sensitivities of the lung function indices are comparable in spirometry and the FOT for the detection of bronchoconstriction induced by $\mathrm{His}$ and MCh in asthmatic children.

Since the introduction of the FOT by Dubois in $1956^{26}$ and its extension toward the application of a wide frequency range of pseudorandom pressure excitation, ${ }^{27}$ the popularity of this lung mechanical measurement technique has increased, particularly as concerns examinations of patients with a limited ability to cooperate. $^{1-3,7-9,11-15,17,18,28-30}$ This beneficial profile of the FOT allows the characterization of lung function abnormalities in children with various respiratory diseases, such as cystic fibrosis, ${ }^{9,11-14}$ neonatal chronic lung disease, ${ }^{9,15}$ wheezy bronchitis, ${ }^{9,16-18}$ or asthma. ${ }^{1-3,9,10}$ Furthermore, the FOT has been used successfully to characterize bronchodilator responsiveness ${ }^{9,18,28}$ and to detect lung function changes following the inhalation of a bronchoconstrictor agonist in children. ${ }^{2,3,16,17}$ However, we are aware of only a few previous studies in which the sensitivities of the FOT and spirometry were compared with regard to the detection of $\mathrm{AH}$ in asthmatic children, ${ }^{1,29,30}$ when the bronchial challenges are performed in accordance with the ATS guidelines. ${ }^{23}$ In 


\section{Responses to histamine}
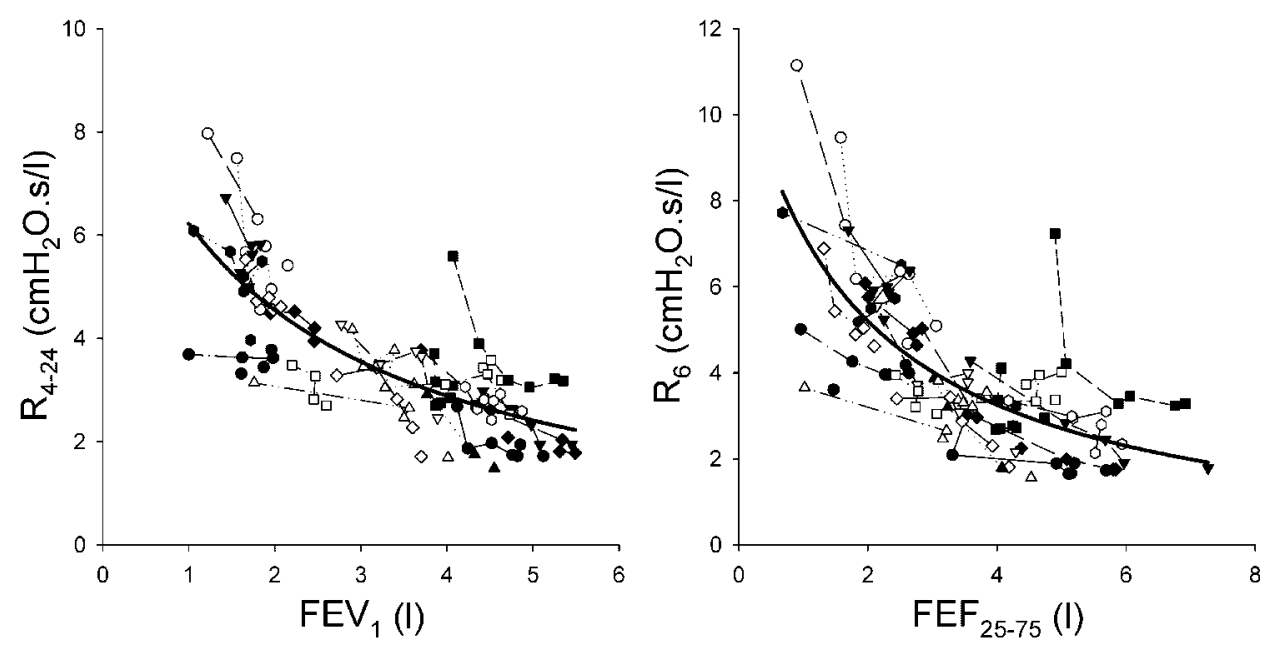

Responses to methacholine
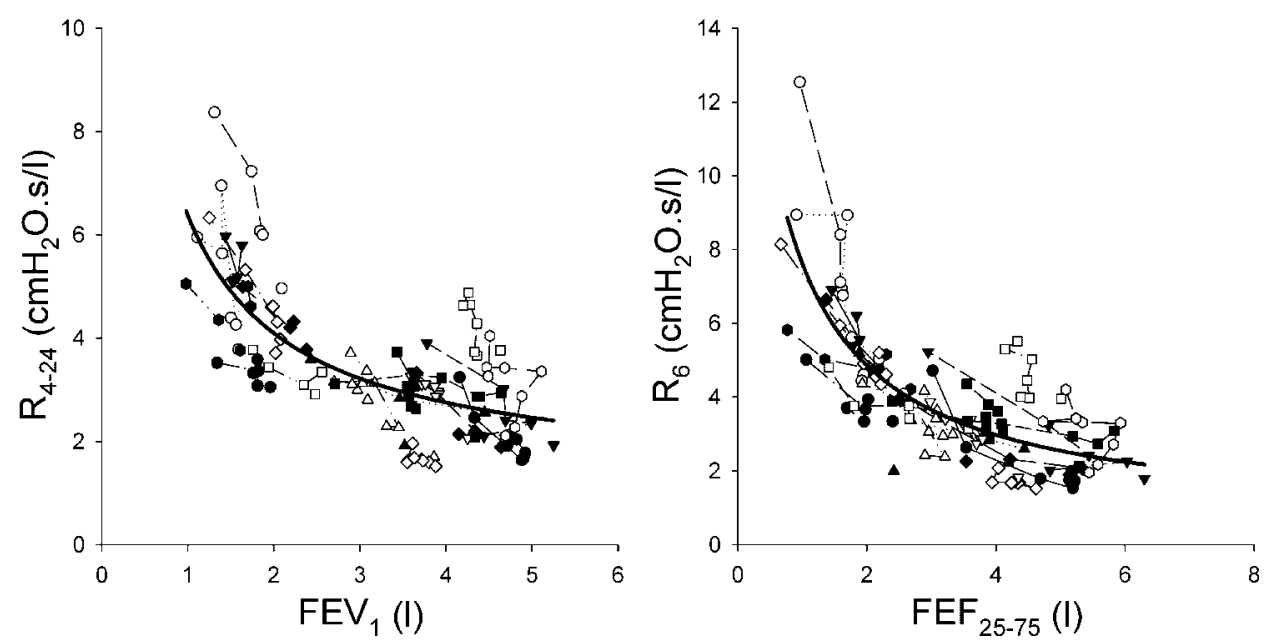

Fig. 4. Correlations observed between spirometric and resistance parameters obtained with forced oscillations following aerosolized histamine (top) or methacholine (bottom) challenges in individual asthmatic children.

agreement with the present findings (Fig. 4), significant correlations between forced expiratory and impedance parameters were found in these previous reports following inhalation of $\mathrm{His}^{30}$ or $\mathrm{MCh}^{29}$ The sensitivity of the resistance and reactance parameters of the respiratory impedance spectra for the detection of bronchoconstriction in asthmatic children following $\mathrm{MCh}$ inhalation also accords with previous findings. ${ }^{1}$ These earlier studies lack a comprehensive analysis of the sensitivities of the lung function parameters involving a consideration of the differences in variability of the techniques applied. Since spirometry is a routine procedure in lung function laboratories for the detection of $\mathrm{AH}$ in the diagnosis of asthma, demonstration of the similar ability of the FOT is of major importance, since this technique can be carried out reliably in a much younger age group (as low as 2 years of age $\mathrm{e}^{3,10}$ ). Nevertheless, children of school age were enrolled in the present study, in order to allow a comparison with spirometry. The diagnosis of asthma via the detection of $\mathrm{AH}$ would require the involvement of an age-matched healthy control group. This would have required the enrolment of healthy children in a similar age range for the two bronchoprovocation tests with His and MCh, but this was not feasible at our institution. Despite our having the limitation the lack of a healthy control group, however, the comparisons of the changes in the FOT with the spirometric indices during bronchoprovocation tests still provides 
valuable information concerning the ability of the former approach to detect airway narrowing. This similar ability suggests that $\mathrm{AH}$ can be detected reliably in asthmatic children by using the FOT.

Strong and highly significant correlations were observed between the corresponding FOT and spirometric parameters relating to the larger $\left(\mathrm{FEV}_{1}\right.$ vs. $\left.\mathrm{R}_{4-24}\right)$ and smaller airways $\left(\mathrm{FEF}_{25-75}\right.$ vs. $\left.\mathrm{R}_{6}\right)$, which suggests that airway narrowing is faithfully reflected by both techniques. Nevertheless, the correlation analysis does not take into account the variability of the measured parameters, which is of great importance in a comparison of the ability of a lung function test to measure bronchoconstriction with subsequent promise to detect AH. Previous studies have established that lung function parameters obtained by measurement techniques utilized during tidal breathing exhibit somewhat greater variability than those based on forced expiration. ${ }^{11}$ In accordance with that finding, we experienced greater short- and long-term variabilities for the FOT parameters than those measured with spirometry. This implies that greater magnitudes of changes can be regarded as positive responses in the FOT parameters (Table 4), which corresponds to previous observations ${ }^{2,17,22}$ and recommendations for higher acceptance limits of clinically important changes. ${ }^{22}$

In order to take the greater magnitudes of the changes and the somewhat higher short-term variability in the FOT parameters into account, the alterations in the lung function indices during the His and MCh challenges were also expressed in $Z$ scores. This analysis revealed comparable $Z$ scores for the lung function parameters determined with the FOT and spirometry in the detection of airway narrowing during both the His and the MCh challenges. However, in agreement with previous findings, ${ }^{1}$ there was a tendency to a greater sensitivity of the FOT parameters relating to the lowfrequency part of the Zrs spectra, which was particularly evident for $\mathrm{R}_{6}$. It is also noteworthy that the reactance parameter $\mathrm{X}_{6}$ and $\mathrm{AX}$ reflected the lung function changes after both His and MCh inhalation. Since these parameters are extracted from the low-frequency reactance, they primarily reflect changes in the elasticity of the total respiratory system. It, therefore, seems likely that, besides inducing a constriction of the conducting airways manifested in elevated forced expiratory lung volumes and resistance parameters, the inhalation of the bronchoconstrictor agonists also led to a stiffening of the respiratory tissues. The most probable mechanism responsible for such a change in the respiratory elasticity is the loss of lung volume via the development of air trapping, due to the uneven deposition of the bronchoprovocation agonists, which was earlier clearly demonstrated during challenges with aerosolized His. ${ }^{21,31}$ The lack of a significant decrease in FVC despite this loss of lung volume may be related to the forced deep inspiration to the total lung capacity prior to the expiration, which has been shown to be likely to reopen the compromised lung regions. ${ }^{21}$

As concerns the greater variabilities in the parameters determined with the FOT than those with spirometry, the sequence of the tests in the present experimental setting warrants consideration. Since the FOT requires normal quiet breathing only, it has no influence on the spirometric outcome. This sequence of the tests ensured the minimal interaction between the two lung function tests. Nevertheless, the deep inspiration and subsequent forced expiration maneuvers necessary for spirometry may affect the lung mechanics, which may be manifested even 5 min later in the FOT recordings. In addition to the potential diminution of the lung functional changes that results from the deep inspirations homogenizing the lung periphery, ${ }^{21}$ these forced breathing maneuvers may also widen the short-term variability of the FOT parameters obtained in the present study, which then ultimately affect the $Z$ scores extracted from the Zrs spectra, and hence the sensitivity of the tests. To check on this hypothesis, we recruited eight asthmatic children of school age on whom two sets of baseline FOT recordings were performed $5 \mathrm{~min}$ apart, without spirometry between them. The short-term variability of each FOT parameter decreased substantially (Table 1), suggesting that the sensitivity of the FOT test for the detection of $\mathrm{AH}$ can be potentially doubled if the measurements are performed without additional lung function tests requiring special breathing maneuvers. The short-term variability of Rrs in this subgroup of children fits well within the range reported in earlier studies $(5-11 \%)$, where FOT was performed without spirometry. ${ }^{3,8}$ The somewhat greater variabilities in the reactance parameters also agree with previous results. ${ }^{1,3,8}$ The deep inspiration (DI) itself required for spirometry may also affect the FOT during bronchial challenges. DI alleviates the airway narrowing by decreasing the enhanced bronchial smooth muscle tone and advancing lung recruitment. However, in asthmatics, this reduction may not be present $^{32}$ or DI may even enhance the airway tone. ${ }^{33}$ Since our subjects were classified as mild intermittent and mild persistent asthmatics, it can be anticipated that the bronchoprotective effect of DI predominated. Thus, it is possible that the His and MCh effects would have been somewhat greater if the FOT had have performed alone to assess the lung function changes.

A further important feature of our study protocol is the lack of randomization of the FOT and spirometric measurements. While this order minimized the interference between the measurement techniques since FOT does not modify the bronchial tone, this timing may have biased our findings if the bronchoconstriction was 
not stable over the measurement period (approximately 3 min after completing each challenge). To exclude the potential bias due to the diminished effect of His or $\mathrm{MCh}$ with time, we performed measurements on five additional children, where the lung function was assessed by spirometry at 1,3 , and 5 min after MCh inhalation at a single dose of $4 \mathrm{mg} / \mathrm{ml}$ for $2 \mathrm{~min}$. These results demonstrated that, within the time frame covered by the spirometry and forced oscillations, no significant reduction in the bronchial tone was observed $\left(\mathrm{FEV}_{1}\right.$ decreases were stable with values of $70.3 \pm 22 \%, 68.3 \pm 24 \%, 68.4 \pm 19 \%$ of the pre-MCh level at 1, 3, and 5 min after $\mathrm{MCh}$ inhalation, respectively, $P=0.74)$. We are, therefore, certain that our protocol allows an exact comparison of the two techniques, even in the presence of an elevated airway tone.

In conclusion, in asthmatic children subjected to bronchoprovocation tests with His and MCh, the resistance and reactance parameters determined with the FOT detected the airway constriction similarly as for the parameters assessed by standard spirometry. The $Z$ scores, which take into account the greater variability in the changes in the FOT parameters when the FOT was performed concomitantly with spirometry revealed that the two lung function measurement methods have similar sensitivities in the assessment of bronchoconstriction. If the FOT was performed alone, the short-term variability of the resistance parameters decreases markedly and approaches that observed for the spirometric indices. Since the FOT requires less cooperation from the patient than in the case of spirometry, use of the FOT may impose less stress on the children and may lead to a decrease in the age at which airway narrowing can be detected during bronchoprovocation tests. This implies that FOT is feasible for the detection of $\mathrm{AH}$ in children and thus its use may contribute to the diagnosis of asthma in the preschool age range.

\section{ACKNOWLEDGMENTS}

The authors thank Balla Mária, Kissné Klimász Zsuzsanna, and Szakácsné Szabó Ágota for their excellent technical assistance. The cooperation of the children is greatly appreciated.

\section{REFERENCES}

1. Bisgaard H, Klug B. Lung function measurement in awake young children. Eur Respir J 1995;8:2067-2075.

2. Hall GL, Gangell C, Fukushima T, Horak F Jr, Patterson H, Stick SM, Sly PD, Franklin PJ. Application of a shortened inhaled adenosine-5' -monophosphate challenge in young children using the forced oscillation technique. Chest 2009;136:184-189.

3. Klug B, Bisgaard H. Measurement of lung function in awake 2-4-year-old asthmatic children during methacholine challenge and acute asthma: a comparison of the impulse oscillation technique, the interrupter technique, and transcutaneous measurement of oxygen versus whole-body plethysmography Pediatr Pulmonol 1996;21:290-300.

4. Cockcroft DW. Direct challenge tests: airway hyperresponsiveness in asthma: its measurement and clinical significance. Chest 138:18S-24S.

5. Sears MR, Greene JM, Willan AR, Wiecek EM, Taylor DR, Flannery EM, Cowan JO, Herbison GP, Silva PA, Poulton R. A longitudinal, population-based, cohort study of childhood asthma followed to adulthood. N Engl J Med 2003;349:1414-1422.

6. Oostveen E, MacLeod D, Lorino H, Farre R, Hantos Z, Desager $\mathrm{K}$, Marchal $\mathrm{F}$. The forced oscillation technique in clinical practice: methodology, recommendations and future developments. Eur Respir J 2003;22:1026-1041.

7. Frey U. Forced oscillation technique in infants and young children. Paediatr Respir Rev 2005;6:246-254.

8. Hall GL, Sly PD, Fukushima T, Kusel MM, Franklin PJ, Horak F Jr, Patterson H, Gangell C, Stick SM. Respiratory function in healthy young children using forced oscillations. Thorax 2007;62:521-526.

9. Thamrin C, Gangell CL, Udomittipong K, Kusel MM, Patterson H, Fukushima T, Schultz A, Hall GL, Stick SM, Sly PD. Assessment of bronchodilator responsiveness in preschool children using forced oscillations. Thorax 2007;62:814-819.

10. Nielsen KG, Bisgaard $H$. Lung function response to cold air challenge in asthmatic and healthy children of 2-5 years of age. Am J Respir Crit Care Med 2000;161:1805-1809.

11. Gangell CL, Hall GL, Stick SM, Sly PD. Lung function testing in preschool-aged children with cystic fibrosis in the clinical setting. Pediatr Pulmonol 2010;45:419-433.

12. Gangell CL, Horak F Jr, Patterson HJ, Sly PD, Stick SM, Hall GL. Respiratory impedance in children with cystic fibrosis using forced oscillations in clinic. Eur Respir J 2007;30:892-897.

13. Lebecque P, Stanescu D. Respiratory resistance by the forced oscillation technique in asthmatic children and cystic fibrosis patients. Eur Respir J 1997;10:891-895.

14. Ren CL, Brucker JL, Rovitelli AK, Bordeaux KA. Changes in lung function measured by spirometry and the forced oscillation technique in cystic fibrosis patients undergoing treatment for respiratory tract exacerbation. Pediatr Pulmonol 2006;41:345-349.

15. Udomittipong K, Sly PD, Patterson HJ, Gangell CL, Stick SM, Hall GL. Forced oscillations in the clinical setting in young children with neonatal lung disease. Eur Respir J 2008;31: 1292-1299.

16. Wilson NM, Bridge P, Silverman M. Bronchial responsiveness and symptoms in 5-6 year old children: a comparison of a direct and indirect challenge. Thorax 1995;50:339-345.

17. Wilson NM, Bridge P, Phagoo SB, Silverman M. The measurement of methacholine responsiveness in 5 year old children: three methods compared. Eur Respir J 1995;8:364-370.

18. Oostveen E, Dom S, Desager K, Hagendorens M, De Backer W, Weyler J. Lung function and bronchodilator response in 4-yearold children with different wheezing phenotypes. Eur Respir J 2010;35:865-872.

19. Bateman ED, Hurd SS, Barnes PJ, Bousquet J, Drazen JM, FitzGerald M, Gibson P, Ohta K, O'Byrne P, Pedersen SE, et al. Global strategy for asthma management and prevention: GINA executive summary. Eur Respir J 2008;31:143-178.

20. Miller MR, Hankinson J, Brusasco V, Burgos F, Casaburi R, Coates A, Crapo R, Enright P, van der Grinten CP, Gustafsson P, et al. Standardisation of spirometry. Eur Respir J 2005;26: 319-338.

21. Monfraix S, Bayat S, Porra L, Berruyer G, Nemoz C, Thomlinson W, Suortti P, Sovijarvi AR. Quantitative measurement of regional lung gas volume by synchrotron radiation computed tomography. Phys Med Biol 2005;50:1-11. 
22. Beydon N, Davis SD, Lombardi E, Allen JL, Arets HG, Aurora P, Bisgaard H, Davis GM, Ducharme FM, Eigen H, et al. An official American Thoracic Society/European Respiratory Society statement: pulmonary function testing in preschool children. Am J Respir Crit Care Med 2007;175:1304-1345.

23. Crapo RO, Casaburi R, Coates AL, Enright PL, Hankinson JL, Irvin CG, MacIntyre NR, McKay RT, Wanger JS, Anderson SD, et al. Guidelines for methacholine and exercise challenge testing-1999. This official statement of the American Thoracic Society was adopted by the ATS Board of Directors, July 1999. Am J Respir Crit Care Med 2000;161:309-329.

24. Stanojevic S, Wade A, Cole TJ, Lum S, Custovic A, Silverman M, Hall GL, Welsh L, Kirkby J, Nystad W, et al. Spirometry centile charts for young Caucasian children: the asthma UK collaborative initiative. Am J Respir Crit Care Med 2009;180:547-552.

25. Lebecque P, Kiakulanda P, Coates AL. Spirometry in the asthmatic child: is FEF 25-75 a more sensitive test than FEV1/ FVC? Pediatr Pulmonol 1993;16:19-22.

26. Dubois AB, Brody AW, Lewis DH, Burgess BF Jr. Oscillation mechanics of lungs and chest in man. J Appl Physiol 1956;8: 587-594.

27. Landser FJ, Nagles J, Demedts M, Billiet L, van de Woestijne KP. A new method to determine frequency characteristics of the respiratory system. J Appl Physiol 1976;41:101-106.
28. Mazurek HK, Marchal F, Derelle J, Hatahet R, Moneret-Vautrin D, Monin P. Specificity and sensitivity of respiratory impedance in assessing reversibility of airway obstruction in children. Chest 1995;107:996-1002.

29. Duiverman EJ, Neijens HJ, Van der Snee-van Smaalen M, Kerrebijn KF. Comparison of forced oscillometry and forced expirations for measuring dose-related responses to inhaled methacholine in asthmatic children. Bull Eur Physiopathol Respir 1986;22:433-436.

30. Lebecque $\mathrm{P}$, Spier S, Lapierre JG, Lamarre A, Zinman R, Coates AL. Histamine challenge test in children using forced oscillation to measure total respiratory resistance. Chest 1987; 92:313-318.

31. Popa V, Chandnani PC, Reardon M. The relationship between conductance and functional residual capacity during drug-induced bronchoconstriction. Chest 1990;97:831-839.

32. Brusasco V, Crimi E, Barisione G, Spanevello A, Rodarte JR, Pellegrino R. Airway responsiveness to methacholine: effects of deep inhalations and airway inflammation. J Appl Physiol 1999; 87:567-573.

33. Gayrard P, Orehek J, Grimaud C, Charpin J. Mechanisms of the bronchoconstrictor effects of deep inspiration in asthmatic patients. Thorax 1979;34:234-240. 